UNIVERSIDADE DE SÃO PAULO

ESCOLA DE ENFERMAGEM

TICIANE CAROLINA GONÇALVES FAUSTINO CAMPANILI

INCIDÊNCIA DE ÚLCERA POR PRESSÃO E DE LESÃO POR FRICÇÃO EM PACIENTES DE UNIDADE DE TERAPIA INTENSIVA CARDIOPNEUMOLÓGICA 
UNIVERSIDADE DE SÃO PAULO

ESCOLA DE ENFERMAGEM

TICIANE CAROLINA GONÇALVES FAUSTINO CAMPANILI

\title{
INCIDÊNCIA DE ÚLCERA POR PRESSÃO E DE LESÃO POR FRICÇÃO EM PACIENTES DE UNIDADE DE TERAPIA INTENSIVA CARDIOPNEUMOLÓGICA
}

\author{
Dissertação apresentada ao Programa de Pós Graduação em \\ Enfermagem na Saúde do Adulto da Escola de Enfermagem da \\ Universidade de São Paulo para obtenção do título de Mestre em \\ Enfermagem \\ Área de Concentração: Programa de Pós-Graduação em \\ Enfermagem na Saúde do Adulto - PROESA \\ Orientadora: Profa. Dra. Vera Lúcia Conceição de Gouveia Santos
}

(Versão corrigida. A versão original está disponível na Biblioteca da EEUSP)

\section{SÃO PAULO}


AUTORIZO A REPRODUÇÃO E DIVULGAÇÃO TOTAL OU PARCIAL DESTE TRABALHO, POR QUALQUER MEIO CONVENCIONAL OU ELETRÔNICO, PARA FINS DE ESTUDO E PESQUISA, DESDE QUE CITADA A FONTE.

Assinatura:

Data:

\author{
Catalogação na Publicação (CIP) \\ Biblioteca "Wanda de Aguiar Horta" \\ Escola de Enfermagem da Universidade de São Paulo
}

Campanili, Ticiane Carolina Gonçalves Faustino Incidência de úlcera por pressão e de lesão por fricção em pacientes de unidade de terapia intensiva cardiopneumológica / Ticiane Carolina Gonçalves Faustino Campanili. São Paulo, 2014. $100 \mathrm{p}$.

Dissertação (Mestrado) - Escola de Enfermagem da Universidade de São Paulo.

Orientadora: Prof. Dr. Vera Lúcia Conceição de Gouveia Santos

Área de concentração: Enfermagem na Saúde do Adulto

1. Úlcera por pressão. 2. Unidades de terapia intensiva. 3. Pacientes internados. I. Título. 
Nome: Ticiane Carolina Gonçalves Faustino Campanili

Título: Incidência de úlcera por pressão e de lesão por fricção em pacientes de unidade de terapia intensiva cardiopneumológica

Dissertação apresentada ao Programa de Pós-Graduação em Enfermagem na Saúde do Adulto da Escola de Enfermagem da Universidade de São Paulo para obtenção do título de Mestre em Enfermagem.

Aprovado em:

\section{Banca Examinadora}

Prof. Dr. Instituição:

Julgamento: Assinatura:

Prof. Dr. Instituição:

Julgamento: Assinatura:

Prof. Dr. Instituição:

Julgamento: Assinatura: 
Campanili TCGF. Incidência de úlcera por pressão e de lesão por fricção em pacientes de unidade de terapia intensiva cardiopneumológica. [dissertação].São Paulo: Escola de Enfermagem, Universidade de São Paulo; 2014.

\section{RESUMO}

Introdução: As lesões de pele representam um grande desafio para os profissionais de saúde que prestam cuidados a pacientes críticos, especialmente os com alterações cardiopneumológicas, pois é frequente ocorrências de úlceras por pressão e de lesões por fricção nessa clientela com aumento de custos no tratamento e do tempo de internação além de desconforto e impacto negativo sobre a qualidade do serviço prestado e de vida dos pacientes. Objetivos: Este estudo objetivou identificar e analisar os coeficientes de incidência de úlceras por pressão e lesões por fricção e os fatores de risco para o seu desenvolvimento em pacientes de Unidade de Terapia Intensiva (UTI) Cardiopneumológica. Métodos: Trata-se de um estudo de coorte, prospectivo, cuja coleta de dados ocorreu durante os meses de novembro de 2013 a fevereiro de 2014, com censura de uma semana. O estudo foi realizado em uma UTI destinado a pacientes com doenças cardíacas e pulmonares de um hospital de grande porte na cidade de São Paulo, após aprovação dos Comitês de Ética em Pesquisa (CEP) da Escola de Enfermagem da Universidade de São Paulo e da instituição, de acordo com protocolo número 20780713.4.0000.5392, com parecer consubstanciado publicado na Plataforma Brasil em 24/10/2013. Participaram da amostra 370 pacientes maiores de 18 anos, que não apresentavam úlceras por pressão e lesões por fricção na admissão, que aceitaram participar do estudo (assinando o Termo de Consentimento Livre e Esclarecido) e que estavam na unidade há menos de 24 horas. Para análise dos dados foram utilizadas análises univariadas e a Classification And Regression Tree (CART). Resultados: Incidências globais de $10,80 \%, 7,02 \%$ e 2,16\%, respectivamente para úlceras por pressão, lesões por fricção e ambas as lesões simultaneamente foram encontradas nos pacientes críticos. Diferentes fatores de risco foram encontrados, conforme o tipo de lesão, sendo o tempo de permanência na UTI igual ou superior a 9,5 dias e idade igual ou superior a 42,5 anos comuns para as úlceras por pressão e lesões simultâneas. Além desses, raça branca; uso de superfícies de suporte e número de artefatos invasivos na admissão; e uso de transfusão sanguínea foram fatores constatados respectivamente para as úlceras por pressão, lesões por fricção e lesões simultâneas Conclusão: Os coeficientes de incidência e os fatores de risco constatados assemelham-se a alguns estudos da literatura, somente para as úlceras por pressão. Para as lesões por fricção e lesões simultâneas, não foram encontrados estudos desenvolvidos junto a pacientes críticos, sendo, no entanto, corroborados alguns dos fatores de risco descritos em grupos e cenários distintos como idosos residentes em instituições de longa permanência e pacientes crônicos hospitalizados. O estudo contribui, portanto, para os conhecimentos relacionados à epidemiologia dessas lesões, recomendando-se a replicação de seus métodos, principalmente para as lesões por fricção em pacientes hospitalizados, isoladamente ou em associação com as úlceras por pressão. Por outro lado, ao favorecerem a maior compreensão do panorama dessas lesões em pacientes cardiopneumológicos críticos, os resultados obtidos poderão favorecer o planejamento de cuidados preventivos específicos para essa clientela.

Palavras chaves: Úlcera por pressão, Unidades de terapia intensiva, Pacientes internados 
Campanili TCGF. Incidence of pressure ulcers and skin tears in patients of intensive care unit cardiopneumologic. [thesis]. São Paulo: Escola de Enfermagem, Universidade de São Paulo; 2014.

\begin{abstract}
Introduction: Skin lesions represent a major challenge for health professionals who care for critical patients cardiopneumologics. In clinical practice, have been frequent occurrences of pressure ulcers and skin tears, by rubbing with increased costs in treatment, prolonged hospitalization, in addition to discomfort and negative impact on the quality of service and the quality of life of patients.Goal: This study aimed to identify and analyze the rate of incidence of pressure ulcers and skin tears and the risk factors for its development in patients in the Intensive Care Unit(ICU) Cardiopneumologic. Methods: This study is a prospective cohort which data collection occurred during the months of November 2013 to February 2014, with censorship of a week. The study was conducted in a Surgical Intensive Care Unit Cardiopneumologic of a large hospital in the city of São Paulo, after approval of the Ethics Committee (EC) of the School of Nursing, University of São Paulo and the institution in accordance with protocol number 20780713.4.0000.5392 with sound embodied the EC Platform published in Brazil on 10/24/2013. A sample of 370 patients older than 18 years who did not have any injuries mentioned (pressure ulcers and skin tears) on admission, and who agreed to participate (by signing the Instrument of Consent) and who were in the unit for less than 24 hours. For data analysis were used univariate analyzes and the Classification And Regression Tree (CART). Results: overall incidences of $10.80 \%$, $7,02 \%$ and $2.16 \%$ respectively for pressure ulcers, skin tears and both lesions simultaneously were found in critically ill patients. Different risk factors were found, depending on the type of injury, and length of stay in ICU less than 9,5 days old and less than 42,5 years common for pressure ulcers and concurrent injuries. Besides these, the white race; Use of support surfaces and the number of invasive devices in entry; and use of blood transfusion were observed factors respectively for pressure ulcers, skin tears and simultaneous injuries Conclusion: The incidence and risk factors observed are similar to some studies in the literature, only for pressure ulcers. For skin tears and simultaneous lesions, no studies have not found together developed the critical patients, however, corroborated some of the risk factors described in groups and different scenarios as seniors residents in long-term hospitalized chronic patients and institutions. The study therefore contributes to the knowledge regarding the epidemiology of these types of injuries, recommending that replication of their methods, especially for lesions friction in acute inpatients and critics, alone or in combination with pressure ulcers. On the other hand, by favoring a greater understanding of these lesions panorama critical cardiopneumologics patients, the results will may facilitate the planning of specific preventive care for these clients.
\end{abstract}

Key words: Pressure ulcers, Intensive Care Unit, Inpatients. 


\section{DEDICATÓRIA}

A queт еи ато...

Pedro e Paulo 


\section{AGRADECIMENTOS}

Se hoje posso deixar registrados esses agradecimentos, foi porque tive a ajuda de muitas pessoas. Sei que corro o risco da memória cansada não corresponder à minha gratidão, mas a todos que participaram dessa árdua conquista, fica o meu muito obrigada.

Alguns nomes não posso deixar de registrar... fazem parte da minha história.

Ao meu filho Pedro, razão da minha vida, obrigada pela energia recarregada em cada abraço apertado;

Ao meu marido Paulo. Seu incentivo foi fundamental para essa conquista. Obrigada pela companhia, amor, e por compreender em alguns momentos a minha ausência.

À minha mãe Ester. Pelo amor e respeito.

Ao meu pai Wilson. Por ter me dado à oportunidade de dar os primeiros passos acadêmicos e chegar até aqui.

Ao meu irmão Wil. Pelo amor silencioso.

Ao meu chefe Adriano Rogério e aos funcionários da UTI Cirúrgica. Obrigada, essa conquista é nossa!

À Dona Maria Aparecida Batistão. Um exemplo a ser seguido. Seu amor ao próximo e à profissão incentivam-me a caminhar e a lutar sempre pelos nossos pacientes.

Ao Instituto do Coração (InCor). Sinto que ele faz parte de mim.

À Coordenação de Enfermagem do InCor, meu muito obrigada.

Às professoras Dra. Ludhmila Abraão Hajjar e Dra Filomena Galas, pela confiança.

À professora Dra. Vera Lúcia Conceição de Gouveia Santos, pela orientação, paciência, amizade e respeito.

Aos pacientes, razão de tudo. O meu mais sincero agradecimento.

À Deus, pela vida!! Obrigada pela oportunidade de dizer a todos o quanto são importantes para mim! 


\section{Lista de Quadros}

Quadro 1 - Estudos sobre a incidência de UP em UTI, de acordo com a região brasileira. .......18

Quadro 2 - Estudos sobre a incidência e fatores de risco de LF, de acordo com o país. ............22

Quadro 3 - Variáveis dependentes e independentes do estudo. ................................................37

Quadro 4 - UP segundo dias de internação (moda) para o diagnóstico, localização e categoria. São Paulo, 2013-2014

Quadro 5 - Caracterização dos pacientes com UP e LF, de acordo com os dias de internação para o diagnóstico da lesão, localização e categoria. São Paulo 2013-2014.

\section{Lista de Figuras}

Figura 1 - Esquema conceitual de fatores de risco para o desenvolvimento de úlcera por pressão. .16

Figura 2 - Classificação do IMC, segundo a Organização Mundial da Saúde. .32

Figura 3 - Distribuição das UP de acordo com a localização e categoria. São Paulo, 20132014 .46

Figura 4 - Fatores de risco para o desenvolvimento de UP, segundo análise CART. São Paulo, 2013-2014.

Figura 5 - Lesões por fricção de acordo com a categoria. São Paulo, 2013-2014. . .51

Figura 6 - Lesões por fricção de acordo com a categoria e localização. São Paulo, 20132014.

Figura 7 - Lesões por fricção de acordo com a categoria e dia de internação na UTI. São Paulo, 2013-2014.

Figura 8 - Fatores de risco para o desenvolvimento de LF, segundo análise CART. São Paulo, 2013-2014.

Figura 9 - Fatores de risco para o desenvolvimento de UP e LF simultâneas, segundo análise CART. São Paulo, 2013-2014. 


\section{Lista de Tabelas}

Tabela 1 - Variáveis clínicas dos pacientes da amostra. São Paulo, 2013-2014 ......................... 41

Tabela 2 - Variáveis cirúrgicas dos pacientes da amostra. São Paulo, 2013-2014...................... 42

Tabela 3 - Incidência de UP segundo variáveis demográficas. São Paulo, 2013-2014............... 43

Tabela 4 - Variáveis clínicas e cirúrgicas quantitativas dos pacientes com e sem UP. São

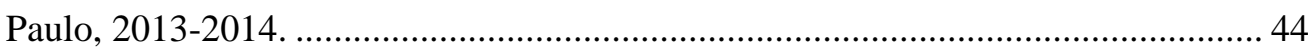

Tabela 5 - Variáveis nominais clínicas e cirúrgicas dos pacientes com e sem UP. São Paulo,

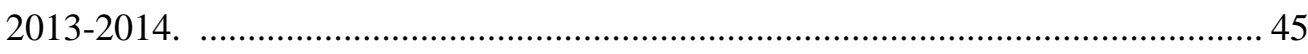

Tabela 6 - Incidência de LF segundo variáveis demográficas. São Paulo, 2013-2014............... 48

Tabela 7 - Variáveis clínicas e cirúrgicas quantitativas dos pacientes com e sem LF. São

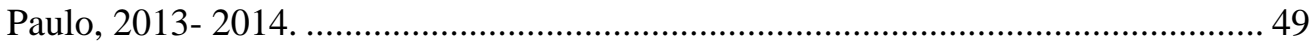

Tabela 8 - Variáveis nominais clínicas e cirúrgicas dos pacientes com e sem LF. São Paulo,

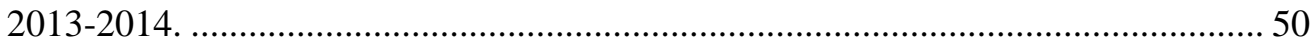

Tabela 9 - Incidência de UP e LF segundo variáveis demográficas. São Paulo, 2013- 2014. .... 54

Tabela 10 - Variáveis clínicas e cirurgicas quantitativas dos pacientes com UP e LF. São

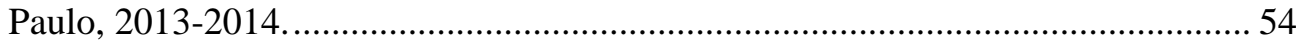

Tabela 11 - Variáveis nominais clínicas e cirúrgicas dos pacientes com e sem UP eLF. São

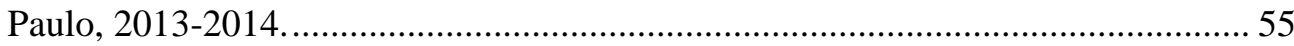




\section{Lista de Siglas}

APACHE

CART

CEC

CEP

DP

ECG

EE-USP

EPUAP

FA

ILPI

IMC

LF

NPUAP

PNSP

$\mathrm{RM}$

SIRS

SS

STAR

SUS

TCLE

UP

UTI

WOCN
Acute Physiology and Chronic Health Evaluation

Classification and Regression Tree

Circulação Extra-Corpórea

Comitê de Ética em Pesquisa

Desvio Padrão

Escala de Coma de Glasgow

Escola de Enfermagem da Universidade de São Paulo

European Pressure Ulcer Advisory Panel

Fibrilação Atrial

Instituição de Longa Permanência para Idosos

Índice de Massa Corporal

Lesão por Fricção

National Pressure Ulcer Advisory Panel

Programa Nacional de Segurança do Paciente

Revascularização do Miocárdio

Síndrome da Resposta Inflamatória Sistêmica

Superfície de Suporte

Skin Tear Classification System

Sistema Único de Saúde

Termo de Consentimento Livre e Esclarecido

Úlcera por Pressão

Unidade de Terapia Intensiva

Wound Ostomy and Continence Nursing Society 


\section{SUMÁRIO}

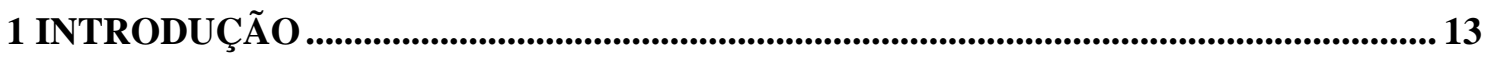

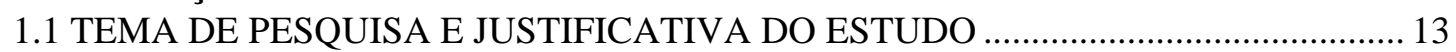

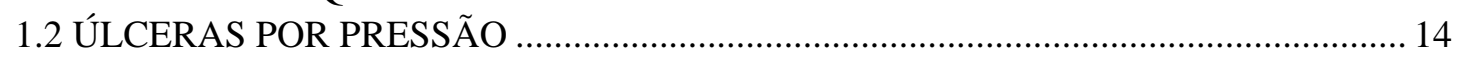

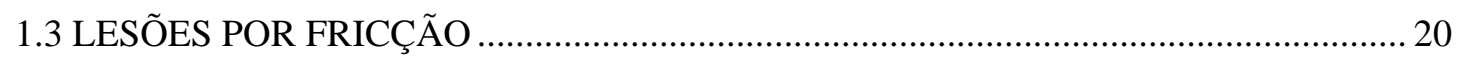

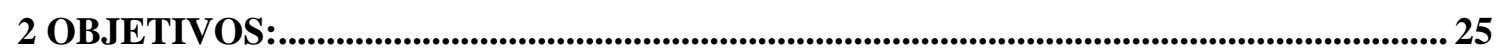

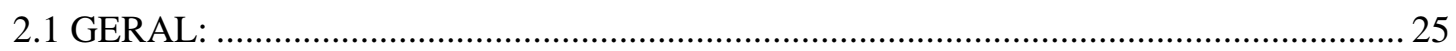

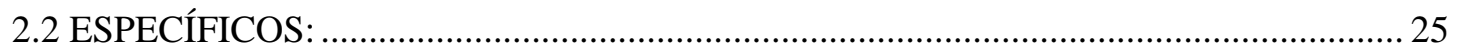

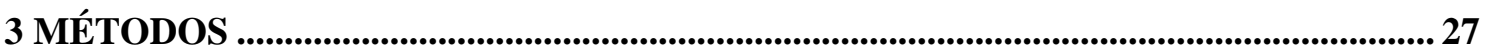

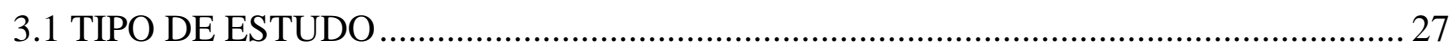

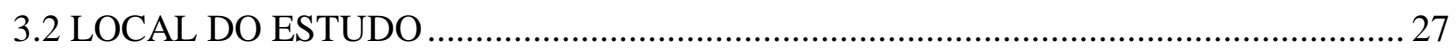

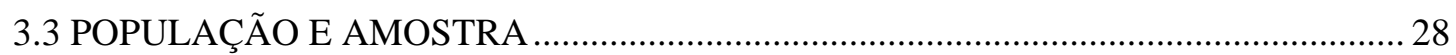

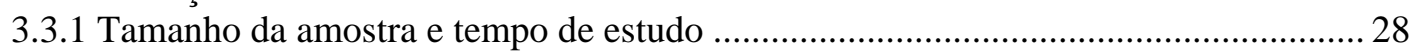

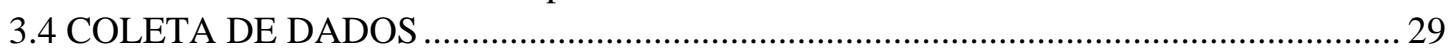

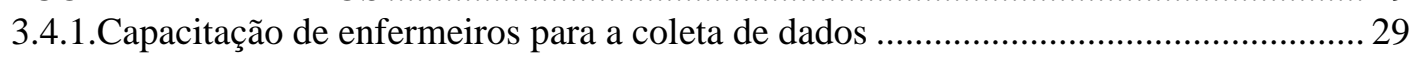

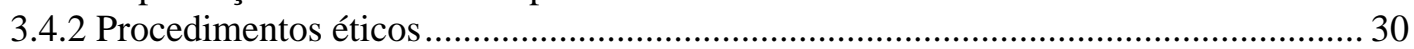

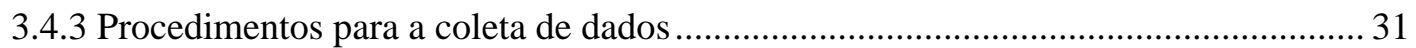

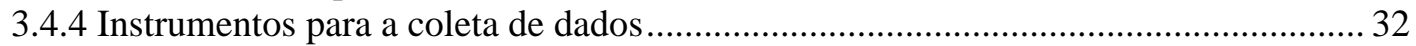

3.4.4.1 Dados sócio-demográficos e clínicos .................................................................. 33

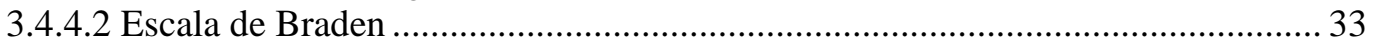

3.4.4.3 Escala de Coma de Glasgow (ECG)................................................................ 34

3.4.4.4 Acute Physiology and Chronic Health Evolution (APACHE )............................ 35

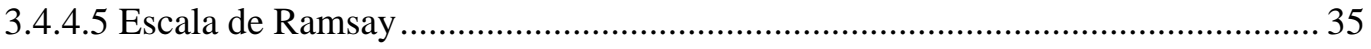

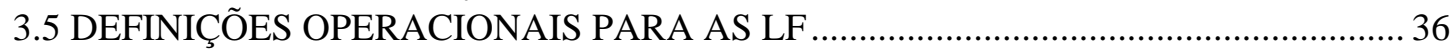

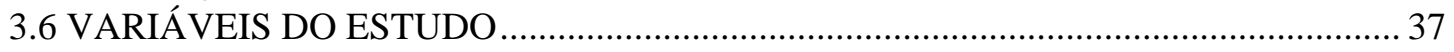

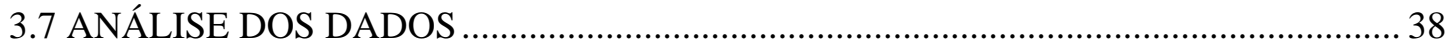

3.7.1 Cálculo de incidência de UP e LF .......................................................................... 38

4 RESULTADOS

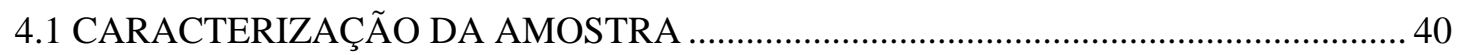

4.2 INCIDÊNCIA E FATORES DE RISCO PARA UP..................................................... 42

4.3 INCIDÊNCIA E FATORES DE RISCO PARA LF ....................................................... 48

4.4 INCIDÊNCIA E FATORES DE RISCO PARA O DESENVOLVIMENTO

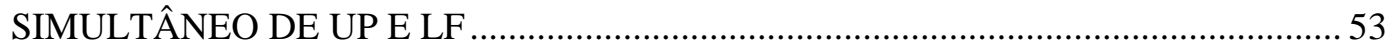

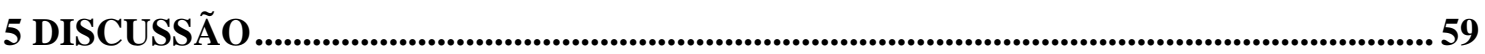

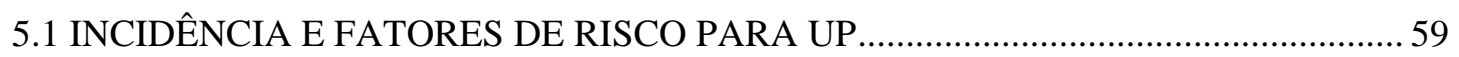

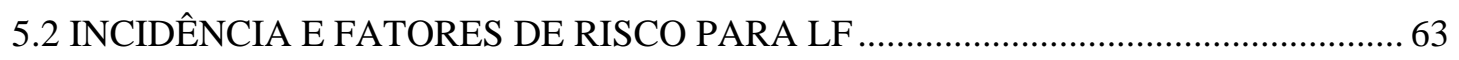

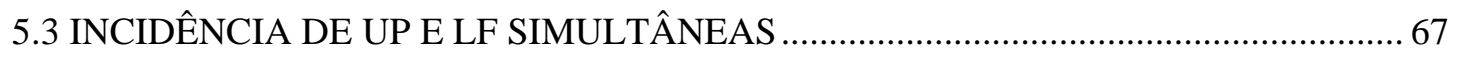

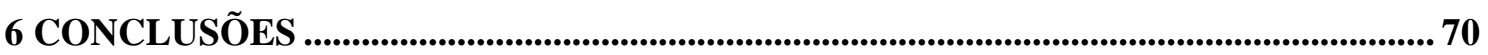

7 CONSIDERAÇÕES FINAIS ......................................................................................................... 72

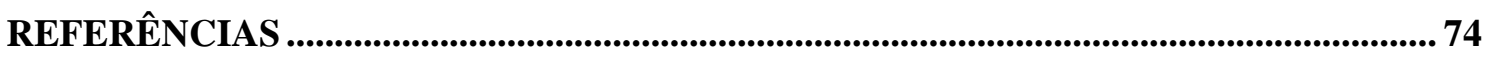

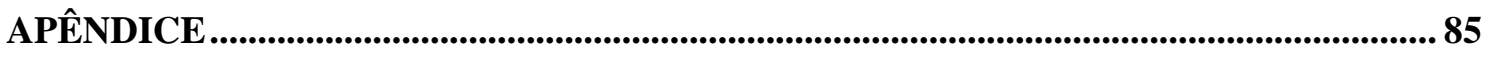

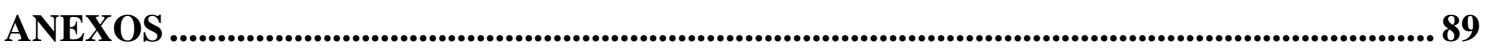




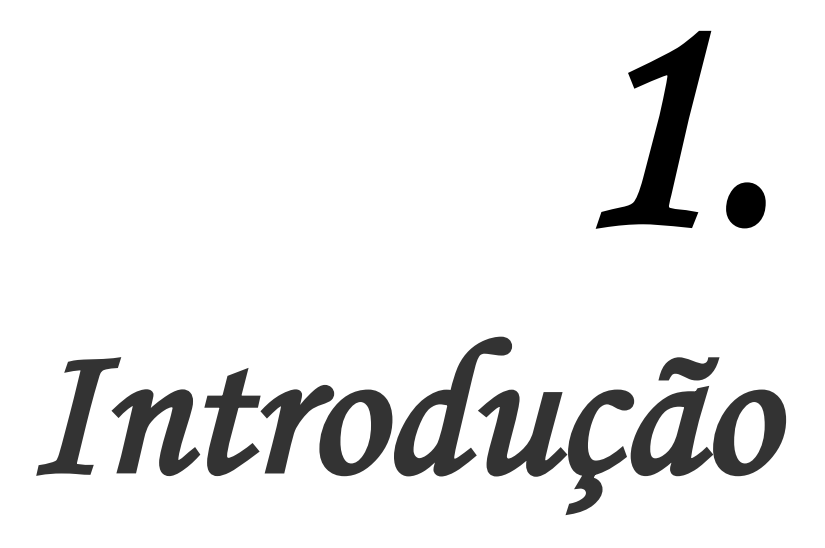




\section{INTRODUÇÃO}

\subsection{TEMA DE PESQUISA E JUSTIFICATIVA DO ESTUDO}

As lesões de pele representam um grande desafio para os profissionais de saúde que prestam cuidados a pacientes críticos, à medida que, na prática clínica, tem se tornado frequente a ocorrência de úlcera por pressão (UP) e de lesão por fricção (LF), com aumento de custos no tratamento, internação hospitalar prolongada, além de desconforto e impacto negativo sobre a qualidade do serviço prestado e a qualidade de vida dos pacientes ${ }^{1,2}$.

Programas de cuidado com a pele para a prevenção de lesões, baseados em diretrizes internacionais ${ }^{3-5}$, têm contribuído para a diminuição no número de lesões de pele em Unidade de Terapia Intensiva (UTI), embora nem todos os fatores de risco para o seu desenvolvimento sejam conhecidos, devido às especificidades de cada paciente, de cada doença associada ${ }^{6}$ e de cada cenário de atenção.

Particularmente na cardiopneumologia, em razão do aperfeiçoamento dos métodos diagnósticos e terapêuticos, as cirurgias reparadoras e corretivas estão sendo indicadas mais tardiamente ou em pacientes em condições mais graves, resultando em maior número de situações de risco pela associação do procedimento com comorbidades e outras doenças preexistentes ${ }^{7}$. Desse modo, a real dimensão do problema das lesões de pele em pacientes internados em UTIs cardiopneumológicas tem despertado o interesse dos profissionais que prestam cuidados a essa clientela.

Atualmente, os fatores de risco para o desenvolvimento de UP e LF estão sendo cada vez mais discutidos e explorados pelos enfermeiros para que se possam elaborar planos de cuidados específicos a cada população, de acordo com suas características clínicas. Rotineiramente, esses fatores são divididos naqueles existentes antes da internação (como idade avançada, diabetes, tabagismo e estado nutricional prejudicado) e os que ocorrem como resultado direto da condição clínica pós-internação (como imobilidade, transfusão sanguínea, uso de artefatos, sedação, circulação extracorpórea, tipo de cirurgia e drogas vasoativas $)^{6-8}$. 
A atuação da equipe de enfermagem em UTI visa à melhora clínica e à estabilidade do paciente, incluindo-se o diagnóstico de sua situação, intervenções e avaliação dos cuidados intensivos, a partir de uma perspectiva humanista voltada para a melhoria da sua qualidade de vida ${ }^{9-12}$.

Considerando-se que os pacientes críticos são altamente vulneráveis ao desenvolvimento de lesões de pele e que há fatores de risco específicos, conforme a doença de base e condições associadas realizou-se este estudo objetivando identificar e analisar os coeficientes de incidência de UP e de LF e os fatores de risco para o seu desenvolvimento, em pacientes de Unidade de Terapia Intensiva Cardiopneumológica.

\section{2 ÚLCERAS POR PRESSÃO}

Dentre as lesões de pele frequentemente encontradas em pacientes críticos, destacam-se as UP pela sua etiologia multifatorial. A UP é definida pela National Pressure Ulcer Advisory Panel (NPUAP) e pelo European Pressure Ulcer Advisory Panel (EPUAP) ${ }^{4,13}$ como um dano localizado na pele e/ou tecido subjacente geralmente sobre uma proeminência óssea, resultante de pressão ou de pressão em combinação com cisalhamento. A classificação varia de acordo com o comprometimento tecidual, subdividindo as lesões em categorias I, II, III, IV. Nos Estados Unidos da América (EUA), o NPUAP adota classificação adicional a essa, incluindo duas outras categorias: suspeita de lesão tissular profunda e categoria indeterminada ${ }^{4,13}$.

Vários são os fatores associados ao desenvolvimento das UP e, dentre esses, especificamente para os pacientes críticos destacam-se a pressão extrínseca associada à idade avançada, o déficit nutricional, a umidade, a imobilidade no leito, a perfusão tecidual diminuída, o uso de drogas vasoativas, a sedação e as comorbidades como diabetes mellitus e doença vascular ${ }^{3,5-12}$.

A diminuição da percepção sensorial acarretada pelos anestésicos e a imobilidade prolongada decorrente da impossibilidade de mobilização do paciente durante $\mathrm{o}$ ato operatório ${ }^{12}$ tornam inerente o aparecimento de áreas de hipoperfusão tecidual no pós-operatório de cirurgias cardiopulmonares. Reconhece-se que os pacientes cuja percepção sensorial está comprometida, ou seja, que não são aptos a 
detectarem sensações que indicam a necessidade de mudança de posição estão entre os mais susceptíveis ao desenvolvimento de $\mathrm{UP}^{14-16}$.

No paciente cirúrgico, costuma-se observar o aparecimento de UP desde o ato operatório até cinco dias após a exposição à pressão sofrida no centro cirúrgico, embora, muitas vezes, elas sejam despercebidas ou apenas descritas como uma hiperemia identificada na $\mathrm{UTI}^{17-19}$.

A tolerância do sistema cardiovascular ao procedimento cirúrgico é influenciada por agentes farmacológicos que visam a manter o retorno venoso e a resistência vascular sistêmica adequada. No entanto, pode ocorrer comprometimento circulatório e respiratório durante a cirurgia, causando hipotensão e consequente alteração da perfusão tissular necessitando de drogas vasoativas para melhorar a circulação sanguínea objetivando a preservação da irrigação do tecido cerebral e do miocárdio ${ }^{17-19}$.

Na pele, em condições normais, a pressão capilar na terminação arterial gira em torno de $32 \mathrm{mmHg}$, enquanto na venosa é de aproximadamente $12 \mathrm{mmHg}$. Existem situações que podem comprometer a perfusão da pele durante sua estadia na $\mathrm{UTI}^{3,4,5,8,17-}$ 19 , como por exemplo:

- a pressão sanguínea diminui em consequência de alterações cardiovasculares, síndrome da resposta inflamatória sistêmica (SIRS), choque séptico, choque hemorrágico e por uso de fármacos; a pressão externa é constante, sendo maior ou menor que $32 \mathrm{mmHg}$, por um tempo prolongado em mesas rígidas ou em camas hospitalares sem adequada superfície de suporte;

- há estabilidade hemodinâmica com elevação da pressão externa sob o corpo ou

- há estabilidade hemodinâmica com pressão externa menor que $32 \mathrm{mmHg}$, porém contínua.

Em qualquer uma das situações referidas, o paciente crítico sofre com a interrupção do fluxo sanguíneo para a área que está sob pressão, interferindo na oxigenação e nutrição dos tecidos naquele local e podendo ocorrer, consequentemente, isquemia, hipóxia, acidose tissular, edema e necrose tecidual ${ }^{7}$. 
A tolerância dos tecidos à pressão e à isquemia depende da natureza dos próprios tecidos e é influenciada pela habilidade da pele e das estruturas de suporte em redistribuir a pressão aplicada ${ }^{3,4,7,8,10}$.

Determinantes críticos para o desenvolvimento de UP são discutidos largamente por especialistas, há mais de 30 anos e, a cada dia, ainda são descobertos novos fatores relacionados à especificidade de cada paciente e de cada doença apresentada ${ }^{14}$.

Na década de 80, Bergstrom, Braden, Laguzza e $\operatorname{Holman}^{15}$ construíram um esquema conceitual envolvendo os determinantes críticos para o desenvolvimento das UP. Segundo esse esquema, as autoras propuseram que a intensidade e duração da pressão e a tolerância da pele e de estruturas subjacentes à pressão (Figura 1) constituem os fatores etiológicos principais na gênese das UP, o que é utilizado até os dias de hoje.

Figura 1 - Esquema conceitual de fatores de risco para o desenvolvimento de úlcera por pressão.

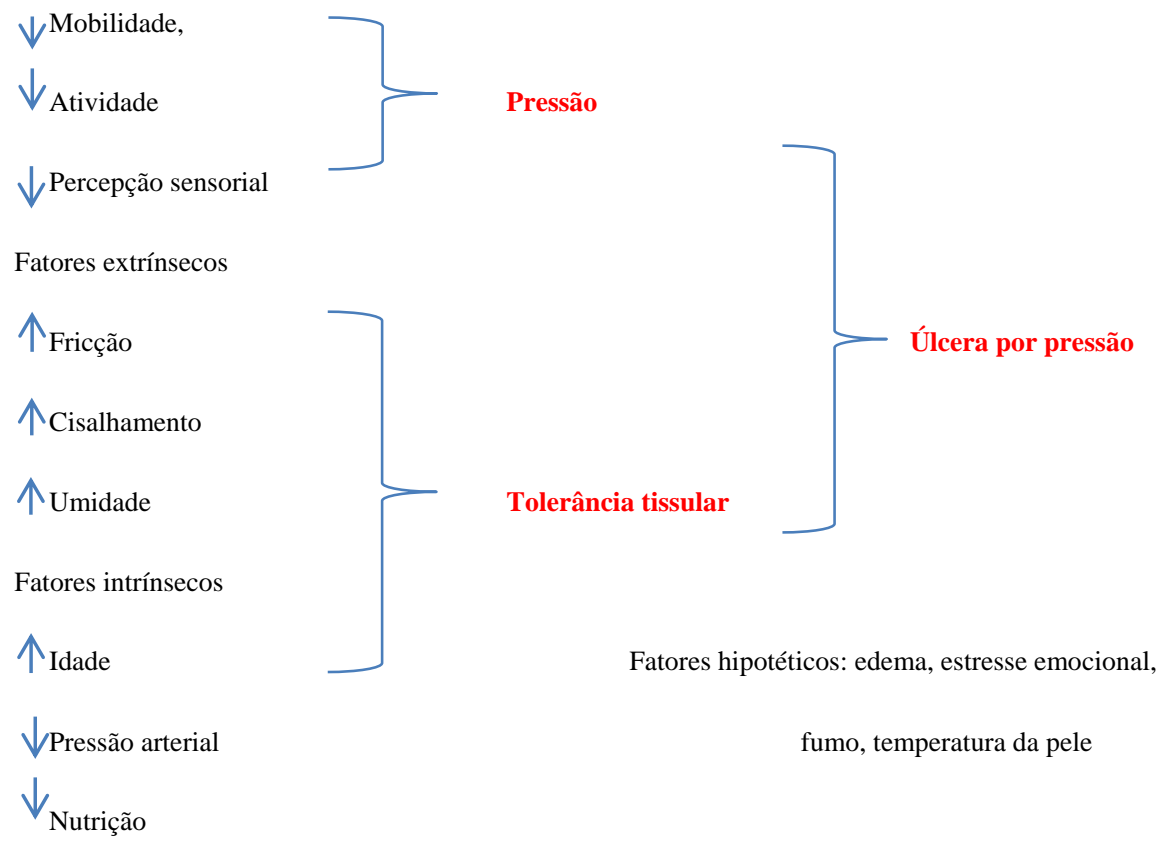

Fonte: Bergstrom N, Braden BJ, Laguzza A, Holman V.The Braden scale for predicting pressure sore risk. 1987; 36(4): 205-10 ${ }^{15}$.

Na prática clínica, fica evidente que a associação de fatores intrínsecos e extrínsecos para o desenvolvimento de UP em pacientes críticos é real e, muitas vezes, 
podem ser evitadas quando a equipe de saúde é devidamente capacitada para a identificação imediata desses fatores predisponentes, de risco ou associados à gênese desse tipo de lesão. Assim, a qualidade da assistência prestada é medida de acordo com o aparecimento de lesões de pele, qualificando o serviço que melhor as previne e não o que mais as trata.

Tendo em vista que as instituições de saúde buscam melhorar a qualidade assistencial e a segurança do paciente, desde a década de 80, inclusive no Brasil, a ocorrência de casos novos de UP tem sido utilizada como indicador da qualidade da assistência dos serviços de saúde, especialmente de enfermagem, exigindo avaliação de resultados dos processos de implantação de protocolos de prevenção. Mais recentemente, em abril de 2013, o Ministério da Saúde instituiu o Programa Nacional de Segurança do Paciente (PNSP), por meio da Portaria MS/GM no 529/2013, na qual um dos objetivos é o monitoramento da incidência de UP, objetivando minimizá-la em pacientes hospitalizados ${ }^{20}$.

Para avaliar a dimensão do problema das UP nas instituições hospitalares, estudos de prevalência e incidência passaram a ser desenvolvidos visando a representar, de forma quantitativa, o evento que acomete dezenas de pacientes hospitalizados ${ }^{5}$, dentre os quais aqueles em UTI, que permanecem acamados, sedados e imóveis durante tempo prolongado.

No Brasil, a incidência de UP em pacientes críticos tem sido explorada em algumas unidades da federação (Quadro 1), principalmente no estado de São Paulo, por profissionais da saúde que, através de suas publicações, buscam retratar a real dimensão do problema ${ }^{7,9,21-34}$. 
Quadro 1 - Estudos sobre a incidência de UP em UTI, de acordo com a região brasileira.

\begin{tabular}{|c|c|c|c|c|}
\hline Autor & Incidência & $\begin{array}{l}\text { Tempo de } \\
\text { Avaliação }\end{array}$ & Cidade/ Estado & $\begin{array}{c}\text { Ano de } \\
\text { Publicação }\end{array}$ \\
\hline Costa $I^{21}$ & $37 \%$ & 3 meses & $\begin{array}{l}\text { Ribeirão Preto, } \\
\text { São Paulo }\end{array}$ & 2003 \\
\hline Rogenski NMB, Santos VLCG ${ }^{7}$ & $41,0 \%$ & 3 meses & $\begin{array}{l}\text { São Paulo, } \\
\text { São Paulo }\end{array}$ & 2005 \\
\hline Sousa CA, Santos I, Silva LD. ${ }^{22}$ & $26,83 \%$ & 3 meses & $\begin{array}{l}\text { Rio de Janeiro } \\
\text { Rio de Janeiro }\end{array}$ & 2006 \\
\hline Fernandes NCS, Torres GV, Vieira D. ${ }^{23}$ & $50 \%$ & 2 meses & $\begin{array}{l}\text { Natal, } \\
\text { Rio Grande do Norte }\end{array}$ & 2008 \\
\hline Fernandes LM, Caliri MHL. ${ }^{24}$ & $62,5 \%$ & 6 meses & $\begin{array}{l}\text { Ribeirão Preto, } \\
\text { São Paulo }\end{array}$ & 2008 \\
\hline Diccini S, Cadamuro C, Ilda LIS. ${ }^{25}$ & $10 \%$ & 15 meses & $\begin{array}{l}\text { São Paulo, } \\
\text { São Paulo }\end{array}$ & 2009 \\
\hline $\begin{array}{l}\text { Cremasco MF, Wenzel F, Sardinha FM, } \\
\text { Zanei SSV, Whitaker IY. }\end{array}$ & $31 \%$ & 3 meses & $\begin{array}{l}\text { São Paulo, } \\
\text { São Paulo }\end{array}$ & 2009 \\
\hline Matos LS, Duarte NLV, Minetto RC. ${ }^{27}$ & $37,03 \%$ & 2 meses & $\begin{array}{c}\text { Brasília, } \\
\text { Distrito Federal }\end{array}$ & 2010 \\
\hline Simão CMF. ${ }^{28}$ & $13,69 \%$ & 1 mês & $\begin{array}{l}\text { São José do } \\
\text { Ribeirão Preto, } \\
\text { São Paulo }\end{array}$ & 2010 \\
\hline $\begin{array}{l}\text { Campos SF, Chagas ACP, Costa ABP, } \\
\text { França REM, Jansenet AK. }\end{array}$ & $28 \%$ & 2 meses & $\begin{array}{l}\text { Belo Horizonte, } \\
\text { Minas Gerais }\end{array}$ & 2010 \\
\hline $\begin{array}{l}\text { Soares DAS, VenDramin FS, Pereira } \\
\text { LMD, Proença PK, Marques MM. }\end{array}$ & $35,3 \%$ & 6 meses & Belém, Pará & 2011 \\
\hline $\begin{array}{l}\text { Bavaresco T, Medeiros RH, Lucena } \\
\text { AF. }^{31}\end{array}$ & $25,67 \%$ & 2 meses & $\begin{array}{c}\text { Porto Alegre, } \\
\text { Rio Grande do Sul }\end{array}$ & 2011 \\
\hline $\begin{array}{l}\text { Serpa LF, Santos VLCG, Oliveira AS, } \\
\text { Caetano VC, Donadon SR. }{ }^{32}\end{array}$ & $11,1 \%$ & 6 meses & $\begin{array}{l}\text { São Paulo, } \\
\text { São Paulo }\end{array}$ & 2011 \\
\hline Rogenski NMB, Kurcgant $\mathrm{P}^{9}$ & $23,1 \%$ & 3 meses & $\begin{array}{l}\text { São Paulo, } \\
\text { São Paulo }\end{array}$ & 2012 \\
\hline $\begin{array}{l}\text { Pereira LC, Luz MHBA, Santana WS, } \\
\text { Bezerra SMG, Figueiredo MLF. }{ }^{33}\end{array}$ & $29,03 \%$ & 3 meses & Teresina, Piauí & 2013 \\
\hline $\begin{array}{l}\text { Ventura JA, Moura LTR de, Carvalho } \\
\text { MFAA. }{ }^{44}\end{array}$ & $18,8 \%$ & 4 meses & $\begin{array}{c}\text { Recife, } \\
\text { Pernambuco }\end{array}$ & 2014 \\
\hline
\end{tabular}

Os estudos nacionais mostram grande variação quer seja nos coeficientes de incidência de UP encontrados em pacientes críticos (10\% a 62,5\%) quer seja nos períodos de avaliação, de 1 a 15 meses como observado no Quadro 1.

Atualmente, sabe-se que para diminuir o coeficiente de incidência de UP os enfermeiros intensivistas precisam desenvolver habilidades clínicas para identificar os 
fatores de risco a que os pacientes estão expostos e, assim, estabelecer programas de prevenção ${ }^{35,36}$. Para a avaliação dos fatores associados e de risco para o desenvolvimento de UP, existem diversos instrumentos testados e padronizados internacionalmente, como as escalas de Braden e de Waterlow ${ }^{4,14,15,35,36}$. Especificamente para pacientes críticos, a escala de Cubbin-Jackson foi idealizada em 1991, englobando itens relevantes como idade, peso, antecedentes médicos, condições da pele, estado mental, mobilidade, estado hemodinâmico, hipotermia, respiração, necessidade de oxigênio, nutrição, incontinência e higiene, administração de hemoderivados, cirurgia e transporte ${ }^{35,36}$. Em 2004, Seongsook et al $^{37}$ relataram que a Escala de Cubbin-Jackson apresenta melhor validade preditiva (sensibilidade de $89 \%$ e especificidade de 61\%) quando comparada às Escalas de Braden e de Douglas.

No Brasil, a escala de Cubbin-Jackson não foi adaptada nem validada ${ }^{36}$, sendo publicada em revista nacional a adaptação e validação da escala para Portugal ${ }^{38}$, o que acarreta grande impasse na identificação de pacientes de risco para o desenvolvimento de UP através desse instrumento em UTIs brasileiras.

Rotineiramente, a Escala de Braden ${ }^{15,39}$, validada para o português por Paranhos e $\operatorname{Santos}^{40}$, em 1999, é largamente utilizada para auxiliar no planejamento dos cuidados propostos por enfermeiros intensivistas, mesmo não sendo desenvolvida para esse tipo de pacientes. Por essa razão, inúmeros autores ${ }^{1,2,4,8,10,12,24,41-43}$ enfatizam que, para a avaliação global do paciente crítico faz-se necessário associar outras escalas com variáveis não abordadas na escala de Braden. Desse modo, há instrumentos específicos para avaliação de outras variáveis relacionadas ao desenvolvimento de UP em pacientes críticos como as escalas de Coma de Glasgow ${ }^{24,44,45}$, de Ramsay ${ }^{12,46}$ e o Acute Physiology And Chronic Health Evaluation - APACHE $\mathrm{II}^{47}$. Essas permitem, respectivamente, avaliar e registrar o nível de consciência, o nível de sedação e o prognóstico clínico (porcentagem de mortalidade esperada), proporcionando avaliação mais completa do paciente e, consequentemente, contribuindo também para a identificação de outros fatores de risco para o desenvolvimento de UP nesse grupo específico $^{48,49}$. 


\subsection{LESÕES POR FRICÇÃO}

Lesão por fricção (LF) é uma ferida traumática, que ocorre principalmente nas extremidades de idosos, resultante de fricção ou de uma combinação de fricção e cisalhamento, levando à separação da epiderme e derme (feridas de espessura parcial) ou separando a epiderme e a derme das estruturas subjacentes (ferida de espessura total) 50,51

Embora sejam lesões encontradas desde a antiguidade ${ }^{52,53}$, mais frequentemente em idosos, as LF estão sendo discutidas mais recentemente em populações e cenários diversos, devido ao desenvolvimento de inúmeras tecnologias (coberturas), à maior longevidade da população e ao aumento da incidência de doenças crônicodegenerativas, como a insuficiência cardíaca e o câncer ${ }^{54}$, que podem contribuir para a sua ocorrência ${ }^{55-61}$.

As LF são necessariamente provocadas por traumas mecânicos, nunca profundos, limitados à derme, e têm como característica principal a presença de um retalho de pele, que pode se apresentar viável a necrosado, em algum momento da sua evolução. Não raro, o retalho de pele pode apresentar-se totalmente separado do leito da ferida, como em traumas causados por fitas adesivas, dificultando o diagnóstico clínico $^{50,51}$. Quanto ao formato e ao tamanho das LF, são determinados pela intensidade do trauma tornando imprevisível sua extensão mantendo sempre um leito friável ${ }^{50-53}$.

Reconhece-se que a idade avançada e, consequentemente, as alterações fisiológicas inerentes ao envelhecimento levam o idoso ao maior risco de desenvolvimento de LF, o que justifica a associação entre esse tipo de lesão com a população idosa e a exploração desse tema em instituições de longa permanência para idosos $50,51,54-59,62$.

A pele do idoso está mais propensa a esse tipo de lesão, pois há aumento da queratinização prematura da epiderme e alargamento e aplainamento dos sulcos intrapapilares, juntamente com a perda do pregueamento da lâmina basal. Há um afrouxamento entre as camadas da epiderme e derme que passam a não resistir satisfatoriamente à fricção, rompendo-se facilmente e dando origem às $\mathrm{LF}^{56-59,62}$. Na derme, por sua vez, os fibroblastos passam a produzir menos colágeno tipo I e mais tipo III. As fibras de colágeno tornam-se rarefeitas, fragmentadas e separadas por grandes 
áreas ocupadas por substância fundamental amorfa. Os mucopolissacarídeos perdem sua função estrutural e apresentam-se como um sedimento amorfo. A pele perde força tênsil, resistência, elasticidade e extensibilidade ${ }^{56-59,62}$. A camada subcutânea torna-se mais delgada e o coxim adiposo menos eficiente na absorção de impacto. A espessura da pele diminui progressivamente, chegando a uma perda de $20 \%$. Há aumento na rigidez músculo-esquelética e na espasticidade muscular, com diminuição da sensibilidade sensorial ${ }^{53,56-59,63-67}$.

Recém-nascidos e crianças também são suscetíveis às LF e constituem o

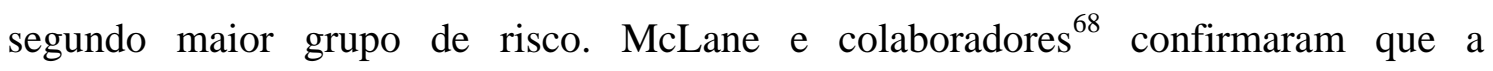
prevalência de LF (17\%) é maior do que a de UP (4\%) na população pediátrica. A faixa etária até 3 meses de idade mostrou-se como a mais susceptível, isso porque, além de apresentar estrato córneo deficiente e junção dermo-epidérmica pouco desenvolvida ao nascimento, a derme é fina, contando com apenas $60 \%$ da espessura quando comparada à derme do adulto. Fitas e coberturas adesivas são apontadas como as principais responsáveis pelas LF nessa clientela e em adultos ${ }^{68-72}$.

Embora idosos e crianças, principalmente os neonatos, constituam os grupos de maior risco para o desenvolvimento de LF, a experiência clínica dá fortes indícios de que essas lesões não estão restritas aos extremos de idade ${ }^{64,72-74}$, tais como indivíduos em estado crítico (em cuidados intensivos, em tratamento de câncer ${ }^{54}$ ou que sofreram traumas importantes como cirurgia de grande porte) ou em cuidados paliativos ${ }^{43-46,75}$.

Com objetivo de identificar, pela primeira vez, a epidemiologia de feridas no sistema de saúde pública da Austrália Ocidental ${ }^{76}$, foi desenvolvido estudo com 5.800 paciente, apresentando $8 \%$ de prevalência de LF. Em recente revisão sistemática acerca da prevalência de LF, Strazzieri-Pulido e colaboradores ${ }^{77}$ relataram que, no cenário hospitalar mundial, a prevalência de LF varia de 3,3\% a 17\%. No Brasil, Amaral, Pulido e $\operatorname{Santos}^{54}$ desenvolveram um estudo inédito para identificar a prevalência de LF em pacientes oncológicos, obtendo prevalência de 3,3\% sem, no entanto, discriminarem a taxa para aqueles internados em UTI.

Em recente revisão sistemática acerca da incidência de LF, Strazzieri-Pulido e colaboradores $^{75}$ não encontraram estudos sobre a incidência de LF em pacientes críticos em UTI no Brasil e no mundo, apenas dados coletados em um hospital de retaguarda na 
Austrália, na comunidade na nova Zelândia e em Instituições de Longa Permanência para Idosos (ILPI) nos Estados Unidos da América (Quadro 2) ${ }^{64,78-81}$.

Segundo essa revisão sistemática $^{75}$, os coeficientes variaram de 0,92 a 4,6\% e vários fatores foram considerados como risco para o desenvolvimento dessas lesões, a saber: idade avançada ${ }^{64,78,80,81}$, quedas e esbarrões acidentais ${ }^{78,79,81}$, sexo feminino ${ }^{78,80,81}$ ,história prévia de $\mathrm{LF}^{64,80}$, déficit cognitivo/ demência ${ }^{64,80}$, dependência para transferência ${ }^{64,78}$ e membros superiores ${ }^{78,79}$ foram os mais citados. Outros fatores mencionados foram púrpura senil, acamado, mudança de decúbito, auxílio para alimentar-se/ alimentação por sonda, escassez de tecido subcutâneo, cadeiras de rodas, cadeiras e camas, pele frágil, falta de equilíbrio, membros inferiores, idoso frágil, dependência para atividades básicas de vida diária, comprometimento nutricional, rigidez e espasticidade, percepção sensorial diminuída, apetite reduzido, polifarmácia, uso de dispositivos auxiliares (artefatos), equimoses e verão ${ }^{64,78-81}$.

Quadro 2 - Estudos sobre a incidência e fatores de risco de LF, de acordo com o país.

\begin{tabular}{|c|c|c|c|c|}
\hline Autor & Incidência & $\begin{array}{l}\text { Tempo de } \\
\text { avaliação }\end{array}$ & $\begin{array}{l}\text { Local } \\
\text { (País) }\end{array}$ & $\begin{array}{c}\text { Ano de } \\
\text { Publicação }\end{array}$ \\
\hline Payne RL, Martin ML, $1990^{64}$. & $2,23 \%$ & 5 mese & EUA & 1990 \\
\hline $\begin{array}{l}\text { Malone ML, Rozario N, Gavinski } \\
\text { M } 1991^{78} \text {. }\end{array}$ & $0,92 \%$ & 12 meses & EUA & 1991 \\
\hline Everett S, Powell T, $1994^{79}$. & não refere & 6 meses & Austrália & 1994 \\
\hline McGough-Csarny J, Kopac CA ${ }^{80}$. & não refere & 6 meses & EUA & 1998 \\
\hline Kennedy P, Kerse N, $2011^{81}$. & $\begin{array}{c}2,1 \% \text { homens; } 4,6 \% \text { mulheres } \\
\text { (aumenta com a idade: } 1,1 \% \\
\text { para os homens; } 6,1 \% \text { para as } \\
\text { mulheres de } 70 \text { a } 74 \text { anos; } 4 \% \\
\text { para os homens e } 30 \% \text { para as } \\
\text { mulheres com } 85 \text { anos ou } \\
\text { mais) }\end{array}$ & 2 anos & $\begin{array}{c}\text { Nova } \\
\text { Zelândia }\end{array}$ & 2011 \\
\hline
\end{tabular}

Fonte: Strazzieri-Pulido KC, Peres GRP, Campanilli TCGF, Santos VLCG. Incidência de lesões por fricção e fatores de risco: revisão de literatura. No prelo ${ }^{75}$

A subnotificação das $\mathrm{LF}^{53}$ dificulta a percepção dos profissionais sobre a verdadeira dimensão do problema que, muitas vezes, é avaliado e tratado como UP. Em 2004, na Pensilvânia, tornou-se obrigatória a notificação das LF ao Sistema Patient Safety Reporting Pennsylvania (PA-PSRS) ${ }^{82}$. No Brasil, as LF não são rotineiramente avaliadas e tampouco notificadas. 
Diferentemente das UP, para as quais existem inúmeras escalas validadas de predição do risco de seu desenvolvimento, ainda não são conhecidas escalas específicas para as LF. Em 1994, White et al ${ }^{53}$ propuseram um instrumento para a avaliação de risco de LF - Skin Integrity Risk Assessment Tool - contendo três agrupamentos de acordo com as características individuais dos pacientes, usados no presente estudo como direcionador para seleção das variáveis estudadas. Essa escala não se encontra adaptada nem validada para o português e, além disso, não inclui escores de risco, mas sim grupos de risco, podendo ser utilizada muito mais como um guia para a construção de novos instrumentos bem como para a análise de resultados.

Para a classificação das LF, o primeiro e mais citado sistema é o de Payne e $\operatorname{Martin}^{64}$ e data de 1990, com uma revisão posterior em $1993^{60}$. O Payne-Martin Classification System for Skin Tears ${ }^{60}$ é baseado no grau de perda do retalho de pele e conta com três categorias de LF. É muito criticado pela sua simplicidade e por não conter informações acerca do retalho, ${ }^{80,81}$. Em 2003, Dunkin e colaboradores ${ }^{83}$ elaboraram a Classification of Pretibial Injuries, baseando-se em lesões pré-tibiais, porém defendidas pelos autores para o uso em todos os locais do corpo. Já em 2007, Carville et $\mathrm{al}^{72}$ propuseram um sistema de classificação das LF - Skin Tear Classification System (STAR) - a partir da revisão de Payne e Martin. O STAR ${ }^{72}$ é constituído de duas partes principais: guia de tratamento (STAR Skin Tear Classification System Guidelines) e sistema de classificação (STAR Classification System), que inclui cinco categorias de LF (1a, 1b, 2a, 2b e 3). Publicado em 2007, o instrumento foi revisado em 2010 e segue sendo utilizado largamente em pacientes que sofrem com esse tipo de lesão de pele. Já se encontra adaptado e validado para o português ${ }^{50,51}$.

Beldon e colaboradores ${ }^{84}$ propuseram em 2008 um sistema de classificação e tratamento de lesões por fricção, subdividindo as lesões em 7 categorias detalhadas, sendo mais extenso e complicado que os outros o que dificultou sua divulgação.

Em cardiologia, não existem quaisquer estudos acerca de incidência ou prevalência desse tipo de lesão, sendo inédito o presente estudo. 


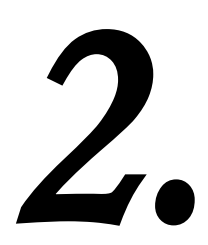

Objetivos 


\section{OBJETIVOS:}

\subsection{GERAL:}

Identificar e analisar os coeficientes de incidência de UP e LF e os fatores de risco para o seu desenvolvimento, em adultos internados em UTI Cardiopneumológica.

\subsection{ESPECÍFICOS:}

- Identificar as características sócio-demográficas, clínicas e cirúrgicas dos pacientes adultos internados na UTI, com e sem UP e LF;

- Caracterizar as UP, desenvolvidas durante o período de coleta de dados, quanto a: localização e classificação;

- Caracterizar as LF, desenvolvidas durante o período de coleta de dados, quanto a: localização e classificação;

- Identificar e analisar a incidência e os fatores de risco em pacientes que apresentam ambas as lesões simultaneamente. 


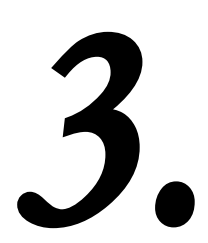

Métodos 


\section{MÉTODOS}

\subsection{TIPO DE ESTUDO}

Trata-se de estudo epidemiológico, de coorte, prospectivo.

\subsection{LOCAL DO ESTUDO}

O estudo foi conduzido na UTI Cirúrgica de um hospital público, universitário, de alta complexidade, especializado em cardiopneumologia. A instituição tem como missão, promover ações de difusão do conhecimento científico, de técnicas e de tecnologias em sua especialidade para o desenvolvimento econômico-social do país e bem-estar da população. Dispõe de $75.000 \mathrm{~m}^{2}$ de área construída em dois prédios, com 535 leitos distribuídos em sete alas de internação, sendo 157 leitos de UTI de alta complexidade (UTI clínica para adultos, UTI neonatal e UTI cirúrgica). Conta com 14 salas de cirurgia, sete salas para estudos hemodinâmicos e eletrofisiológicos, 12 salas de diagnóstico de alta complexidade (tomografia, ressonância e medicina nuclear) e 60 consultórios médicos. Aproximadamente $80 \%$ dos atendimentos são dedicados a pacientes cujo tratamento é financiado pelo Sistema Único de Saúde (SUS). O hospital também atende pacientes particulares e com cobertura de empresas de saúde suplementar.

A instituição conta com auxílio de um Grupo de Estudos denominado Grupo de Curativos, destinado ao cuidado da pele íntegra ou de feridas (UP, feridas operatórias e úlceras venosas e arteriais), constituído exclusivamente por enfermeiros, com um representante de cada unidade de internação. Apesar da existência do grupo, não há protocolos de prevenção e de tratamento de lesões de pele implantados na instituição.

A UTI Cirúrgica, dividida em UTI I e II, dispõe de 71 leitos (31 e 40 respectivamente) e sob os cuidados de uma única chefia de enfermagem, presta cuidados aos pacientes no pós-operatório de cirurgias cardiopulmonares. Para o atendimento desses pacientes, as unidades contam com o serviço de profissionais qualificados, em três turnos de trabalho (manhã, tarde e noite), com carga horária total 
de 40 horas semanais. A média de admissão na UTI é de 12 pacientes/dia, considerando-se somente os dias úteis; sua taxa de ocupação média é de 94,2\% e a média de permanência é de cerca de 6 dias. A escala de Braden é utilizada na UTI Cirúrgica para estratificar os pacientes em risco para o desenvolvimento de UP, sendo o escore $\leq 16$ empregado como de corte. Os escores dos pacientes são notificados à coordenação de enfermagem mensalmente, por meio de impresso elaborado pelo grupo de indicadores de qualidade existente na Instituição. O tratamento das lesões notificadas e a busca ativa diária por lesões de pele nas UTI ficam a cargo do Grupo de Curativos.

\subsection{POPULAÇÃO E AMOSTRA}

A população do estudo foi constituída de todos os pacientes adultos internados na UTI Cirúrgica, durante três meses consecutivos, e a amostra, por pacientes que atenderam aos seguintes critérios de inclusão:

- ter idade maior ou igual a 18 anos,

- não apresentar UP na admissão na UTI,

- não apresentar LF na admissão na UTI,

- ter sido admitido na UTI há menos de 24 horas, e

- aceitar participar do estudo.

\subsubsection{Tamanho da amostra e tempo de estudo}

A amostra foi constituída de 370 pacientes admitidos na UTI Cirúrgica, que atenderam aos critérios de inclusão, no período de 26 de novembro de 2013 a 26 de fevereiro de 2014, com censura de uma semana.

O cálculo amostral foi baseado no estudo desenvolvido por Rogenski e Santos ${ }^{7}$ (incidência de $41 \%$ de UP em UTI), considerando-se nível de significância de 5\% e precisão da estimativa absoluta de 5\%, gerando amostra necessária de 370 pacientes. Para o cálculo da amostra utilizaram-se apenas dados de UP por não existirem dados de incidência de LF em pacientes críticos. 


\subsection{COLETA DE DADOS}

\subsubsection{Capacitação de enfermeiros para a coleta de dados}

Inicialmente, o projeto foi apresentado à chefia de enfermagem da UTI, impresso em duas vias, e encaminhado ao Serviço de Educação Continuada da instituição para análise de seu conteúdo, após apreciação do enfermeiro chefe e da diretora de enfermagem da instituição.

Com o conteúdo aprovado, o projeto foi divulgado verbalmente na UTI. Três enfermeiras mostraram interesse e afinidade com o tema da pesquisa e foram convidadas a colaborar com a pesquisadora na coleta de dados.

As enfermeiras colaboradoras foram submetidas a um processo de capacitação, coordenado e ministrado pela pesquisadora, que incluiu aulas teórico-práticas sobre exame físico da pele, avaliação de risco para o desenvolvimento de UP e LF e aplicação dos instrumentos de coleta de dados (dados sócio-demográficos, clínicos e cirúrgicos, Escala de Braden ${ }^{15,39}$, Escala de Coma de Glasgow ${ }^{24,44,45}$, Escala de Ramsay ${ }^{12,46}$, APACHE II ${ }^{47}$ ).

Essa capacitação foi realizada por meio de reuniões formais, divididas em quatro etapas:

1. ETAPA: aula teórica ministrada pela pesquisadora, abordando:

- Exame físico da pele (inspeção visual);

- Definição e classificação de UP, de acordo com NPUAP/ EPUAP ${ }^{4}$;

- Definição e classificação de LF, de acordo com STAR ${ }^{50,51}$;

- Fatores de risco para o desenvolvimento de UP e LF, gerais e específicos para pacientes críticos;

- Instrumentos a serem utilizados no estudo (Instrumento com dados sócio demográficos clínicos e cirúrgicos (APÊNDICE I), Escala de Braden ${ }^{15,39}$, Escala de Coma de Glasgow ${ }^{24,44,45}$, Escala de Ramsay ${ }^{12,46}$, APACHE II $^{47} \mathrm{e}$ STAR $^{50,51}$ )

2. ETAPA: discussão e identificação de UP e LF nos pacientes hospitalizados, de acordo com as classificações padronizadas, à beira do leito; 
3. ETAPA: avaliação prática individualizada das enfermeiras em capacitação, nos processos de aplicação da escala de Braden ${ }^{15,39}$ e de classificação das UP e das LF, de acordo com casos clínicos e fotos apresentados pela pesquisadora;

4. ETAPA: Discussão e avaliação clínica de três pacientes, por meio de relato de caso e fotos, aplicando-se a escala de Braden ${ }^{15,39}$ e classificação das lesões de acordo com NPUAP/EPUAP ${ }^{4}$ e/ou STAR $^{50,51}$, além da identificação dos fatores de risco para o desenvolvimento das mesmas.

Os enfermeiros foram considerados aptos para o início da coleta de dados ao obterem $100 \%$ de concordância com a pesquisadora (padrão ouro de avaliação), na etapa 4.

\subsubsection{Procedimentos éticos}

Inicialmente, o projeto de pesquisa foi inserido na Plataforma Brasil e, posteriormente, submetido ao Comitê de Ética em Pesquisa (CEP) da Escola de Enfermagem da Universidade de São Paulo EE-USP (Instituição proponente da pesquisa). O projeto foi aprovado de acordo com protocolo número 20780713.4.0000.5392, com parecer consubstanciado do CEP publicado na Plataforma Brasil em 24/10/2013.

Após aprovação, encaminhou-se uma cópia do projeto à Comissão Científica da Instituição coparticipante para apreciação do diretor clínico, que tomou ciência da documentação e autorizou início da coleta de dados em 25 de novembro de 2013.

Durante o período de coleta de dados, todos os pacientes admitidos na UTI, que obedeceram aos critérios de inclusão, foram convidados a participar do estudo, sendolhes apresentados os objetivos e procedimentos de coleta de dados da pesquisa. Procedeu-se à coleta de dados somente após a assinatura do Termo de Consentimento Livre e Esclarecido - TCLE (ANEXO I) pelo paciente ou seu responsável, em duas vias, ficando uma via com a pesquisadora e a outra com o participante do estudo ou com seu responsável. O responsável pelo paciente foi orientado quando o paciente não 
apresentou condições físicas e/ou mentais para compreender as orientações e/ou assinar o TCLE.

\subsubsection{Procedimentos para a coleta de dados}

Após a inserção no estudo, procedeu-se à coleta de dados na seguinte ordem:

1. Transcrição dos dados sócio-demográficos clínicos e cirúrgicos do paciente para o impresso desenvolvido pela pesquisadora;

2. Aplicação da escala de Braden;

3. Aplicação do APACHE II (apenas nas primeiras 24 de admissão na UTI);

4. Aplicação da Escala de Ramsay, para pacientes sob efeito de agentes anestésicos, ou aplicação da Escala de Glasgow para aqueles pacientes sem efeito de tal medicamento; e

5. Realização do exame físico na orientação céfalo-podálico, com atenção para os artefatos inseridos na pele e presença de superfícies de suporte.

Após a primeira avaliação, os pacientes eram visitados diariamente para a realização do exame físico em busca de UP e LF, da presença de artefatos inseridos na pele e da presença de superfícies de suporte. Segundo o consenso do NPUAP/EPUAP ${ }^{4}$ para prevenção de UP, pacientes críticos devem ser avaliados diariamente quanto à presença dessa lesão. Além do exame físico, eram aplicadas as escalas de Braden, Ramsay ou Glasgow. Todos os dados eram diariamente organizados em uma planilha individualizada.

A avaliação diária descrita foi aplicada até a ocorrência de algum dos seguintes desfechos: desenvolvimento de UP, desenvolvimento de LF, alta ou transferência da UTI, óbito ou saída voluntária do estudo. Para os desfechos UP e LF, o paciente que desenvolveu UP isolada durante o seguimento continuou no estudo para a avaliação da ocorrência de LF simultânea (no período) e vice-versa, ou seja, o que desenvolveu LF isolada também continuou no estudo para a avaliação do surgimento de UP. Os dados foram coletados durante três meses consecutivos.

Todos os pacientes foram acompanhados durante a internação, com censura de uma semana, ou seja, ao término do período estipulado para a coleta dos dados, após o 
último dia de admissão no estudo, os pacientes foram acompanhados por mais uma semana.

As UP foram avaliadas quanto às suas características, incluindo localização e categoria, de acordo com a proposta da NPUAP/ EPUAP ${ }^{4}$ (ANEXO II ). Quanto às LF, além da localização foram classificadas de acordo com o STAR ${ }^{50,51}$ (ANEXO III ).

Quanto ao Índice de Massa Corporal (IMC), calculado para todos os pacientes participantes do estudo, utilizou-se a fórmula: $\mathrm{IMC}=\mathrm{Peso} /$ Altura $^{2}$. Sua categorização baseou-se naquela estabelecida pela Organização Mundial de Saúde ${ }^{85}$, em intervalos $<18,4$ baixo peso; 18,5-24,9 peso normal; 25-30 sobrepeso e $>30$ obeso.

Figura 2 - Classificação do IMC, segundo a Organização Mundial da Saúde.

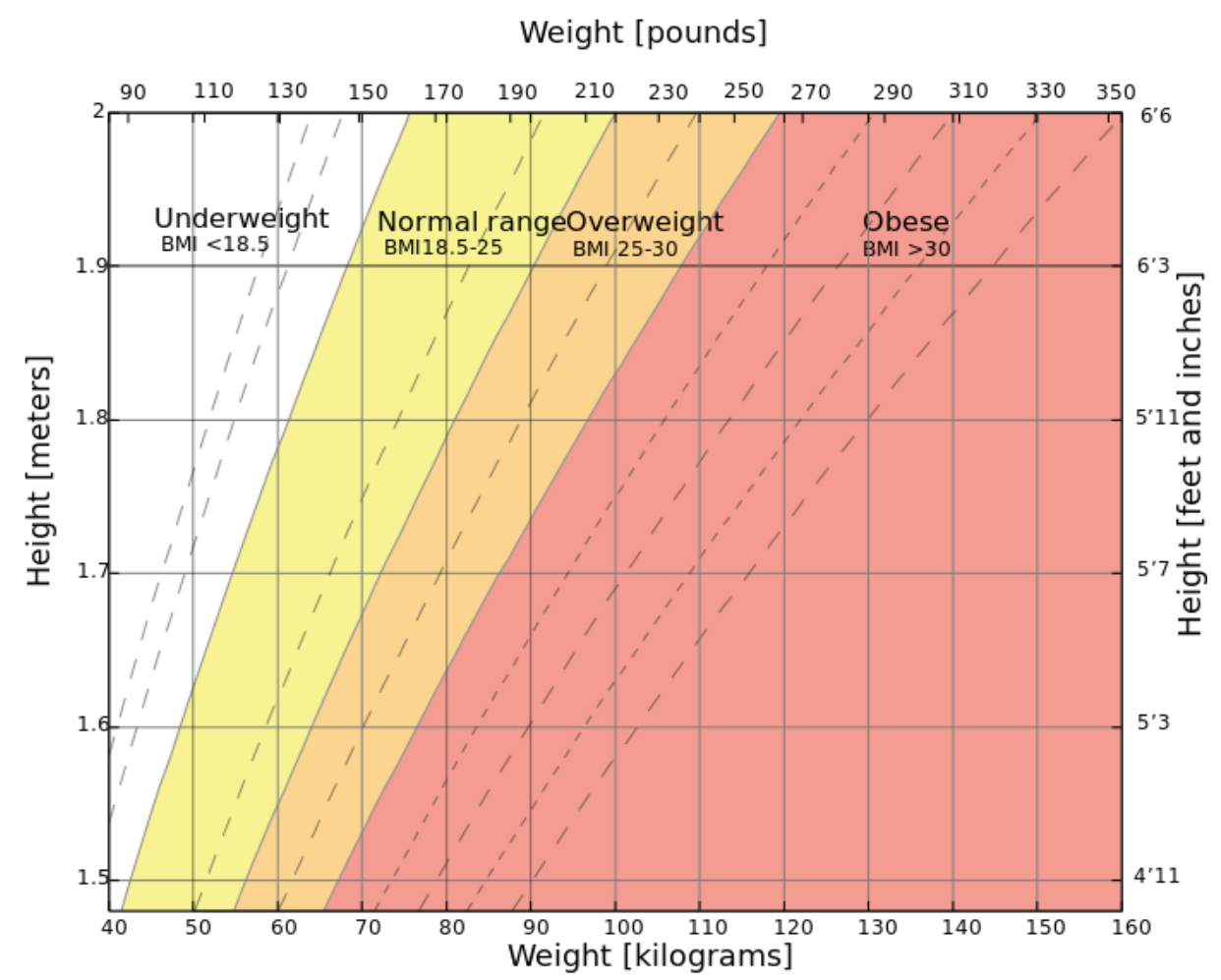

Fonte: World Health Organization. BMI Classification. Global Database on Body Mass index: World Health organization; 2013. Disponível em http://www.who.int/en/, 2014 ${ }^{85}$.

\subsubsection{Instrumentos para a coleta de dados}

Para a coleta de dados foram utilizados os instrumentos descritos a seguir. 


\subsubsection{Dados sócio-demográficos clínicos e cirúrgicos}

Este instrumento (APÊNDICE I) foi desenvolvido pela pesquisadora e contém as seguintes variáveis: nome, registro de internação, idade, raça, sexo, peso, altura, índice de massa corporal - IMC, comorbidades e hábitos prévios (diabetes mellitus DM, hipertensão arterial sistêmica - HAS, dislipidemia - DL, acidente vascular encefálico - AVE, fibrilação atrial- FA e tabagismo, tipo de procedimento cirúrgico realizado, tempo de procedimento, uso e tempo de circulação extracorpórea, uso de hemoderivados, uso e concentração de drogas vasoativas na admissão, tipo e número de artefatos (cateteres venosos e arteriais, drenos), duração da internação, data do aparecimento da lesão (UP e/ou LF), alta da UTI ou óbito.

Frequência de aplicação: os dados sócio demográficos, comorbidades, hábitos e dados cirúrgicos foram coletados na admissão, enquanto os demais dados clínicos, foram também coletados diariamente, durante a internação na UTI.

\subsubsection{Escala de Braden}

Para a identificação dos pacientes em risco de desenvolvimento de UP, Braden e Bergstrom $^{15}$ desenvolveram uma escala composta de seis sub escalas: percepção sensorial, atividade, mobilidade, umidade, nutrição, fricção e cisalhamento. A escala de Braden tem se mostrado como instrumento eficaz para a tomada de decisões do enfermeiro no planejamento de medidas preventivas a serem adotadas, de acordo com o risco de cada paciente para o desenvolvimento de UP. Essa escala foi adaptada e validada para o Brasil por Paranhos e $\operatorname{Santos}^{40}$, em 1999, e será a versão utilizada no presente estudo (ANEXO IV). A pontuação das sub escalas varia de 1 a 4, exceto para fricção e cisalhamento, que varia de 1 a 3 pontos, totalizando escores de 6 a 23. Segundo o Consenso do Wound Ostomy and Continence Nursing Society ${ }^{14}$ (WOCN), no paciente crítico, a escala de Braden deve ser aplicada na admissão ou até 24 após a admissão e, pelo menos, a cada 48 horas ou quando ocorrer alteração em suas condições de saúde, já que apresentam inúmeros fatores de risco. Usualmente, o escore 16 denota que o paciente adulto tem risco para o desenvolvimento de UP, entretanto, na presença de outros fatores como idade maior que 65 anos, febre, baixa ingestão de proteína, pressão diastólica menor que $60 \mathrm{mmHg}$ e/ou instabilidade hemodinâmica, os pacientes 
com escores 17 e 18 também são considerados como pacientes em risco. Desde 2002, tem-se se utilizado a seguinte classificação de risco ${ }^{86}$ : em risco (escores 15 a 18), risco moderado (escores 13 e 14), alto risco (10 a 12) e risco muito alto (escores $\leq 9)$. Neste estudo, adotou-se o escore 18 como nota de corte para o risco de desenvolvimento de $\mathrm{UP}^{11,14,35,86}$.

Frequência de aplicação: diariamente.

\subsubsection{Escala de Coma de Glasgow (ECG) $)^{24,44,45}$}

Trata-se de uma escala neurológica que se constitui em método confiável e objetivo de registro do nível de consciência do indivíduo. Embora tenha sido idealizada para avaliar o nível de consciência após o trauma encefálico, atualmente a escala tem sido aplicada em diferentes situações. Foi publicada oficialmente em 1974, na revista Lancet, por Graham Teasdale e Bryan J. Jennett, professores de neurologia na University of Glasgow. Tendo em vista a possibilidade de expansão de sua utilização, em 1970, o National Institutes of Health, Public Health Service, U.S. Department of Health and Human Services financiou dois estudos internacionais paralelos que avaliaram, respectivamente, o estado de coma de pacientes com traumatismos cranianos graves e o prognóstico médico do coma. Os pesquisadores desenvolveram, então, o chamado Índice de Coma que, posteriormente, transformou-se na Escala de Coma de Glasgow, à medida que os dados estatísticos aplicados refinaram o sistema de pontuação. A escala (ANEXO V) compreende três testes: respostas de abertura ocular, fala e capacidade motora. Os três valores separadamente e somados são considerados. A primeira variável - abertura ocular - pode ser avaliada quanto a: abertura espontânea ( 4 pontos), voz ( 3 pontos), dor ( 2 pontos), ou não abre (1 ponto); resposta verbal orientada (5 pontos), confusa ( 4 pontos) palavras inapropriadas (3 pontos), palavras incompreensíveis ( 2 pontos) e nenhuma (1 ponto); resposta motora obedece a comandos (6 pontos), localiza dor (5 pontos), movimento de retirada (4 pontos), flexão anormal ( 3 pontos), extensão anormal ( 2 pontos) e nehuma (1 ponto). A pontuação pode variar de 3 a 15 e o escore 8 sugere necessidade de intubação endotraqueal.

Frequência de aplicação: diariamente para os pacientes sem sedação. 


\subsubsection{Acute Physiology and Chronic Health Evolution (APACHE) ${ }^{47}$}

Os índices de gravidade têm como objetivo principal a descrição quantitativa do grau de disfunção orgânica de pacientes gravemente enfermos e o risco de morte nas primeiras 24 horas de internação na UTI. Essa gravidade é traduzida em valor numérico, a partir das alterações clínicas e laboratoriais existentes ou do tipo/número de procedimentos utilizados. O Acute Physiology and Chronic Health Evolution (APACHE) foi desenvolvido em 1981 e submetido a uma revisão e simplificação em 1985, sendo denominado APACHE II. Para o seu cálculo, habitualmente aplicado nas primeiras 24 horas de internação na UTI, são utilizadas 12 variáveis clínicas, fisiológicas e laboratoriais padronizadas, pontuadas de zero a quatro, conforme o grau de desvio da normalidade apresentado; além disso, pontos são atribuídos a idade, presença de doença crônica e variáveis fisiológicas, cuja soma fornece uma pontuação final que permite calcular o risco de óbito para o paciente clínico ou cirúrgico (0 a $100)^{3}$. Essa pontuação se subdivide em: risco baixo (APACHE<11), com $0 \%$ de mortalidade; risco alto (APACHE entre 11 e 20), com 32\% de mortalidade; e risco crítico (APACHE >20), com 75\% de mortalidade. O APACHE II (ANEXO VI) é ferramenta utilizada e testada internacionalmente há vários anos e foi apresentada pelo Ministério da Saúde brasileiro como escore a ser usado para análise da gravidade dos pacientes adultos, admitidos em UTI, conforme Portaria 3432, de 12 de agosto de $1998^{87}$.

Frequência de aplicação: nas primeiras 24 horas de admissão.

\subsubsection{Escala de Ramsay ${ }^{12,46}$}

É um tipo de escala subjetiva, utilizada para avaliar o grau de sedação de pacientes (ANEXO VII). Visa a evitar a sedação insuficiente (o paciente pode sentir dor) ou demasiadamente excessiva (colocando-o em risco de morte). Tem sido usada principalmente para avaliar pacientes em UTI. A escala de Ramsay foi descrita, pela primeira vez em 1974, pelo médico Michael Ramsay, como parte de um estudo sobre o efeito do esteróide anestésico. Valores de 1 a 6 são atribuídos de acordo com as 
respostas dadas pelo paciente a estímulos específicos, caracterizando a seguinte classificação:

- Grau 1: paciente ansioso, agitado;

- Grau 2: cooperativo, orientado, tranquilo;

- Grau 3: sonolento, atendendo aos comandos;

- Grau 4: dormindo, responde rapidamente ao estímulo glabelar ou ao estímulo sonoro vigoroso;

- Grau 5: dormindo, responde lentamente ao estímulo glabelar ou ao estímulo sonoro vigoroso;

- Grau 6: dormindo, sem resposta.

Frequência de aplicação: nas primeiras 24 horas de admissão ou se fizer uso de sedativo.

\subsection{DEFINIÇÕES OPERACIONAIS PARA AS LF}

Foram consideradas LF todas as lesões de pele causadas por trauma incidental, fricção e retirada traumática de adesivos de acordo com $\operatorname{STAR}^{50,51}$. As LF relacionadas à retirada traumática de fitas adesivas deveriam estar próximas às áreas de fixação de cateteres, drenos e ferida operatória.

Desse modo, de acordo com a origem, as LF foram descritas como:

- LF por trauma espontâneo: aquelas lesões provocadas pelo próprio paciente como resultado da movimentação descoordenada de braços e pernas;

- LF durante a mobilização: provocadas durante a mobilização do paciente no leito ou transferência para poltrona ou cadeiras de rodas;

- LF por retirada traumática de adesivos: lesões provocadas pela retirada de adesivos próximos à inserção de cateteres (venoso e arterial), drenos e ferida operatória. 


\subsection{VARIÁVEIS DO ESTUDO}

As variáveis do estudo apresentam-se listadas no Quadro 3.

Quadro 3 - Variáveis dependentes e independentes do estudo.

\begin{tabular}{|c|c|c|}
\hline \multicolumn{3}{|c|}{ VARIÁVEIS DEPENDENTES } \\
\hline Úlcera por pressão & Variável Nominal & Sim/Não \\
\hline Lesão por fricção & Variável Nominal & Sim/Não \\
\hline \multicolumn{3}{|c|}{ VARIÁVEIS INDEPENDENTES } \\
\hline \multicolumn{3}{|l|}{ DEMOGRÁFICAS } \\
\hline Sexo & Variável Nominal & Feminino / Masculino \\
\hline Idade & Variável Contínua & Em anos \\
\hline Raça & Variável Nominal & Branca/Negra/Amarela/Parda \\
\hline \multicolumn{3}{|l|}{ CLÍNICAS } \\
\hline Índice de massa corporal (IMC) & Variável Numérica Intervalar & $<18,4 ; 18,5-24,9 ; 25-30 ;>30$ \\
\hline Diabetes Mellitus (DM) & Variável Nominal & Sim/Não \\
\hline Hipertensão Arterial Sistêmica (HAS) & Variável Nominal & Sim/Não \\
\hline Dislipidemia & Variável Nominal & Sim/Não \\
\hline Acidente Vascular Encefálico (AVE) & Variável Nominal & Sim/Não \\
\hline Fibrilação Atrial (FA) & Variável Nominal & Sim/Não \\
\hline Tabagismo & Variável Nominal & Sim/Não \\
\hline Escala de Braden & Variável Numérica Intervalar & Escore de 6 a 23 \\
\hline APACHE II & Variável Numérica Intervalar & Escore de 0 a 100 \\
\hline Ramsay & Variável Numérica Intervalar & Escore de 1 a 6 \\
\hline Glasgow & Variável Numérica Intervalar & Escore de 3 a 15 \\
\hline Superfície de suporte & Variável Nominal & Sim/Não \\
\hline $\begin{array}{l}\text { Lesões nas extremidades (fúngica, amputação ou } \\
\text { isquemia) }\end{array}$ & Variável Nominal & Sim/Não \\
\hline Artefatos inseridos na pele (admissão da UTI) & Variável Numérica Intervalar & Em unidades \\
\hline Número de artefatos no aparecimento da lesão & Variável Numérica Intervalar & Em unidades \\
\hline Tempo de internação antes da admissão UTI & Variável Contínua & Em dias \\
\hline Tempo de internação na UTI & Variável Contínua & Em dias \\
\hline \multicolumn{3}{|l|}{$\underline{\text { CIRÚRGICAS }}$} \\
\hline Revascularização do miocárdio & Variável Nominal & Sim/Não \\
\hline Plástica valvar cardíaca & Variável Nominal & Sim/Não \\
\hline Troca de valva cardíaca & Variável Nominal & Sim/Não \\
\hline Correção vascular & Variável Nominal & Sim/Não \\
\hline Outro tipo de cirurgia cardiopneumológica & Variável Nominal & Sim/Não \\
\hline Tempo de cirurgia & Variável Contínua & Em minutos \\
\hline Tempo de circulação extracorpórea & Variável Contínua & Em minutos \\
\hline Transfusão sanguínea & Variável Nominal & Sim/Não \\
\hline Drogas vasoativas & Variável Nominal & Sim/Não \\
\hline
\end{tabular}




\subsection{ANÁLISE DOS DADOS}

Os dados foram descritos por meio de média e desvio-padrão para as variáveis contínuas e frequências absolutas e relativas para as categóricas. A associação da incidência de UP e LF com as variáveis demográficas, clínicas e cirúrgicas foram feitas utilizando-se o teste exato de Fisher para as variáveis categóricas, teste t-Student para as variáveis numéricas que apresentaram distribuição normal e o teste de Wilcoxon-Mann-Whitney, para aquelas com outra distribuição.

Após as análises univariadas, construiu-se uma árvore de decisão com o algoritmo Classification And Regression Tree (CART), para identificar os fatores de risco para o desenvolvimento de UP isolada, LF isolada e UP e LF simultâneas. Esse método é não paramétrico e procura as variáveis que são capazes de distinguir os grupos de maneira mais homogênea possível. Optou-se pela utilização dessa técnica de análise estatística, pela fácil interpretação dos resultados, através de gráficos (árvore). Outra vantagem apresentada pelo CART é que ele não depende de testes de hipóteses. Devido à baixa prevalência dos efeitos estudados, neste estudo a regressão logística, método frequentemente utilizado em estudos de coorte, teria problemas de estimação ${ }^{88}$ As análises foram feitas utilizando-se o Programa R 3.1.0 e o nível de significância foi fixado em $5 \%$.

\subsubsection{Cálculo de incidência de UP e LF}

A incidência expressa o número de casos novos de determinada condição ou doença na população, durante um determinado período de tempo. A incidência reflete a dinâmica com que os casos aparecem no grupo e a força da morbidade. Para estabelecer a incidência, é necessário especificar a duração do tempo de observação de surgimento dos casos novos ${ }^{11,14}$ que, neste estudo, foi de três meses.

Para o cálculo da incidência, utilizou-se a seguinte fórmula:

$$
\mathrm{n}^{\circ} \text { de "casos novos" em determinado período }
$$

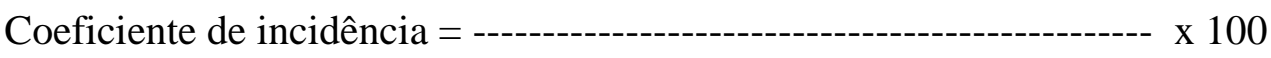

$\mathrm{n}^{\circ}$ de pessoas expostas ao risco no mesmo período 


$$
\begin{array}{r}
4 . \\
\text { Resultados }
\end{array}
$$




\section{RESULTADOS}

Os resultados são apresentados nos seguintes tópicos: Caracterização da amostra; Incidência e fatores de risco para UP; Incidência e fatores de risco para LF; Incidência e fatores de risco para o desenvolvimento simultâneo de UP e LF.

\subsection{CARACTERIZAÇÃO DA AMOSTRA}

De acordo com os critérios de inclusão no estudo, 370 pacientes compuseram a sua amostra, apresentando idade média de 57,22 anos $(\mathrm{DP}=15,85)$ variação de 18-96 anos; sendo 202 (54,60\%) do sexo masculino e $307(83,00 \%)$ da raça branca.

Quanto às características clínicas, a amostra apresentou IMC médio de 25,87 $\mathrm{Kg} / \mathrm{m}^{2}(\mathrm{DP}=4,11)$ em sobrepeso, com variação de 17 a 38,80; e comorbidades como: DM (100/ 27,02\%); HAS (221/ 59,72\%); DL (112/ 30,27\%); tabagismo (51/ 13,78\%); AVE (24/ 6,48\%) e FA (40/ 10,81\%); escore médio de APACHE II de 22,21 ( $\mathrm{DP}=5,01)$, com variação de 2 a 32; escore médio de Braden de 9,65 ( $\mathrm{DP}=2,85)$, com variação de 6 a 23; escore médio de Ramsay de 5,09 ( $\mathrm{DP}=1,65)$, com variação de 2 a 6; escores médios de Glasgow de 5,78 (DP=5,03) na admissão e de 14,60 ( $\mathrm{DP}=1,23)$ na alta, com variação de 3 a 15; tempo médio de permanência na UTI de 5,51 dias (DP=5,59), com variação de 1 a 63 dias; uso de transfusão sanguínea em 98 pacientes $(26,48 \%)$ e de drogas vasoativas em 285 (77,02\%) participantes do estudo. Devido ao estado crítico dos pacientes, foram necessários artefatos inseridos na pele para a monitorização cardíaca e pulmonar, para a administração de drogas e para a drenagem de líquidos (cateteres venosos e arteriais, drenos torácicos, marcapasso provisório epicárdico e cateteres vesicais), perfazendo a média de 5,43 ( $\mathrm{DP}=2,19)$ artefatos por paciente, com variação de 0 a 11 artefatos por paciente na admissão (Tabela 1). 
Tabela 1 - Variáveis clínicas dos pacientes da amostra. São Paulo, 2013-2014.

\begin{tabular}{|c|c|c|}
\hline Variáveis clínicas & $\mathbf{n}=\mathbf{3 7 0}$ & \\
\hline - Comorbidades & $\mathrm{n}(\%)$ & --- \\
\hline DM & $100(27,02)$ & \\
\hline HAS & $221(59,72)$ & \\
\hline DL & $112(30,27)$ & \\
\hline Tabagismo & $51(13,78)$ & \\
\hline AVE & $24(6,48)$ & \\
\hline FA & $40(10,81)$ & \\
\hline - Transfusão sanguínea & $98(26,48)$ & --- \\
\hline \multirow[t]{2}{*}{ - Drogas vasoativas } & $285(77,02)$ & --- \\
\hline & Média (DP) & Variação \\
\hline - IMC & $25,87(4,11)$ & $17-38,80$ \\
\hline - APACHE II & $22,21(5,01)$ & $2-32$ \\
\hline - Ramsay & $5,09(1,65)$ & $2-6$ \\
\hline \multicolumn{3}{|l|}{ - Glasgow } \\
\hline Admissão & $5,78(5,03)$ & --- \\
\hline Ao final da participação no estudo & $14,60(1,23)$ & $3-15$ \\
\hline Braden & $9,65(2,85)$ & $6-23$ \\
\hline Número de artefatos (admissão) & $5,43(2,19)$ & $0-11$ \\
\hline Tempo de permanência na UTI (dias) & $5,51(5,59)$ & $1-63$ \\
\hline
\end{tabular}

n (\%)- valor absoluto e percentual de pacientes

Dentre os participantes, 120 pacientes $(32,43 \%)$ foram submetidos à revascularização do miocárdio $(\mathrm{RM})$ e 74 (20,00\%) trocaram valvas cardíacas; utilizouse circulação extracorpórea (CEC) em 210 pacientes (56,75\%), com tempo médio de 94,90 minutos $(\mathrm{DP}=40,30)$, em procedimentos cirúrgicos que tiveram tempo médio de 278,30 minutos (DP=99,90) (Tabela2). 
Tabela 2 - Variáveis cirúrgicas dos pacientes da amostra. São Paulo, 2013-2014.

\begin{tabular}{lc}
\hline Variáveis cirúrgicas & $\mathbf{n = 3 7 0}$ \\
\hline Procedimento cirúrgico & $\mathbf{n}(\boldsymbol{\%})$ \\
- Revascularização do miocárdio & $120(32,43)$ \\
- Troca de valva & $74(20,00)$ \\
$*$ Mitral & $33(8,91)$ \\
$*$ Mitral e Aórtica & $3(0,81)$ \\
$*$ Tricúspide & $2(0,54)$ \\
$*$ Aórtica & $36(9,72)$ \\
- Plástica de valva & $30(8,10)$ \\
$*$ Mitral & $18(4,86)$ \\
$*$ Mitral e Aórtica & $1(0,27)$ \\
$*$ Tricúspide & $2(0,54)$ \\
$*$ Aórtica & $5(1,35)$ \\
- Transplante cardíaco & $4(1,08)$ \\
- Transplante pulmonar & $1(0,27)$ \\
- Outros** & $1(0,27)$ \\
\hline Uso de CEC & $144(38,91)$ \\
Tempo de CEC (min.) & $210(56,75)$ \\
\hline
\end{tabular}

n (\%)- valor absoluto e percentual de pacientes

** Outros: tratamento clínico para rejeição após transplante cardíaco e pulmonar, choque séptico, choque cardiogênico, cirurgia para colocação de prótese de quadril e colecistectomia.

Dos 370 pacientes que integraram a amostra do estudo, $350(94,59 \%)$ receberam alta da UTI; $17(4,59 \%)$ foram a óbito e $3(0,81 \%)$ permaneceram internados na UTI após o término do estudo.

\subsection{INCIDÊNCIA E FATORES DE RISCO PARA UP}

Detectaram-se 40 UP em 40 pacientes, caracterizando coeficiente global de incidência de 10,80\%; sendo de 7,83\% em homens e 2,97\% em mulheres ( $p=0,018)$; e 9,72\% na raça branca. Para a idade, verifica-se incidência de 6,48\% em pessoas com idade igual e superior a 60 anos (Tabela 3). 
Tabela 3 - Incidência de UP segundo variáveis demográficas. São Paulo, 2013-2014.

\begin{tabular}{|c|c|c|c|}
\hline \multirow[b]{2}{*}{ Variáveis demográficas } & \multicolumn{2}{|c|}{ Úlcera por pressão } & \multirow{2}{*}{$\mathbf{P}$} \\
\hline & $\begin{array}{c}\text { Sim } \\
\mathbf{n}(\%)\end{array}$ & $\begin{array}{c}\text { Não } \\
\text { n(\%) }\end{array}$ & \\
\hline Idade & & & 0,400 \\
\hline 18 a 29 anos & - & $26(7,02)$ & \\
\hline 30 a 39 anos & $3(0,81)$ & $27(7,29)$ & \\
\hline 40 a 49 anos & $5(1,35)$ & $47(12,70)$ & \\
\hline 50 a 59 anos & $8(2,16)$ & $62(16,75)$ & \\
\hline 60 anos e mais & $24(6,48)$ & $168(45,40)$ & \\
\hline Sexo & & & $\mathbf{0 , 0 1 8}$ \\
\hline Feminino & $11(2,97)$ & $157(42,43)$ & \\
\hline Masculino & $29(7,83)$ & $173(46,75)$ & \\
\hline Raça & & & 0,206 \\
\hline Branca & $36(9,72)$ & $271(73,24)$ & \\
\hline Negra & - & $27(7,29)$ & \\
\hline Amarela & $1(0,27)$ & $6(1,62)$ & \\
\hline Parda & $3(0,81)$ & $26(7,02)$ & \\
\hline
\end{tabular}

n (\%)- valor absoluto e percentual de pacientes

Ainda quanto à idade, constatou-se que houve diferença estatisticamente significativa $(\mathrm{p}=0,014)$ entre as médias para os pacientes com $(63$ anos; $\mathrm{DP}=13,46)$ e sem UP (56,52 anos; DP=15,99). 
Tabela 4 - Variáveis clínicas e cirúrgicas quantitativas dos pacientes com e sem UP. São Paulo, 2013-2014.

\begin{tabular}{lccc}
\hline & \multicolumn{2}{c}{ Úlceras por pressão } & \multirow{2}{*}{ Variáveis clínicas } \\
\cline { 2 - 3 } & $\begin{array}{c}\text { Sim } \\
\text { Média (DP) }\end{array}$ & $\begin{array}{c}\text { Não } \\
\text { Média (DP) }\end{array}$ & \\
\hline IMC & $25,54(4,15)$ & $25,91(4,11)$ & 0,591 \\
$\begin{array}{l}\text { Tempo de internação até a admissão na UTI } \\
\text { (dias) }\end{array}$ & $9,23(11,88)$ & $9,51(34,85)$ & 0,363 \\
Permanência na UTI (dias) & $13,68(11,84)$ & $4,52(3,06)$ & $<\mathbf{0 , 0 0 1}$ \\
Número de artefatos (admissão) & $5,63(2,52)$ & $5,41(2,14)$ & 0,551 \\
APACHE II & $22,33(4,74)$ & $22,20(5,05)$ & 0,689 \\
Ramsay & $5,10(1,69)$ & $5,09(1,65)$ & 0,901 \\
Braden & $9,70(3,07)$ & $9,64(2,82)$ & 0,761 \\
Tempo de CEC (min.) & $119,71(68,21)$ & $92,17(35,19)$ & $\mathbf{0 , 0 3 0}$ \\
Tempo cirúrgico (min.) & $292,58(133,33)$ & $276,64(95,55)$ & 0,387 \\
\hline
\end{tabular}

A Tabela 4 mostra que, dentre as variáveis clínicas quantitativas, os grupos mostraram-se significativamente diferentes apenas quanto ao tempo de permanência na UTI, superior entre aqueles com UP $(13,68 ; \mathrm{DP}=11,84)(\mathrm{p}<0,001)$ e entre as variáveis cirúrgicas o tempo de CEC, maior entre o grupo com UP $(119,71 ; \mathrm{DP}=68,21)$ $(\mathrm{p}=0,030)$. 
Tabela 5 - Variáveis nominais clínicas e cirúrgicas dos pacientes com e sem UP. São Paulo, 2013-2014.

\begin{tabular}{|c|c|c|c|}
\hline \multirow[b]{2}{*}{ Variáveis clínicas } & \multicolumn{2}{|c|}{ Úlceras por pressão } & \multirow[b]{2}{*}{$\mathbf{P}$} \\
\hline & $\begin{array}{c}\text { Sim } \\
\mathbf{n}(\%)\end{array}$ & $\begin{array}{c}\text { Não } \\
\text { n (\%) }\end{array}$ & \\
\hline Diabetes & & & 0,004 \\
\hline Sim & $19(5,13)$ & $81(21,89)$ & \\
\hline Não & $21(5,67)$ & $249(67,29)$ & \\
\hline HAS & & & $\mathbf{0 , 5 0}$ \\
\hline Sim & $26(7,02)$ & $195(52,70)$ & \\
\hline Não & $14(3,78)$ & $135(36,48)$ & \\
\hline Tabagismo & & & 0,809 \\
\hline Sim & $6(1,62)$ & $45(12,16)$ & \\
\hline Não & $34(9,18)$ & $285(77,02)$ & \\
\hline Dislipidemia & & & 0,362 \\
\hline Sim & $15(4,05)$ & $97(26,21)$ & \\
\hline Não & $25(6,75)$ & $233(62,97)$ & \\
\hline Fibrilação atrial & & & 0,213 \\
\hline Sim & $2(0,54)$ & $38(10,27)$ & \\
\hline Não & $38(10,27)$ & $292(78,91)$ & \\
\hline AVE & & & 0,734 \\
\hline Sim & $3(0,81)$ & $21(5,67)$ & \\
\hline Não & $37(10,00)$ & $309(83,51)$ & \\
\hline Drogas vasoativas & & & 0,842 \\
\hline Sim & $32(8,64)$ & $253(68,37)$ & \\
\hline Não & $8(2,16)$ & $77(20,81)$ & \\
\hline Superfície de suporte & & & $<0,001$ \\
\hline Sim & $14(3,78)$ & $7(1,89)$ & \\
\hline Não & $26(7,02)$ & $323(87,29)$ & \\
\hline Transfusão Sanguínea & & & 0,254 \\
\hline $\operatorname{Sim}$ & $14(3,78)$ & $84(22,70)$ & \\
\hline Não & $26(7,02)$ & $246(66,48)$ & \\
\hline Revascularização do miocárdio & & & $\mathbf{0 , 8 5 8}$ \\
\hline Sim & $12(3,24)$ & $108(29,18)$ & \\
\hline Não & $28(7,56)$ & $222(60,00)$ & \\
\hline Troca de valva & & & 0,488 \\
\hline \multicolumn{4}{|l|}{ Sim } \\
\hline Mitral (M) & $3(0,81)$ & $30(8,10)$ & \\
\hline Aórtica(Ao) & $4(1,08)$ & $32(8,64)$ & \\
\hline Tricúspide & $1(0,27)$ & $1(0,27)$ & \\
\hline M e Ao & - & $3(0,81)$ & \\
\hline Não & $32(8,64)$ & $264(71,35)$ & \\
\hline Plastia valva & & & $\mathbf{0 , 0 5 9}$ \\
\hline Sim & - & $30(8,10)$ & \\
\hline Não & $40(10,81)$ & $300(81,08)$ & \\
\hline Transplante Cardíaco & & & 0,108 \\
\hline $\operatorname{Sim}$ & $1(0,27)$ & - & \\
\hline Não & $39(10,54)$ & $330(89,18)$ & \\
\hline Transplante Pulmonar & & & 0,108 \\
\hline $\operatorname{Sim}$ & $1(0,27)$ & - & \\
\hline Não & $39(10,54)$ & $330(89,18)$ & \\
\hline
\end{tabular}

n (\%)- valor absoluto e percentual de pacientes 
A Tabela 5 mostra que as variáveis DM e uso de superfícies de suporte apresentaram diferenças estatisticamente significativas entre os grupos $(p=0,004$; $\mathrm{p}<0,001$ respectivamente) com e sem UP.

Das 40 UP encontradas, $16(40,00 \%)$ foram classificadas em categoria I, 16 $(40,00 \%)$ em categoria II e $8(20,00 \%)$ como suspeita de lesão tissular profunda, acometendo, principalmente a região sacra (Figura 3).

Figura 3 - Distribuição das UP de acordo com a localização e categoria. São Paulo, 2013-2014

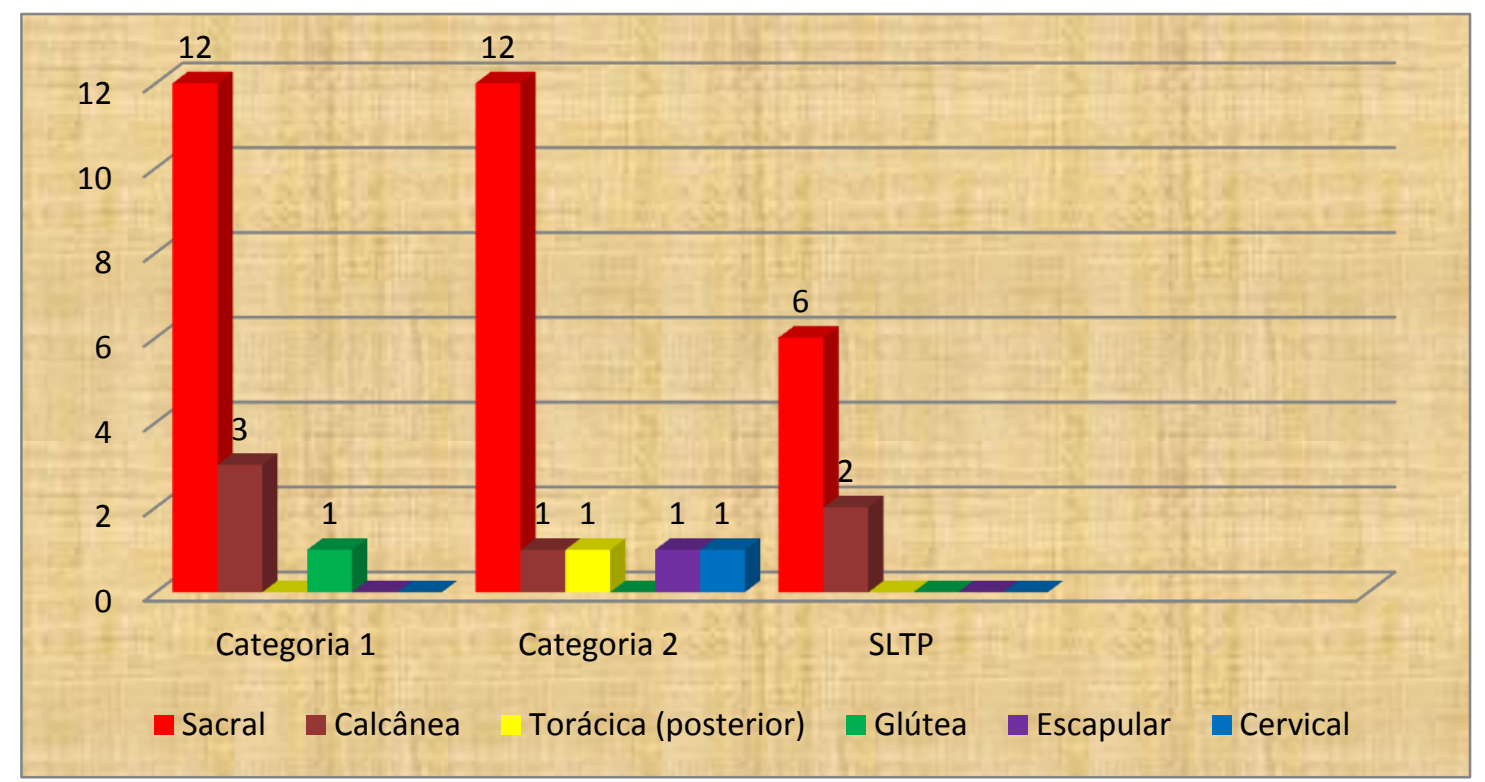

As UP foram identificadas do $2^{\circ}$ ao $23^{\circ}$ dias de internação na UTI, sendo o $3^{\circ}$ dia aquele em que maior número de UP foi diagnosticado, constatando-se oito feridas na região sacral e duas nos calcâneos (Quadro 4). 
Quadro 4 - UP segundo dias de internação (moda) para o diagnóstico, localização e categoria. São Paulo, 2013-2014.

\begin{tabular}{|c|c|c|}
\hline Dias de internação & Localização & Categoria \\
\hline 3,5 e 23 & Sacral & II \\
$2,3,4$ e 5 & Sacral & I \\
2 & Calcânea & I \\
7 & Cervical (face anterior) & II \\
10 & Escapular & II \\
12 & Glútea & I \\
7 & Sacral & SLTP \\
3 e 4 & Calcânea & SLTP \\
2 & Torácica (posterior) & II \\
\hline
\end{tabular}

De acordo com a análise CART, verificaram-se três fatores que melhor discriminam o grupo que apresentou UP, ou seja, os fatores de risco para o desenvolvimento das UP: tempo de permanência na UTI maior ou igual a 9,5 dias, idade igual ou superior a 42,5 anos e raça branca, apresentados na Figura 4.

Figura 4 - Fatores de risco para o desenvolvimento de UP, segundo análise CART. São Paulo, 2013-2014.

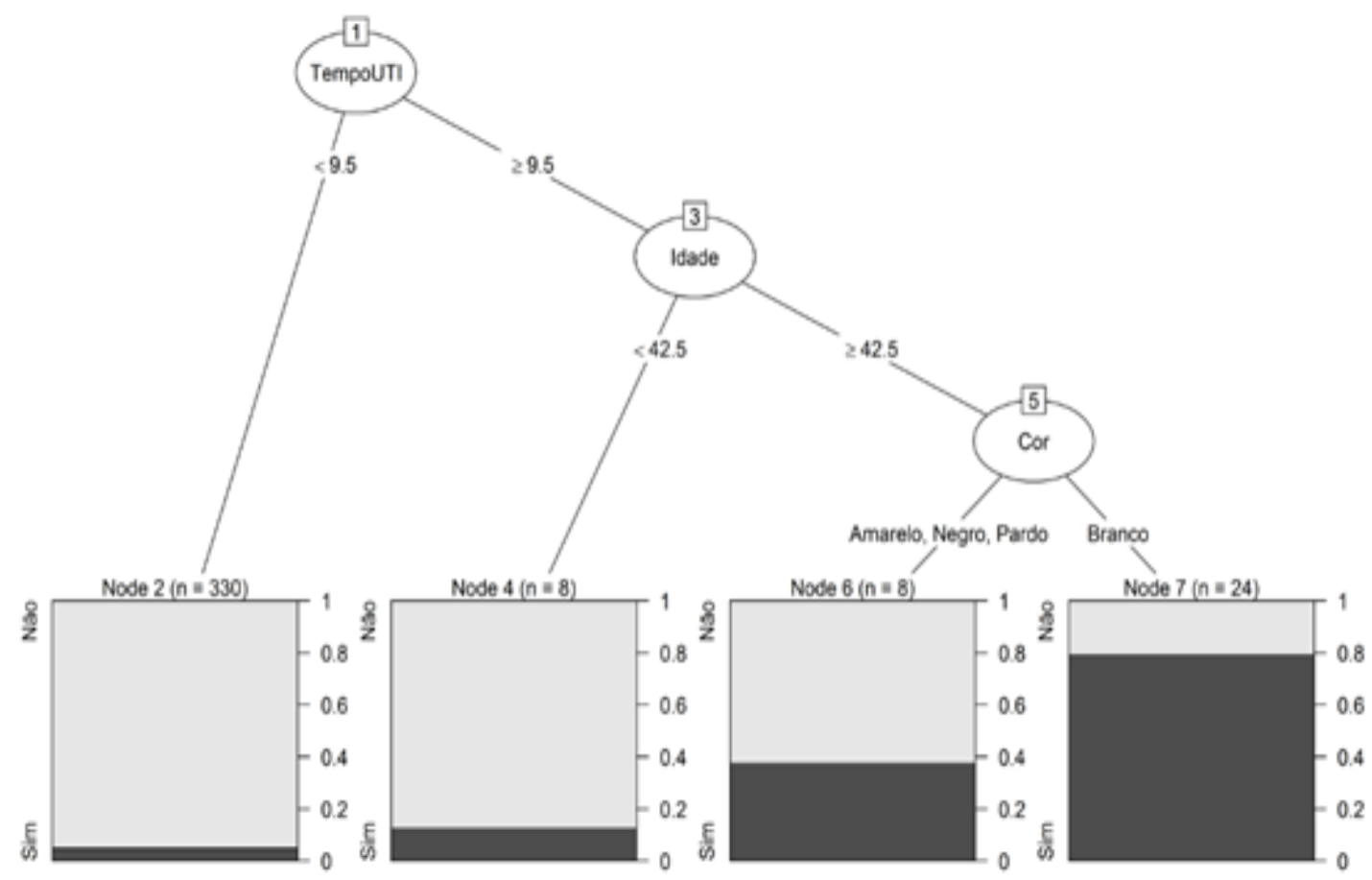




\subsection{INCIDÊNCIA E FATORES DE RISCO PARA LF}

Identificaram-se 26 LF em 26 pacientes, caracterizando incidência global de $7,02 \%$, sendo de $4,86 \%$ entre os homens e de 2,16\% para as mulheres; pacientes da raça branca apresentaram incidência de 5,67\%. Para a idade, verifica-se incidência de 4,10\% em pessoas com idade igual e superior a 60 anos (Tabela 6).

Tabela 6 - Incidência de LF segundo variáveis demográficas. São Paulo, 2013-2014.

\begin{tabular}{lccc}
\hline & \multicolumn{2}{c}{ Lesão por fricção } & \\
\cline { 2 - 3 } Variáveis demográficas & $\begin{array}{c}\text { Sim } \\
\mathbf{n}(\%)\end{array}$ & $\begin{array}{c}\text { Não } \\
\mathbf{n}(\%)\end{array}$ & 0,475 \\
\hline Idade & & & \\
18 a 29 anos & $1(0,27)$ & $25(6,75)$ & \\
30 a 39 anos & - & $30(8,10)$ & \\
40 a 49 anos & $3(0,81)$ & $49(13,24)$ & \\
50 a 59 anos & $7(1,89)$ & $63(17,02)$ & \\
60 anos e mais & $15(4,05)$ & $177(47,83)$ & \\
Sexo & & & \\
Feminino & $8(2,16)$ & $160(43,24)$ & \\
Masculino & $18(4,86)$ & $184(49,72)$ & \\
Raça & & & \\
Branca & $21(5,67)$ & $286(77,29)$ & \\
Negra & $1(0,27)$ & $26(7,02)$ & \\
Amarela & $2(0,54)$ & $5(1,35)$ & \\
Parda & $2(0,54)$ & $27(7,29)$ & \\
\hline
\end{tabular}

n (\%)- valor absoluto e percentual de pacientes

Quanto às médias etárias dos componentes de ambos os grupos, constataram-se $62,81(\mathrm{DP}=14,34)$ e $56,80(\mathrm{DP}=15,90)$, respectivamente para os pacientes com e sem $\mathrm{LF}$, sem diferença estatística entre eles $(\mathrm{p}=0,062)$. 
Tabela 7 - Variáveis clínicas e cirúrgicas quantitativas dos pacientes com e sem LF. São Paulo, 2013- 2014.

\begin{tabular}{lccc}
\hline \multicolumn{1}{c}{ Variáveis clínicas } & \multicolumn{2}{c}{ Lesão por fricção } & \\
& Sim & Não & Média (DP) \\
& Média (DP) & \\
\hline ÍMC & $24,34(1,90)$ & $25,99(4,21)$ & $<\mathbf{0 , 0 0 1}$ \\
$\begin{array}{l}\text { Tempo de internação até a admissão na UTI } \\
\text { (dias) }\end{array}$ & $10,92(12,99)$ & $9,37(34,18)$ & $\mathbf{0 , 0 2 0}$ \\
Permanência na UTI (dias) & $10,50(9,79)$ & $9,37(34,18)$ & $<\mathbf{0 , 0 0 1}$ \\
Número de artefatos admissão & $6,54(1,92)$ & $5,35(2,18)$ & $\mathbf{0 , 0 0 7}$ \\
APACHE II & $21,19(5,13)$ & $22,29(5,00)$ & 0,684 \\
Ramsay & $5,54(1,30)$ & $5,06(1,67)$ & 0,138 \\
Braden & $8.96(2,35)$ & $9,70(2,88)$ & 0,379 \\
Tempo de CEC (min.) & $107,35(66,36)$ & $93,83(37,28)$ & 0,186 \\
\hline Tempo de cirurgia (min.) & $298,43(90,29)$ & $276,72(100,64)$ & 0,316 \\
\hline
\end{tabular}

Quanto às variáveis clínicas quantitativas, a Tabela 7 mostra que o IMC ( $p<0,001)$ foi menor entre os pacientes com LF estando o peso dentro da normalidade, comparado ao grupo sem LF que estava sobrepeso. Os tempos de internação até à admissão na UTI de 10,92 ( $\mathrm{p}=0,020)$ dias, de permanência na UTI de 10,50 dias $(\mathrm{p}<0,001)$, bem como o número de artefatos na admissão $(6,54(\mathrm{p}=0,007))$ foram maiores entre os pacientes com LF comparativamente àqueles sem LF com valor estatístico significativo. 
Tabela 8 - Variáveis nominais clínicas e cirúrgicas dos pacientes com e sem LF. São Paulo, 2013-2014.

\begin{tabular}{|c|c|c|c|}
\hline \multirow[b]{2}{*}{ Variáveis } & \multicolumn{2}{|c|}{ Lesão por fricção } & \multirow[b]{2}{*}{$\mathbf{P}$} \\
\hline & $\begin{array}{c}\text { Sim } \\
\mathbf{n}(\%)\end{array}$ & $\begin{array}{c}\text { Não } \\
\text { n(\%) }\end{array}$ & \\
\hline Diabetes & & & 0,493 \\
\hline Sim & $5(1,35)$ & $95(25,67)$ & \\
\hline Não & $21(5,67)$ & $249(67,29)$ & \\
\hline HAS & & & 0,838 \\
\hline Sim & $26(7,02)$ & $195(52,70)$ & \\
\hline Não & $14(3,78)$ & $135(36,48)$ & \\
\hline Tabagismo & & & 0,555 \\
\hline Sim & $2(0,54)$ & $49(13,24)$ & \\
\hline Não & $24(6,48)$ & $295(79,82)$ & \\
\hline Dislipidemia & & & 0,270 \\
\hline Sim & $5(1,35)$ & $107(28,91)$ & \\
\hline Não & $21(5,67)$ & $237(64,05)$ & \\
\hline Fibrilação atrial & & & 0,181 \\
\hline Sim & $5(1,35)$ & $35(9,45)$ & \\
\hline Não & $21(5,67)$ & $309(83,51)$ & \\
\hline AVE & & & 0,396 \\
\hline Sim & - & $24(6,48)$ & \\
\hline Não & $26(7,02)$ & $320(86,48)$ & \\
\hline Transfusão Sanguínea & & & 0,002 \\
\hline Sim & $14(3,78)$ & $84(22,70)$ & \\
\hline Não & $12(3,24)$ & $260(70,27)$ & \\
\hline Drogas vasoativas & & & 0,014 \\
\hline Sim & $25(6,75)$ & $260(70,27)$ & \\
\hline Não & $1(0,27)$ & $84(24,70)$ & \\
\hline Superfície de suporte & & & $<0,001$ \\
\hline Sim & $25(6,75)$ & $60(16,21)$ & \\
\hline Não & $1(0,27)$ & $284(76,75)$ & \\
\hline Revascularização do miocárdio & & & 0,518 \\
\hline Sim & $10(2,70)$ & $16(4,32)$ & \\
\hline Não & $110(29,72)$ & $234(63,24)$ & \\
\hline Troca de valva & & & 0,003 \\
\hline \multicolumn{4}{|l|}{ Sim } \\
\hline Mitral (M) & $7(1,89)$ & $26(7,02)$ & \\
\hline Aórtica (Ao) & $4(1,08)$ & $32(8,64)$ & \\
\hline Tricúspide & - & $2(0,54)$ & \\
\hline M e Ao & $1(0,27)$ & $2(0,54)$ & \\
\hline Não & $14(3,78)$ & $282(76,21)$ & \\
\hline Plastia valva & & & 0,709 \\
\hline Sim & $1(0,27)$ & $29(7,83)$ & \\
\hline Não & $25(6,75)$ & $315(85,13)$ & \\
\hline Transplante Cardíaco & & & 1,00 \\
\hline Sim & - & $1(0,27)$ & \\
\hline Não & $26(7,02)$ & $343(92,70)$ & \\
\hline Transplante Pulmonar & & & 1,00 \\
\hline Sim & - & $1(0,27)$ & \\
\hline Não & $26(7,02)$ & $343(92,70)$ & \\
\hline
\end{tabular}

n (\%)- valor absoluto e percentual de pacientes 
As variáveis transfusão sanguínea $(p=0,002)$, drogas vasoativas $(p=0,014)$, uso de superfície de suporte $(\mathrm{p}<0,001)$ e troca de valva $(\mathrm{p}=0,003)$ mostraram diferenças estatisticamente significativas entre os grupos com e sem LF (Tabela 8).

Das 26 LF encontradas, predominaram aquelas classificadas como categoria 3 (22/ 84,61\%), na região peri-ferida esternal $(11 / 42,30 \%)$, todas relacionadas a traumas desencadeados por fita adesiva, desenvolvidas principalmente nos $3^{\circ}$ (11 LF) e $4^{\circ}(5$ LF) dias de internação na UTI, respectivamente nas Figuras 5, 6 e 7.

Figura 5 - Lesões por fricção de acordo com a categoria. São Paulo, 2013-2014.

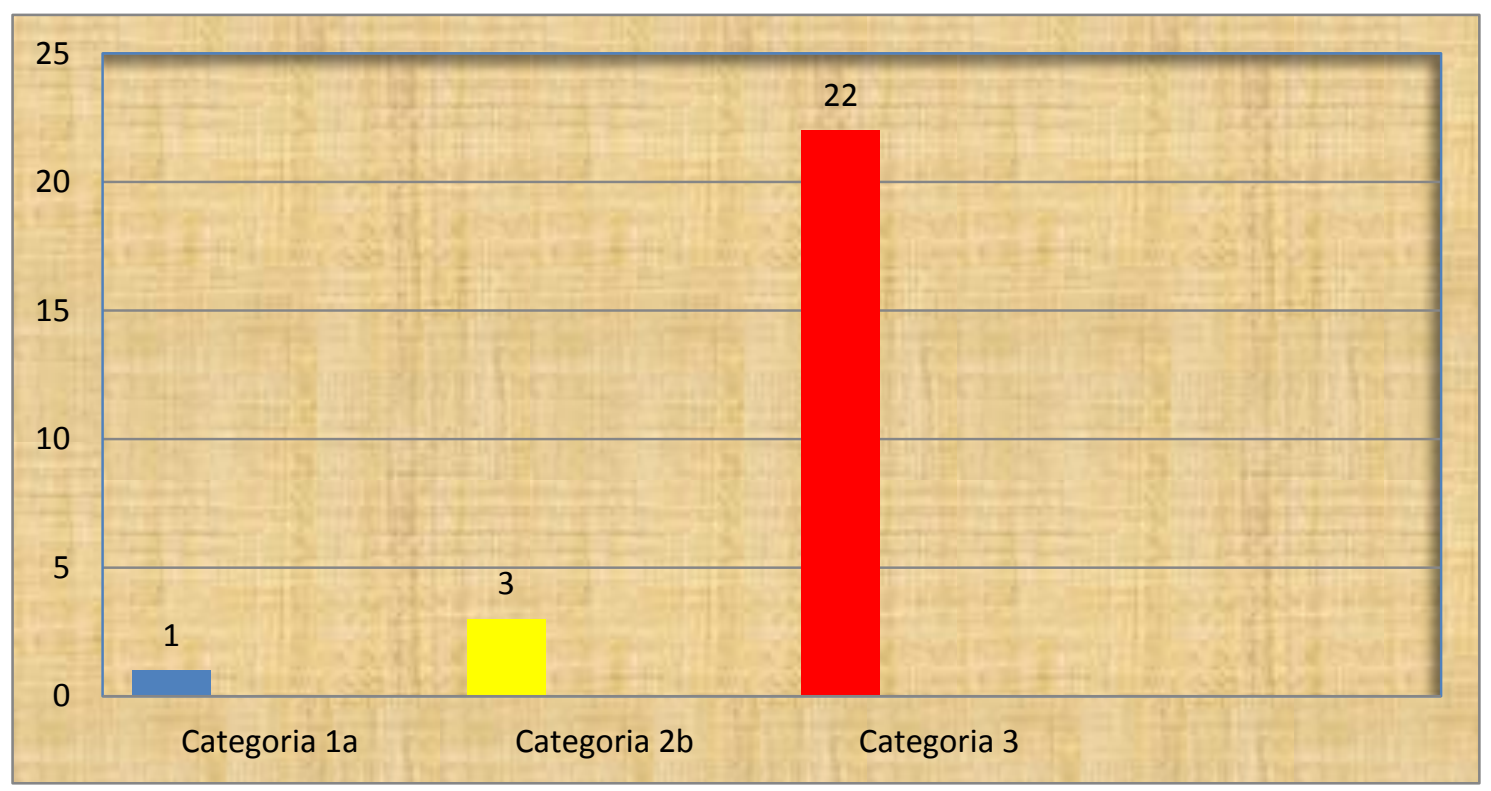


Figura 6 - Lesões por fricção de acordo com a categoria e localização. São Paulo, 2013-2014.

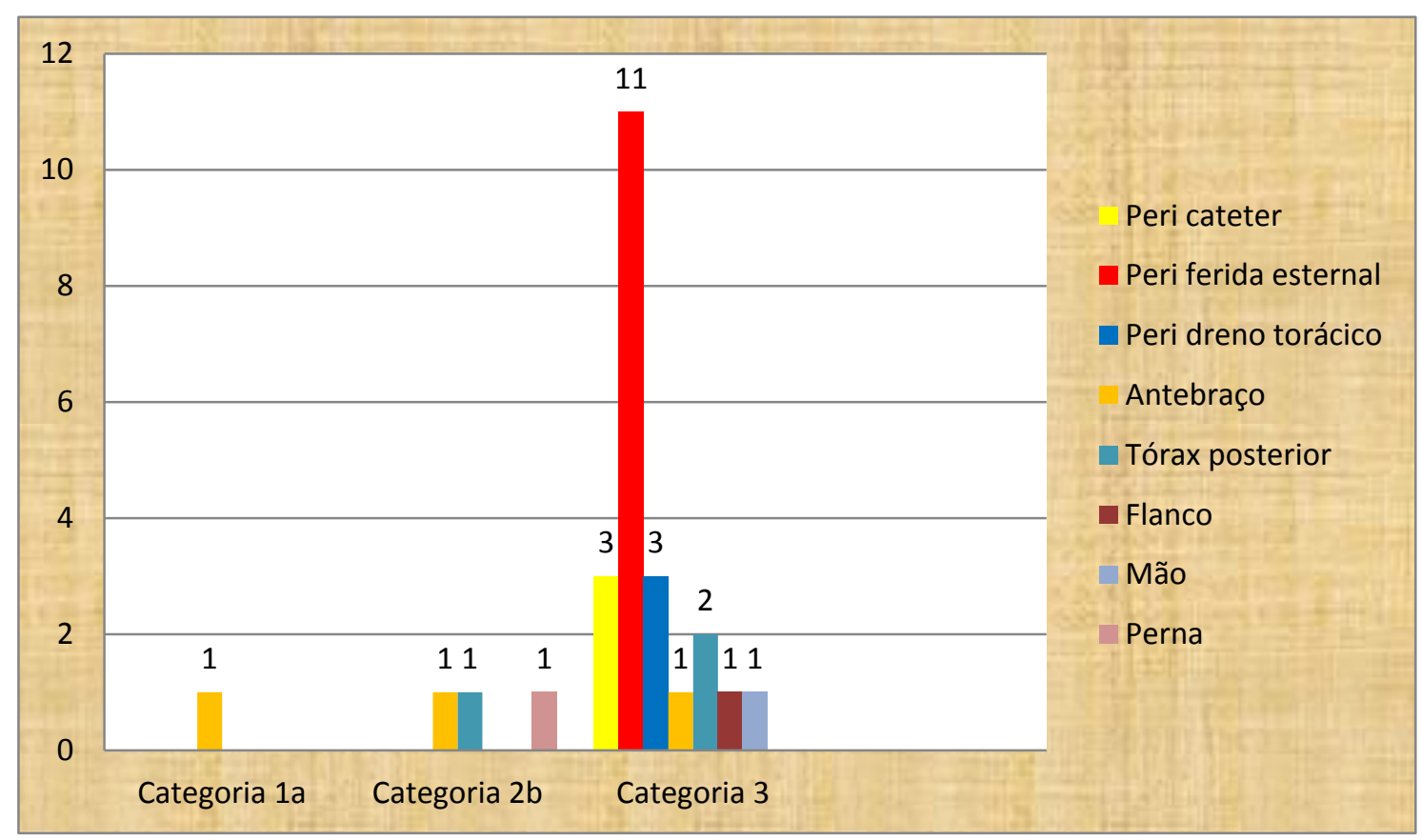

Figura 7 - Lesões por fricção de acordo com a categoria e dia de internação na UTI. São Paulo, 2013-2014.

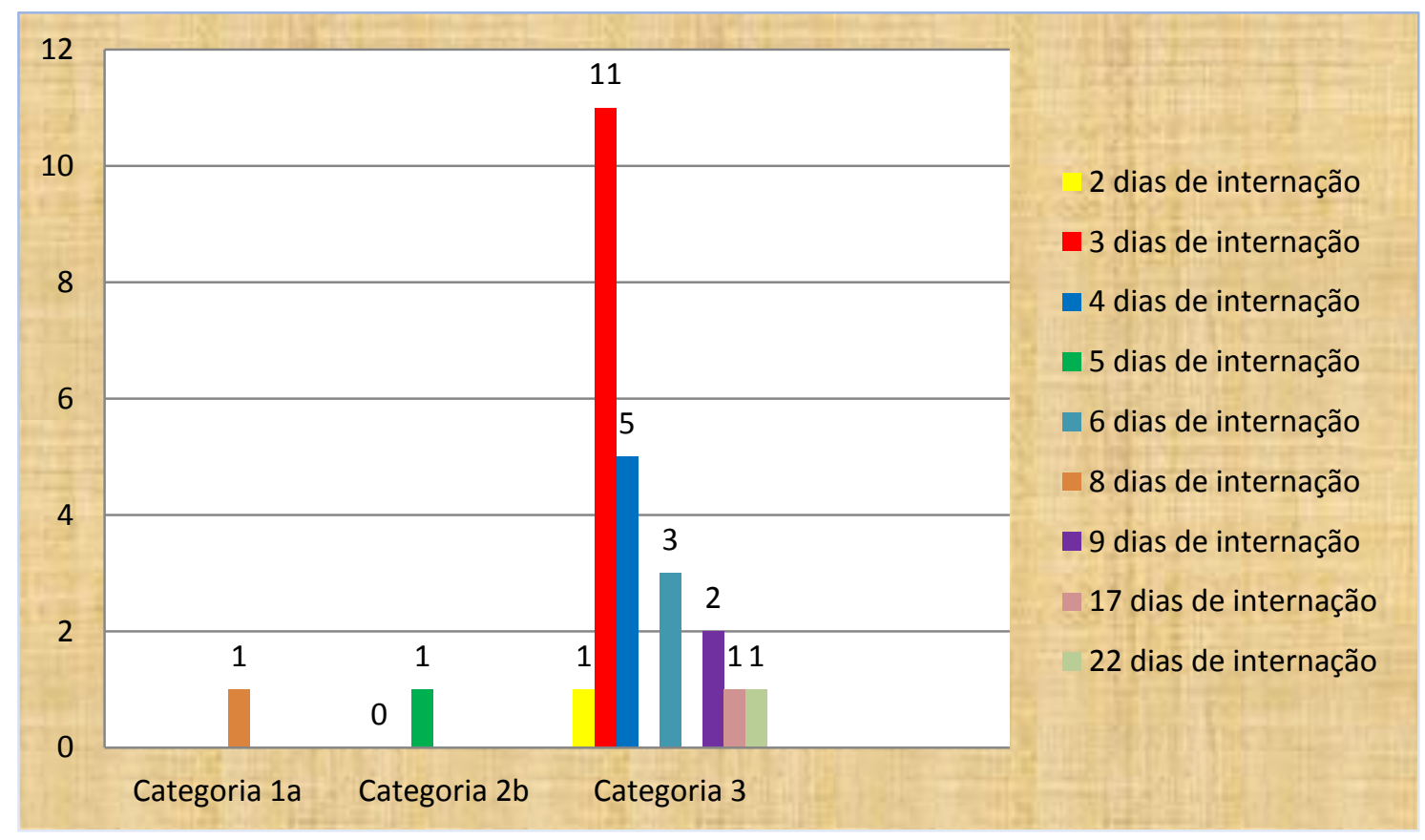


As variáveis que mais discriminaram o grupo com lesão por fricção, de acordo com a árvore de decisão CART foram o emprego de superfície de suporte e o número de artefatos na admissão na UTI, como mostrado na Figura 8.

Figura 8 - Fatores de risco para o desenvolvimento de LF, segundo análise CART. São Paulo, 2013-2014.

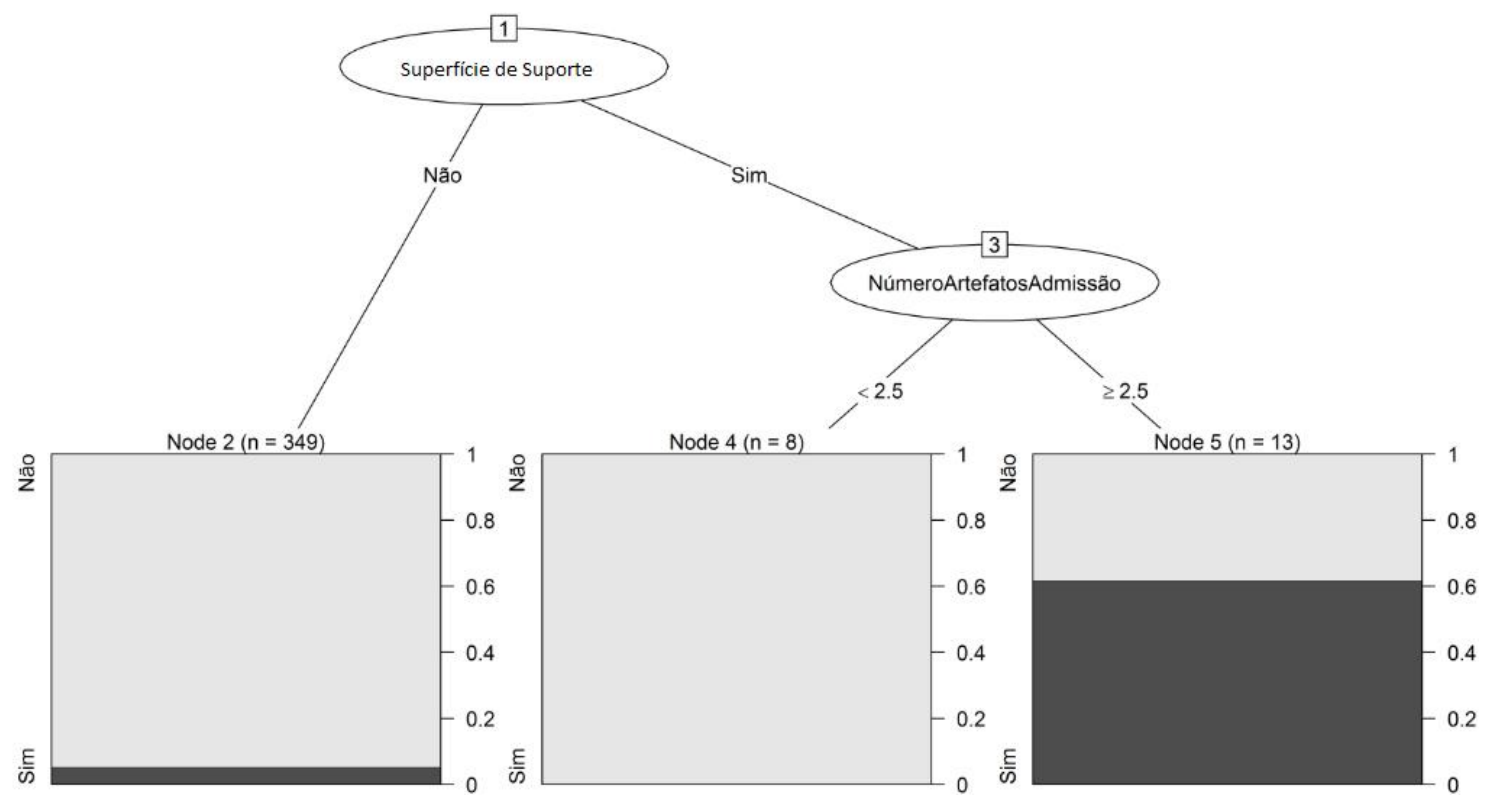

\subsection{INCIDÊNCIA E FATORES DE RISCO PARA O DESENVOLVIMENTO SIMULTÂNEO DE UP E LF}

No estudo, oito pacientes desenvolveram ambas as lesões, acarretando coeficiente de incidência de $2,16 \%$; sendo $1,89 \%$ para o sexo masculino e $0,27 \%$ para o feminino; pessoas da raça branca mostraram incidência de 1,89\%. Para a idade, verificase incidência de apenas $1,08 \%$ em pessoas com idade igual e superior a 60 anos (Tabela 9). 
Tabela 9 - Incidência de UP e LF segundo variáveis demográficas. São Paulo, 2013- 2014.

\begin{tabular}{|c|c|c|c|}
\hline \multirow[b]{2}{*}{ Variáveis demográficas } & \multicolumn{2}{|c|}{ UP e LF } & \multirow[b]{2}{*}{$\mathbf{P}$} \\
\hline & $\begin{array}{c}\text { Sim } \\
\mathbf{n}(\%)\end{array}$ & $\begin{array}{c}\text { Não } \\
\text { n(\%) }\end{array}$ & \\
\hline Idade & & & 0,815 \\
\hline 18 a 29 anos & - & $26(7,02)$ & \\
\hline 30 a 39 anos & - & $30(8,10)$ & \\
\hline 40 a 49 anos & $2(0,54)$ & $50(13,51)$ & \\
\hline 50 a 59 anos & $2(0,54)$ & $68(18,37)$ & \\
\hline 60 anos e mais & $4(1,08)$ & $188(50,81)$ & \\
\hline Sexo & & & 0,077 \\
\hline Feminino & $1(0,27)$ & $167(45,13)$ & \\
\hline Masculino & $7(1,89)$ & $195(52,71)$ & \\
\hline Raça & & & 0,779 \\
\hline Branca & $7(1,89)$ & $300(81,08)$ & \\
\hline Negra & - & $27(7,29)$ & \\
\hline Amarela & - & $7(1,89)$ & \\
\hline Parda & $1(0,27)$ & $28(7,56)$ & \\
\hline
\end{tabular}

n (\%)- valor absoluto e percentual de pacientes

Quanto às médias etárias dos componentes de ambos os grupos, constataram-se $63,75(\mathrm{DP}=16,25)$ e 57,08 $(\mathrm{DP}=15,83)$, respectivamente para os pacientes com e sem UP e LF simultâneas, sem diferença estatística entre eles ( $\mathrm{p}=0,240)$.

Tabela 10 - Variáveis clínicas e cirúrgicas quantitativas dos pacientes com UP e LF. São Paulo, 2013-2014.

\begin{tabular}{lccc}
\hline \multicolumn{1}{c}{ Variáveis clínicas } & Sim & UP e LF & \\
& Média (DP) & Média (DP) & \\
\hline IMC & $23,94(2,07)$ & $25,91(4,14)$ & 0,181 \\
\hline $\begin{array}{l}\text { Tempo de internação até a admissão na UTI } \\
\text { dias) }\end{array}$ & $20,50(18,29)$ & $7,58(33,77)$ & $\mathbf{0 , 0 0 8}$ \\
Permanência na UTI & $18,88(11,65)$ & $5,22(5,034)$ & $<\mathbf{0 , 0 0 1}$ \\
\hline Número de artefatos admissão & $7,38(2,44)$ & $5,39(2,16)$ & $\mathbf{0 , 0 1 1}$ \\
APACHE II & $22,50(4,95)$ & $22,20(5,02)$ & 0,717 \\
\hline Ramsay & $5,50(1,41)$ & $5,08(1,66)$ & 0,461 \\
\hline Braden & $10,00(4,07)$ & $9,64(2,824)$ & 0,659 \\
\hline Tempo de CEC (min.) & $123,83(90,74)$ & $94,08(38,04)$ & 0,075 \\
\hline Tempo de cirurgia (min.) & $327,14(86,35)$ & $277,19(100,09)$ & 0,192 \\
\hline
\end{tabular}


Quanto às variáveis clínicas quantitativas, a Tabela 10 mostra que os tempos de internação até à admissão na UTI $(\mathrm{p}=0,008)$ e de permanência na UTI $(\mathrm{p}<0,001)$, bem como o número de artefatos na admissão $(\mathrm{p}=0,011)$ foram significativamente maiores entre os pacientes com LF comparativamente àqueles sem LF.

Tabela 11 - Variáveis nominais clínicas e cirúrgicas dos pacientes com e sem UP e LF. São Paulo, 2013-2014.

\begin{tabular}{|c|c|c|c|}
\hline \multirow[b]{2}{*}{ Variáveis clínicas } & \multicolumn{2}{|c|}{ UP e LF } & \multirow[b]{2}{*}{$\mathbf{P}$} \\
\hline & $\begin{array}{l}\text { Sim } \\
\mathbf{n}(\%)\end{array}$ & $\begin{array}{c}\text { Não } \\
\text { n(\%) }\end{array}$ & \\
\hline Diabetes & & & 0,100 \\
\hline Sim & $2(0,54)$ & $98(26,48)$ & \\
\hline Não & $6(1,62)$ & $264(71,35)$ & \\
\hline HAS & & & 0,065 \\
\hline Sim & $2(0,54)$ & $219(59,18)$ & \\
\hline Não & $6(1,62)$ & $143(38,64)$ & \\
\hline Tabagismo & & & 0,304 \\
\hline Sim & $2(0,54)$ & $49(13,24)$ & \\
\hline Não & $6(1,62)$ & $313(84,59)$ & \\
\hline Dislipidemia & & & 0,444 \\
\hline Sim & $1(0,27)$ & $111(30,00)$ & \\
\hline Não & $7(1,89)$ & $251(67,83)$ & \\
\hline Fibrilação atrial & & & 1,000 \\
\hline Sim & 0 & $40(10,80)$ & \\
\hline Não & $8(2,10)$ & $322(87,10)$ & \\
\hline AVE & & & 1,000 \\
\hline Sim & 0 & $24(6,48)$ & \\
\hline Não & $8(2,16)$ & $338(91,35)$ & \\
\hline Transfusão Sanguínea & & & $<0,001$ \\
\hline Sim & $7(1,89)$ & $91(24,59)$ & \\
\hline Não & $1(0,27)$ & $271(73,24)$ & \\
\hline Drogas vasoativas & & & 0,688 \\
\hline Sim & $7(1,89)$ & $278(75,13)$ & \\
\hline Não & $1(0,27)$ & $84(22,70)$ & \\
\hline Superfície de suporte & & & $<0,001$ \\
\hline Sim & $5(1,35)$ & $16(4,32)$ & \\
\hline Não & $3(0,81)$ & $346(93,51)$ & \\
\hline RM & & & 0,446 \\
\hline Sim & $1(0,27)$ & $119(32,16)$ & \\
\hline Não & $7(1,89)$ & $243(65,67)$ & \\
\hline Troca de valva & & & 0,143 \\
\hline \multicolumn{4}{|l|}{ Sim } \\
\hline Mitral (M) & $2(0,54)$ & $31(8,37)$ & \\
\hline Aórtica (Ao) & $2(0,54)$ & $34(9,18)$ & \\
\hline Tricúspide & 0 & $2(0,54)$ & \\
\hline M e Ao & 0 & $3(0,81)$ & \\
\hline Não & $4(1,08)$ & $292(78,91)$ & \\
\hline Plastia valva & & & 1,000 \\
\hline Sim & 0 & $30(8,10)$ & \\
\hline Não & $8(2,16)$ & $332(89,72)$ & \\
\hline Transplante Cardíaco & & & 1,000 \\
\hline Sim & 0 & $1(0,27)$ & \\
\hline Não & $8(2,16)$ & $361(97,56)$ & \\
\hline Transplante Pulmonar & & & 1,000 \\
\hline Sim & 0 & $1(0,27)$ & \\
\hline Não & $8(2,16)$ & $361(97,56)$ & \\
\hline
\end{tabular}


As variáveis transfusão sanguínea $(\mathrm{p}<0,001)$ e o uso de superfície de suporte $(\mathrm{p}<0,001)$ mostraram diferenças estatisticamente significativas entre os grupos com e sem ambas as lesões simultaneamente (Tabela 11).

O Quadro 5 mostra que houve proximidade ou coincidência de surgimento ou diagnóstico de ambas as lesões para cinco dentre oito pacientes $\left(4^{\circ}\right.$ e $5^{\circ}$ dias, $5^{\circ}$ e $6^{\circ}$ dias, $7^{\circ}$ e $9^{\circ}$ dias e $9^{\circ}$ dia). Além disso, a presença de ambas as lesões parecem caracterizar a maior gravidade dos pacientes, tendo em vista que cinco deles faleceram.

Quadro 5 - Caracterização dos pacientes com UP e LF, de acordo com os dias de internação para o diagnóstico da lesão, localização e categoria. São Paulo 2013-2014.

\begin{tabular}{|c|c|c|c|c|c|c|c|c|}
\hline Características & Pac.1 & Pac.2 & Pac.3 & Pac.4 & Pac.5 & Pac.6 & Pac.7 & Pac.8 \\
\hline $\begin{array}{l}\text { Dias internação para } \\
\text { aparecimento de UP }\end{array}$ & 10 & 3 & 9 & 7 & 9 & 13 & 5 & 5 \\
\hline $\begin{array}{l}\text { Dias internação para } \\
\text { aparecimento de LF }\end{array}$ & 17 & 22 & 9 & 9 & 9 & 5 & 6 & 4 \\
\hline Localização UP & Escápula & Calcâneo & Sacra & Sacra & Sacra & Sacra & Sacra & Sacra \\
\hline Localização LF & $\begin{array}{c}\text { Tórax } \\
\text { posterior }\end{array}$ & Peri-dreno & Flanco & Antebraço & Antebraço & Braço & Mão & $\begin{array}{l}\text { Peri- ferida } \\
\text { esternal }\end{array}$ \\
\hline $\begin{array}{l}\text { Categoria UP } \\
\text { (NPUAP/EPUAP) }^{4}\end{array}$ & II & SLTP & SLTP & II & II & II & I & I \\
\hline LF- STAR ${ }^{50,51}$ & 3 & 3 & 3 & $1 \mathrm{a}$ & 3 & $2 b$ & 3 & 3 \\
\hline Destino & Óbito & Óbito & Óbito & UTI & Óbito & UTI & Óbito & Alta \\
\hline
\end{tabular}

De acordo com a árvore de decisão (CART), as variáveis que mais discriminaram o grupo com ambas as lesões simultaneamente foram tempo de permanência na UTI $\geq 9,5$ dias; idade $\geq 42,5$ anos e uso de transfusão sanguínea, como mostra a Figura 9. 
Figura 9 - Fatores de risco para o desenvolvimento de UP e LF simultâneas, segundo análise CART. São Paulo, 2013-2014.

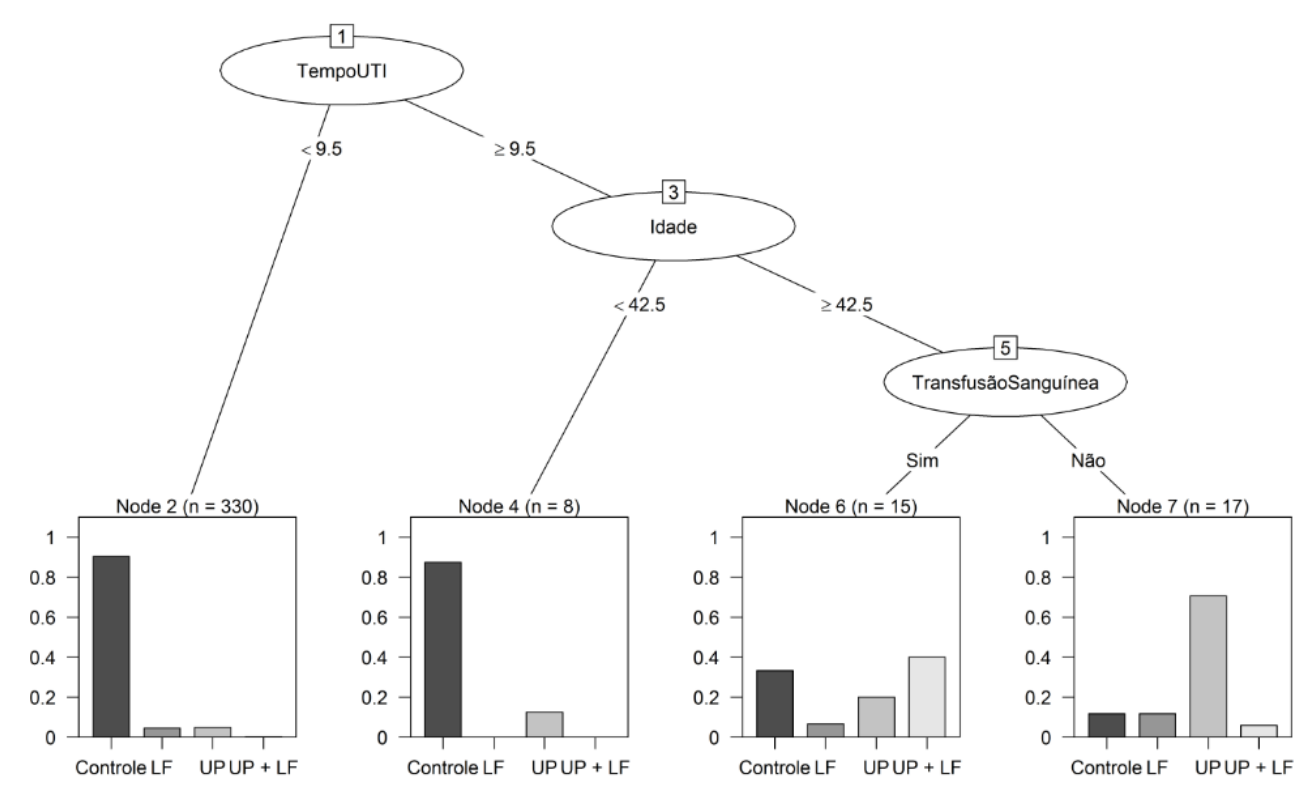




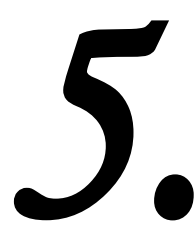

Discussão 


\section{DISCUSSÃO}

Incidências globais de $10,80 \%, 7,02 \%$ e 2,16\%, respectivamente para UP, LF e ambas simultaneamente foram encontradas no presente estudo junto a pacientes críticos atendidos em Unidade de Terapia Intensiva Cirúrgica Cardiopneumológica. Diferentes fatores de risco foram encontrados, conforme o tipo de lesão, sendo o tempo de permanência na UTI igual ou superior a 9,5 dias e a idade igual ou superior a 42,5 anos comuns para as UP e lesões simultâneas. Raça branca; uso de superfícies de suporte e número de artefatos invasivos na admissão; e uso de transfusão sanguínea foram fatores constatados respectivamente para as UP, LF e lesões simultâneas.

A seguir discutem-se os coeficientes de incidência e fatores de risco para cada tipo de ferida aqui estudada.

\subsection{INCIDÊNCIA E FATORES DE RISCO PARA UP}

Na última década, estudos internacionais em UTI têm mostrado coeficientes de incidência de UP entre 3,2 e $38,75 \%$ \%9-95.

Em pacientes cardiopatas no pós-operatório de cirurgia cardíaca, Chen et al ${ }^{96}$ encontraram incidência de $16,4 \%$. Já O’Brien et $\mathrm{al}^{97}$, realizando estudo retrospectivo, com 2695 pacientes cirúrgicos adultos, em um hospital geral quaternário americano, relatam incidência de $10,7 \%$, corroborando os achados do presente estudo.

No Brasil, a incidência em UTI varia de 10 a $62,5 \% \%^{7,9,31-34}$. Serpa et al ${ }^{32}$ encontraram resultado praticamente idêntico $(11,1 \%)$ aos constatados neste estudo. Embora também com pacientes críticos, o coeficiente foi geral para quatro UTI distintas (duas unidades neurológicas, uma cardiológica e uma geral), em dois hospitais privados na cidade de São Paulo, diferentemente do serviço público em que os dados do presente estudo foram coletados.

O menor índice encontrado no Brasil (10\%) - também similar ao presente estudo - foi relatado por Diccini et $\mathrm{al}^{25}$, que exploraram a incidência em pacientes internados em UTI neurocirúrgica, enquanto Fernandes e Caliri ${ }^{24}$ encontraram a maior incidência $(62,5 \%)$ em UTI de um hospital terciário de grande porte. 
Em estudo sobre a incidência de UP em um hospital universitário, utilizando a mesma metodologia aqui empregada, Rogenski e Santos $^{7}$ encontraram incidência de $41 \%$ entre os pacientes críticos, antes da implantação de protocolo de prevenção. Mais

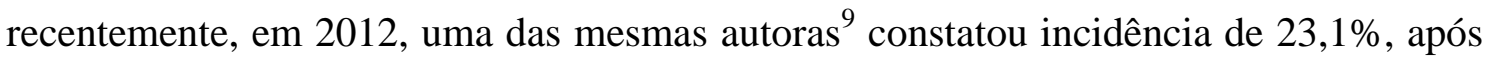
implantação do respectivo protocolo, portanto, incidência ainda bastante elevada, apesar de redução significativa.

Associados ao desenvolvimento de UP estão os fatores desencadeantes ou de risco. Em estudo retrospectivo, utilizando 222 prontuários de pacientes com doenças variadas, submetidos a cirurgias com mais de duas horas, Lumbley et al ${ }^{98}$ relacionaram o desenvolvimento de UP a fatores que comprometem a perfusão tecidual como a hipertensão e o diabetes. Em ampla revisão da literatura sobre o uso de vasopressores em pacientes críticos e a formação de UP, Cox ${ }^{99}$ constatou como fatores de risco para desenvolvimento de UP o uso de vasopressor (noradrenalina), a idade e a permanência prolongada em UTI, enquanto O'Brien et $\mathrm{al}^{97}$, o uso de hemoderivados no intra operatório. Alguns desses fatores são também discutidos por Scarlatti ${ }^{19}$, como a idade avançada, diabetes mellitus e hipertensão arterial, incluindo outros como o peso corporal e doenças crônicas (vasculopatias, neuropatias e anemia). Ressalta-se que dois dos fatores apresentados (tempo de permanência na UTI e idade) também foram constatados no presente estudo.

Em recente revisão sistemática (54 estudos) objetivando identificar fatores de risco independentes para UP, Coleman et $\mathrm{al}^{35}$ concluíram que existem fatores primários e secundários ao desenvolvimento de UP: mobilidade/ atividade, perfusão (incluindo diabetes, doença vascular, pressão arterial, tabagismo e edema) e hiperemia reativa, como primários; e hidratação da pele, idade, alterações metabólicas, nutrição e estado geral de saúde como secundários.

$\mathrm{Na}$ atualidade, os profissionais de enfermagem estão sendo cada vez mais incentivados a identificar precocemente os fatores de risco e os explorarem cientificamente. Hyun et $\mathrm{al}^{100}$ referem que mais fatores de risco precisam ser reconhecidos e analisados em populações específicas, para que planos de cuidados sejam melhor elaborados. 
No presente estudo, os fatores de risco encontrados também são corroborados em parte pelos resultados de Corniello et al ${ }^{101}$, que identificaram idade superior a 69 anos e permanência na UTI maior que oito dias; e de $\operatorname{Cox}^{6}$, que identificou a raça branca, internação maior que 11 dias em UTI e idade superior a 69 anos.

A idade é um fator largamente discutido, isoladamente ou em associação a outras variáveis como doenças cardiovasculares, hábitos de vida e permanência em UTI, pois implica em alterações fisiológicas próprias do processo de envelhecimento. A perda de massa muscular, a diminuição de resposta inflamatória, dos níveis de albumina e da tela subcutânea associados à redução na adesão derme e epiderme proporcionam maior risco de ruptura da integridade da pele que já não tem adequada capacidade para redistribuir a carga mecânica a ela imposta, constituindo um item de importante representação para a estratificação de risco ${ }^{91,92,101-107}$. A Escala de Braden, embora seja a mais utilizada e estudada, nacional e internacionalmente, não inclui o fator idade ${ }^{103}$.

Os especialistas argumentam que as escalas de risco devem ser elaboradas de acordo com os fatores de risco específicos de cada população com base em análises multivariadas. Na prática clínica, observa-se a necessidade do emprego de escalas de avaliação de risco que incluam a idade como um dos fatores envolvidos na gênese das UP, como a escala de Cubin-Jackson ${ }^{35}$.

Quanto à permanência na UTI, em estudo prospectivo com 140 pacientes, Sayar et $\mathrm{al}^{91}$ relatam que o tempo de estadia dos pacientes em UTI é um fator predisponente de UP $(\mathrm{p}<0,001)$ sempre associado à mobilidade e ao nível de consciência dos pacientes, similarmente aos nossos achados, onde os pacientes mostraram-se confinados ao leito e com mobilidade reduzida devido ao grande número de artefatos inseridos na pele, ao uso de sedativos e ao próprio temor do paciente em se movimentar e sentir dor e desconforto.

A permanência aumentada em UTI cardiopneumológica é decorrente do restabelecimento do estado fisiológico de pacientes submetidos a procedimentos invasivos, da associação de tecnologias que permitem recondicionamento de órgãos e do controle de doenças associadas. A população com alterações cardiopulmonares procura os serviços de saúde mais tardiamente devido a tratamentos clínicos alternativos, deixando os procedimentos cirúrgicos como opção tardia. Os pacientes que 
desenvolveram UP neste estudo apresentaram a integridade cutânea comprometida predominantemente no terceiro dia de internação. Karadag et al ${ }^{108}$ descrevem que 97,9\% das UP aparecem nos primeiros três dias de internação pós-operatória. Schoonhoven et al ${ }^{109}$ e Serpa et al $^{32}$ constataram que as UP foram diagnosticadas nos primeiros dois dias de admissão na UTI e que medidas preventivas devem ser usadas durante e após procedimentos cirúrgicos. Nesses estudos, a região sacra também foi a mais acometida, por lesões categoria II, confirmando os resultados obtidos entre os pacientes do presente estudo bem como na literatura atual que retrata que as UP categoria II são mais frequentes em pacientes com alterações sistêmicas que afetam a perfusão tecidual, como as doenças cardiorrespiratórias e o diabetes melitus, enquanto as UP categoria I são encontradas principalmente em pacientes em fase pós operatória imediata 4,11,14,35,109-111. A região preferencial justifica-se pela permanência do paciente em decúbito dorsal durante períodos prolongados, pela instabilidade hemodinâmica e pelo uso de artefatos que impossibilitam ou dificultam a mudança de decúbito programada nas primeiras 24 horas de admissão na UTI pós-operatória. Ainda em cirurgia cardíaca, a instabilidade esternal imediata amedronta a equipe de enfermagem para mobilização precoce dos pacientes. Esses têm o esterno suturado com fios de aço que permitem movimentação no leito mais efetiva somente após a extubação que acontece, em média, seis horas depois da admissão na UTI ou até após 24 horas de admissão, quando o paciente já pode executar movimentação mais ativa, saindo da cama e sentando-se na poltrona ${ }^{4,35,109,111}$.

Outros fatores de risco, como sexo, controverso na literatura não foi aqui constatado como preditor de UP; Alderden at al ${ }^{104}$ descrevem a população masculina da raça branca como a mais acometida pelas UP o que, embora predominante no presente estudo, o sexo masculino não se confirmou como fator preditor na análise CART, enquanto a raça branca foi preditor. Em dois outros estudos ${ }^{105,106}$, a raça surgiu como um preditor independente de desenvolvimento de UP, no entanto, os achados foram contraditórios já que em um dos estudos ${ }^{105}$ a raça branca foi associada com risco aumentado para UP (assim como neste estudo) e, no outro ${ }^{106}$, encontrou-se a raça negra. Em se tratando de raça, Colemam et $\mathrm{al}^{35}$ concluem que raça e sexo não são fatores independentes significativos para o aparecimento de UP, mas fazem parte de uma complexa interação de fatores desencadeantes dessa lesão. 
O êxito na prevenção da UP é amplamente condicionado aos conhecimentos e habilidades dos profissionais de saúde sobre o assunto, principalmente dos membros da equipe de enfermagem que prestam assistência direta e contínua aos pacientes. Porém, é necessário um entendimento dos fatores individuais e institucionais que influenciam o conhecimento e o uso das evidências científicas, de forma que estratégias possam ser planejadas e utilizadas nas instituições, reduzindo e melhorando cada vez mais os coeficientes de incidência em populações específicas ${ }^{4,11,14,35,111-113}$, como os pacientes críticos em pós-operatório de cirurgias cardiopulmonares.

\subsection{INCIDÊNCIA E FATORES DE RISCO PARA LF}

As LF constituem um tema antigo, atualmente revisitado e explorado por novos pesquisadores que buscam sistematizar sua classificação, desenvolver instrumentos de avaliação de risco, sistematizar medidas de tratamento e identificar sua epidemiologia. Este estudo sobre a incidência de LF em pacientes críticos é inédito tanto no Brasil como no mundo.

Os estudos epidemiológicos são, portanto, escassos embora se reconheça que essas lesões predominam em instituições de longa permanência, ou seja, para pacientes crônicos e, principalmente, idosos ${ }^{63,64,76-78}$, despertando o interesse de pesquisadores quanto à ocorrência dessas lesões em unidades hospitalares, como desenvolvido por Everett e colaboradores em 1994 em um hospital de retaguarda ${ }^{79}$, e na comunidade ${ }^{81}$.

No único estudo desenvolvido em uma unidade de atenção primária rural da Nova Zelândia, Kennedy e colaboradores ${ }^{81}$ levantaram a incidência de LF pré-tibiais em pacientes com 65 anos ou mais, constatando coeficientes de $2,1 \%$ entre os homens e de 4,6\% para as mulheres. Apesar de cenários completamente distintos, os coeficientes praticamente são inversos ao presente estudo, sendo superior entre os homens $(4,86 \%)$ comparativamente às mulheres $(2,16 \%)$.

Ainda no cenário internacional, a incidência de LF varia de $0,92 \%$ a 2,23\% em ILPI. A menor incidência $(0,92 \%)$ foi identificada por Malone e colaboradores ${ }^{78}$, em um estudo retrospectivo ( $n=349$ idosos), em que identificaram 321 LF durante um ano de avaliação em uma ILPI. Os autores consideraram que a incidência poderia ser até três 
vezes maior do que a encontrada, já que os registros não eram confiáveis. Payne e Martin $^{64}$, por sua vez, conduziram um estudo em 10 ILPI nos EUA, totalizando 896 leitos. Durante cinco meses de estudo, 20 pacientes foram diagnosticados com LF, o que representa incidência de 2,23\% de LF no período. Esses 20 pacientes apresentaram um total de $50 \mathrm{LF}$, com média de 2,5 LF por paciente ${ }^{64}$.

Observou-se, no referido estudo acima ${ }^{64}$, que a maior parte dos traumas foi causada por objetos que caíram sobre as pernas ou que estavam fora do campo de visão, enquanto as quedas foram minoria com aumento no verão.

Como se pode verificar são poucos os estudos que trazem valores de incidência de LF no cenário internacional, com resultados bastante heterogêneos entre si e em cenários muito distintos das unidades hospitalares de atendimento aos pacientes críticos.

No presente estudo a coleta de dados foi realizada em ambiente fechado e, embora tenha ocorrido durante o verão brasileiro (novembro de 2013 a fevereiro de 2014), a temperatura na UTI é constante (em torno de $21^{\circ} \mathrm{C}$ ) e os pacientes permanecem com camisolas de algodão, com abertura dorsal, sendo as lesões desencadeadas nesse ambiente predominantemente por fitas adesivas que recobriam os artefatos inseridos na pele para manutenção da vida e as feridas operatórias, principalmente na região esternal (11 LF/ 42,31\%) e não por objetos que circundavam o paciente ou por queda.

Quanto aos fatores de risco para o desenvolvimento de LF no presente estudo, verificou-se que o emprego de superfície de suporte e o número de artefatos inseridos na pele na admissão foram fatores determinantes para a ocorrência de LF na amostra.

Embora muitos autores discutam fatores de risco para LF apenas McGoughCsarny et al ${ }^{80}$ apresentam o uso de artefatos como fator de risco para $\mathrm{o}$ desenvolvimento de LF, assim como encontrado em nosso estudo. O grande número de artefatos inseridos na pele foi diretamente proporcional ao número de curativos protetores, para estabilização dos artefatos ou cobertura das feridas operatórias, confeccionado com fitas transparentes adesivas.

Entende-se que a pele edemaciada pelo processo inflamatório sistêmico associada ao uso de coberturas de filme transparente provocaram a formação de LF nas áreas sob essas coberturas. De acordo com Compton e colaboradores ${ }^{113}$, o edema 
tissular $(\mathrm{p}=0,002)$ é um fator preditor de lesão de pele. No presente estudo, todas as LF foram desencadeadas por trauma relacionado a coberturas adesivas.

O outro fator encontrado no presente estudo como responsável pelo desenvolvimento de LF - uso de superfícies de suporte - é bastante interessante, uma vez que o resultado obtido se contrapõe aos objetivos e características desse tipo de artefato que visa à redistribuição da carga mecânica para prevenção de UP.

As superfícies de suporte (SS) são dispositivos especializados em redistribuir a pressão, desenvolvidos para controlar a carga sobre os tecidos e o microclima, estando descritas nas diretrizes da NPUAP/EPUAP ${ }^{4}$ e traduzido para o português por StrazzieriPulido e Santos ${ }^{114,115}$. Diferentemente dos colchões, colchonetes, almofadas e coxins convencionais, que conferem tão somente sustentação e algum conforto, as SS devem ser capazes de redistribuir a pressão normalmente concentrada sob as áreas de proeminências ósseas. Além dessa especificidade, obrigatória a todas elas, algumas ainda prometem controlar temperatura, fricção, cisalhamento e umidade.

Existem inúmeras superfícies de suporte, incluindo colchão, sistema de redistribuição da pressão integrado na cama, colchonetes piramidais, coxins e $\operatorname{almofadas}^{3,114,115}$.

Apesar da comercialização de inúmeros dispositivos para prevenção de lesões de pele, não há consenso para seu uso, sendo a utilização dos artefatos determinada de acordo com o diagnóstico individual e protocolos institucionais.

Na UTI, onde os dados foram coletados, acima dos colchões de viscoelástico, são utilizados colchões perfilados, como SS, confeccionado em espuma de poliuretano e de cor clara (tipo caixa de ovo), densidade 28 , com comprimento de $188 \mathrm{~cm}$, largura de $90 \mathrm{~cm}$, espessura total de $6 \mathrm{~cm}$ dividida em $3 \mathrm{~cm}$ na espícula e $3 \mathrm{~cm}$ na base. O produto é revestido com capa composta de $89,75 \%$ de filme de Polímeros Vinílicos Cloretados (PVC) acoplado com 10,25\% de tela de poliéster de alta tenacidade com fios de 300.60 .1 e 165.30 .3 , espessura de $0,40 \mathrm{~mm}$ sendo $0,35 \mathrm{~mm}$ de filme e $0,05 \mathrm{~mm}$ de tela fosca de cor azul, gramatura de $517 \mathrm{~g} / \mathrm{m}$ linear, sendo 450 de filme e 67 de tela; atóxico, impermeável, inodoro, macio à sensação de tato, elástico resistente em toda a extensão das bordas (tipo vapt/vupt) cujas dimensões devem adequar-se à finalidade de proteger a espuma. As especificações da SS atendem as recomendações da NPUAP ${ }^{3,114,115}$ quando 
se refere a espuma, sua formação e dimensões ( mínimo de $2,5 \mathrm{~cm}$ de espícula), porem cria ambiente desfavorável as orientações quando se preconiza o uso de capas impermeáveis desfavorecendo o microclima existente, tornando o meio mais úmido.

Nessa UTI, as SS de espuma piramidal são indicadas para pacientes com algumas condições de risco para desenvolvimento de UP como: idade superior a sessenta anos, uso de assistência circulatória mecânica, uso de ventilação artificial, em procedimento dialítico ou após transplantes, além da avaliação individualizada dos enfermeiros assistencias quanto à sua necessidade em pacientes hemodinamicamente instáveis e em uso de drogas vasoativas por período superior a três dias. Essas condições referem-se a pacientes com maior dependência dos cuidados de enfermagem e que requerem ajuda para transferências e movimentação/ mobilização no leito, fatores associados às maiores chances de ocorrência de LF. McGough-Csarny et al 80 mostraram que $81,8 \%$ dos pacientes com LF eram totalmente dependentes de cuidados. No estudo de White et $\mathrm{al}^{52}, 19$ residentes totalmente dependentes, que necessitaram de auxílio para as atividades de vida diária, apresentaram grande número de LF, principalmente nas extremidades superiores. Elas ocorreram durante a rotina de prestação de cuidados.

De acordo com a NPUAP ${ }^{4,114,115}$, existem algumas vantagens na utilização da superfície piramidal, como a facilidade para sua instalação e baixo custo. Porém, há desvantagens significativas como a necessidade de cobertura plástica da superfície para pacientes incontinentes, causando desequilíbrio de temperatura, pois o ambiente entre os lençóis se torna quente e úmido; além da necessidade de uma superfície que proporcione adequada redistribuição da pressão confeccionados com espuma adequada, permitindo melhor redistribuição da carga mecânica ${ }^{114,115}$. De todas as maneiras, esse tipo de superfície de suporte é considerado bastante ineficaz comparativamente às demais superfícies existentes ${ }^{3,114,115}$.

As LF em pacientes adultos hospitalizados são frequentemente subnotificadas e podem ser confundidas com UP categoria II ou mesmo com úlceras vasculogênicas, dependendo da localização, ou ainda apenas ignoradas pelo desconhecimento dos profissionais de saúde quanto a sua prevenção e tratamento. 
Devido à escassez de publicações sobre LF, principalmente em pacientes hospitalizados, vê-se a necessidade de realização de outros estudos epidemiológicos sobre o tema para elucidar os fatores que levam à ocorrência dessas lesões em diferentes cenários, como em UTI. Prevenir implica na identificação das pessoas em risco para LF, todavia, isso só é possível quando se sabe como e por que elas acontecem ${ }^{62}$.

\subsection{INCIDÊNCIA DE UP E LF SIMULTÂNEAS}

A incidência das duas lesões de pele foi de 2,16\%, acometendo oito pacientes. Usando a árvore de regressão (CART) observa-se que a associação de tempo de internação na UTI (internação $\geq 9$ dias), idade $\geq 42$ anos e o uso de transfusão sanguínea são fatores desencadeantes de UP e LF na amostra deste estudo.

Os fatores de risco comuns entre as UP e LF (idade e permanência na UTI) foram discutidos no decorrer dos itens relacionados a cada lesão, deixando-se a variável transfusão sanguínea para ser discutida neste segmento.

Atualmente, as taxas de transfusão sanguínea no pós-operatório de cirurgias cardiopulmonares ainda são bastante elevadas embora variáveis de acordo com protocolos locais e a avaliação clínica individualizada. De qualquer maneira, a cirurgia cardíaca é a especialidade em que mais se consomem hemocomponentes e hemoderivados ${ }^{116}$.

A etiologia do sangramento após a cirurgia cardíaca é multifatorial e está relacionada à complexidade cirúrgica, uso de $\mathrm{CEC}$, heparina, dano vascular, hipotermia dentre outros. Desse modo, a transfusão sanguínea objetiva restaurar o volume sistólico e o nível sérico de hemoglobina para melhorar a oxigenação tecidual. No entanto, atualmente já se questiona se a perfusão tecidual é realmente melhorada com tal procedimento, tendo em vista que os pacientes com anemia no pós-operatório (hemoglobina entre 7 e 8,5g/dl) raramente atingem o ponto dependência - oferta demanda ${ }^{116-121}$.

Os hemocomponentes utilizados no pós-operatório são selecionados e estocados após doação voluntária de sangue total, pelos familiares dos pacientes hospitalizados ou por anônimos motivados por campanhas em rádio e televisão. O paciente que necessita 
de hemocomponentes recebe, portanto, parte do sangue total (hemácias, plasma, plaquetas) de acordo com suas demandas, estando exposto a inúmeros efeitos adversos como infecção, Síndrome da Resposta Inflamatória Sistêmica, alterações renais e alteração da perfusão tissular ${ }^{117}$.

A alteração da perfusão da pele tem sido atribuída às alterações dos hemoderivados decorrentes da sua estocagem, especialmente as hemácias, que sofrem alterações morfológicas, aglomerando-se e formando micro rolhas, o que compromete o transporte de oxigênio na microcirculação. Além disso, há liberação de substâncias tóxicas, como a hemoglobina livre que altera a ação do óxido nítrico comprometendo a espasticidade da musculatura lisa; e aumento da adesão das hemácias estocadas nos capilares, promovendo a oclusão capilar e hipóxia tecidual ${ }^{116-121}$. Outro efeito deletério da transfusão sanguínea é a ativação da resposta inflamatória sistêmica com aumento da ativação neutrofílica e maiores níveis de interleucina 6, aumento da permeabilidade capilar e, consequentemente, edema tecidual, levando a pele à maior vulnerabilidade para o desenvolvimento de lesões ${ }^{113,118-121}$.

A transfusão sanguínea é uma variável largamente estudada como preditor de risco para infecção pós-operatória, permanência prolongada na UTI e tempo prolongado de ventilação mecânica ${ }^{117-121} \mathrm{e}$, em nosso estudo, para o aparecimento de UP e LF simultaneamente. Dois estudos retrospectivos em cardiologia sugeriram associação entre transfusão de hemácias e aumento da morbi-mortalidade, sendo essa relação dose dependente. Koch ${ }^{119}$ e Murphy ${ }^{120}$ sugeriram associação da transfusão de sangue com maiores taxas de complicações cardíacas, tempo prolongado de ventilação mecânica, insuficiência renal, complicações isquêmicas e maior tempo de internação hospitalar. Outro estudo $^{118}$, desenvolvido no Instituto do Coração em São Paulo, demonstrou a transfusão sanguínea como fator independente para o desenvolvimento de efeitos adversos como inflamação sistêmica, insuficiência renal e sangramento. Deve-se enfatizar, no entanto, que surgem cada vez mais pesquisas visando a minimizar os efeitos deletérios da transfusão, permitindo a maior segurança em seu uso, com menos complicações clínicas ${ }^{116}$. Exemplifica-se o emprego da reutilização do sangue aspirado do paciente para ele mesmo após filtração (“cell saver") ${ }^{118}$. 
6.

Conclusões 


\section{CONCLUSÕES}

Incidências globais de 10,80\%,7,02\% e 2,16\%, respectivamente para úlceras por pressão, lesões por fricção e ambas as lesões simultaneamente foram encontradas nos pacientes críticos. Diferentes fatores de risco foram encontrados, conforme o tipo de lesão, sendo o tempo de permanência na UTI igual ou superior a nove dias e idade igual ou superior a 42 anos comuns para as úlceras por pressão e lesões simultâneas. Além desses, raça branca; uso de superfícies de suporte e número de artefatos invasivos na admissão; e uso de transfusão sanguínea foram fatores constatados respectivamente para as úlceras por pressão, lesões por fricção e lesões simultâneas. 


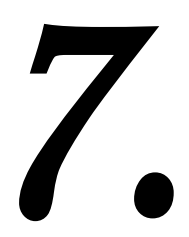

Considerações Finais 


\section{CONSIDERAÇÕES FINAIS}

O estudo inédito em nosso meio como na literatura internacional, pelo menos no que tange à incidência e fatores de risco para as LF isoladas e associadas às UP, contribui para a literatura sobre a epidemiologia dessas lesões em pacientes críticos, particularmente aqueles em pós-operatório de cirurgias cardiopneumológicas. Esse grupo populacional, com características bastante específicas, certamente se beneficiará com o desenvolvimento de protocolos de prevenção e tratamento também específicos, à medida da divulgação dos resultados aqui encontrados.

Apesar da limitação do estudo relacionada ao seu desenvolvimento em apenas uma UTI, esse pode ser o primeiro de vários outros estudos com replicação de seus métodos. A falta de um instrumento de avaliação de risco para o desenvolvimento de LF (ainda em elaboração por dois grupos internacionais, americano-canadense e australiano) dificulta a seleção e análise das possíveis variáveis preditoras, exigindo sua ampliação e, por conseguinte, também a ampliação da casuística.

A qualidade da assistência à saúde vem sendo amplamente discutida em âmbitos nacional e internacional, em razão dos altos custos para a manutenção dos serviços, dos escassos recursos disponíveis e do envelhecimento global da população. Desse modo, a abordagem sistemática de prevenção de UP e LF em pacientes críticos com alterações cardiopulmonares, principalmente sob a orientação de um enfermeiro estomaterapeuta, é uma estratégia fundamental para a redução dos coeficientes de incidência dessas lesões, melhorando, portanto, a qualidade da assistência global e integral prestada. 
Referências 


\section{REFERÊNCIAS}

1. Yepesa D, Molina F, León W, Pérez E. Incidencia y factores de riesgo en relación con las úlceras por presión en enfermos críticos. Med Intensiva. 2009; 33(6):276-81.

2. Coloma SDDS, Garrido NA, García KL. Evolución de la incidencia de las úlceras por presión tras la mejora de un protocolo de prevención en cuidados intensivos. Gerokomos. 2008; 19(4):207-212.

3. National Pressure Ulcer Advisory Panel. Terms and definitions related to support surfaces [Internet]. Disponível em: http://www.npuap.org [Versão 29/01/2007]. Acessado em 21/09/2014.

4. European Pressure Ulcer Advisory Panel and National Pressure Ulcer Advisory Panel. Prevention and treatment of pressure ulcers: quick reference guide. Washington DC: National Pressure Ulcer Advisory Panel; 2009. Disponivel em: http://www.epuap.org/guideline. Acessado em 21/09/2014.

5. Pressure Ulcer Prevention. Prevalence and incidence in context. International Guidelines. [Published by] Medical Education Partnership. 2009.

6. Cox J. Predictors of pressure ulcers in adult critical care patients. Am J Crit Care. 2011 Sept;20(5):364-75.

7. Rogenski NMB, Santos VLCG. Estudo sobre a incidência de úlceras por pressão em um hospital universitário. Rev. Latinoam. Enferm. 2005 jul.-ago.;13(4):47480 .

8. Rogan J. Pressure ulcer risk during the perioperative period focusing on surgery duration and hypothermia. Wounds UK. 2007;3(4):66-74.

9. Rogenski NMB, Kurcgant P. Incidência de úlcera por pressão após implementação de um protocolo de prevenção. Rev. Latinoam. Enferm. 2012 mar.-abr.;20(2):[07 telas]. Disponível em: www.eerp.usp.br/rlae.

10. Shanin ES, Dassen T, Halfens RJ. Pressure ulcer prevalence and incidence in intensive care patients: a literature review. Nurs CritCare. 2008;13(22):71-9.

11. Wound Ostomy and Continence Nurses Society (WOCN). Guideline for prevention and management of pressure ulcers. Glenview, 2003. p.2-11.

12. Rodrigues Junior GR, Amaral JLG. Influence of sedation on morbidity and mortality in the intensive care unit. São Paulo Med. J. 2004;122(1):8-11.

13. Santos VLCG, Caliri MHL. Conceito e Classificação de Úlcera por Pressão: atualização do NPUAP. Rev. Estima. 2007;5(3):43-4. 
14. Wound Ostomy and Continence Nurses Society (WOCN). Guideline for prevention and management of pressure ulcers. Mount Laurel: [editor unkown]; 2010. p.95.

15. Bergstrom N, Braden BJ, Laguzza A, Holman V. The Braden scale for predicting pressure sore risk. Nurs Res. 1987 Jul-Aug;36(4):205-10.

16. Fernandes LM. Úlceras de pressão em pacientes críticos hospitalizados: uma revisão integrativa da literatura [dissertação]. Ribeirão Preto (SP): Escola de Enfermagem de Ribeirão Preto/USP; 2000.

17. Lewicki LJ, Mion L, Splane KG, Samstag D, Secic M. Patient risk factors for pressure ulcers during cardiac surgery. AORN J. 1997;65(5):933-42.

18. Sewchuk D, Padula C,Osborne B. Prevention and early detection of pressure ulcers in patients undergoing cardiac surgery. J Wound Ostomy Continence Nurs. 2008;35(1):66-75.

19. Scarlatti KC, Michel JLM, Gamba MA, Gutiérrez MGR. Úlcera por pressão em pacientes submetidos à cirurgia: incidência e fatores associados. Rev. Esc. Enferm. USP. 2011;45(6):1372-9.

20. BRASIL. Ministério da Saúde. Portaria MS/GM no 529, de 1 de abril de 2013. Institui o Programa Nacional de Segurança do Paciente (PNSP). Diário Oficial [da] República Federativa do Brasil, Poder Executivo. Brasília, DF, 2 abr. 2013. Seção 1, p.43-4.

21. Costa IG. Incidência de úlcera de pressão e fatores de risco relacionados em pacientes de um Centro de Terapia Intensiva. [dissertação]. Ribeirão Preto: Escola de Enfermagem de Ribeirão Preto da Universidade de São Paulo; 2003. $133 \mathrm{p}$.

22. Sousa CA, Santos I, Silva LD. Aplicando recomendações da Escala de Braden e prevenindo úlceras por pressão: evidências do cuidar em enfermagem. Rev. bras. enferm. [online]. 2006;59(3):279-84.

23. Fernandes NCS, Torres GV, Vieira D. Fatores de risco e condições predisponentes para úlcera de pressão em pacientes de terapia intensiva. Rev. eletrônica enferm. 2008;10(3):733-46. Disponível em: http://www.fen.ufg.br/revista/v10/n3/v10n3a19.htm.

24. Fernandes LM, Caliri MHL. Uso da escala de Braden e de Glasgow para identificação do risco para úlceras de pressão em pacientes internados em centro de terapia intensiva. Rev. Latinoam enferm. 2008 nov.-dez. 2008;16(6). Disponível em: http:// www.eerp.usp.br/rlae

25. Diccini S, Camaduro C, Ilda LIS. Incidência de úlcera por pressão em pacientes neurocirúrgicos de hospital universitário. Acta paul. enferm. [online]. 2009;22(2):205-9. ISSN 1982-0194 . Disponível em: http://dx.doi.org/10.1590/S0103-21002009000200014. 
26. Cremasco MF, Wenzel F, Sardinha FM, Zanei SSV, Whitaker IY. Úlcera por pressão: risco e gravidade do paciente e carga de trabalho de enfermagem. Acta paul. enferm. [online]. 2009;22:897-902. ISSN 1982-0194.

27. Matos LS, Duarte NLV, Minetto RC. Incidência e prevalência de úlcera por pressão no CTI de um Hospital Público do DF. Rev. eletrônica enferm. 2010;12(4):719-26. Disponível em: http://www.fen.ufg.br/revista/v12/n4/v12n4a18.htm

28. Simão CMF. Úlcera por pressão em unidades de terapia intensiva e conformidade das ações de enfermagem [dissertação]. Ribeirão Preto: Universidade de São Paulo, Escola de Enfermagem de Ribeirão Preto; 2010 [Acessado em 31/01/2013]. Disponível em: http://www.teses.usp.br/teses/disponiveis/22/22132/tde-16112010-095225/.

29. Campos SF, Chagas ACP, Costa ABP, França REM, Jansenet AK. Fatores associados ao desenvolvimento de úlceras de pressão: o impacto da nutrição. Rev. nutr. [online]. 2010; 23(5):703-14.

30. Soares DA, VenDramin FS, Perreira LMD, Proença PK, Marques MM. Análise da incidência de úlcera de pressão no Hospital Metropolitano de Urgência e Emergência em Ananindeua, PA. Rev. bras. cir. plást. [online]. 2011;26(4):57881. ISSN 1983-5175.

31. Bavaresco T, Medeiros RH, Lucena AF. Implantação da Escala de Braden em uma unidade de terapia intensiva de um hospital universitário. Rev. Gaúch. enferm. [online]. 2011;32(4):703-10. ISSN 1983-1447.

32. Serpa LF, Santos VLCG, Oliveira AS, Caetano VC, Donadon SR. Incidência de Úlceras por Pressão em Pacientes Críticos. Rev Estima. 2011;9(3):21-6.

33. Pereira LC, Luz MHBA, Santana WS, Bezerra SMG, Figueiredo MLF. Incidence of pressure ulcers in an intensive care unit of a public hospital. Rev. enferm. UFPI. 2013 Oct-Dec;2(4):21-7.

34. Ventura JA, Moura LTR de, Carvalho MFAA. Braden scale and incidence of pressure ulcers in an intensive care unit. Rev. enferm. UFPE on line. 2014 jul.;8(7):2047-53.

35. Coleman C, Gorecki C; Nelson E; Closs SJ; Defloor T; Halfens R; Nixon J. Patient risk factors for pressure ulcer development: systematic review. Int J Nurs Stud. 2013 Jul;50(7):974-1003.

36. Serpa LF, Santos VLCG, Paranhos WY. Escalas de Avaliação de risco para o desenvolvimento de úlceras por pressão. In: Blanes L; Lydia Ferreira M, organizadores. Prevenção e Tratamento de Úlcera por Pressão. São Paulo: Atheneu. 2014. p. 13-27. 
37. Seongsook RNJ, Ihnsook RNJ, Younghee RNL. Validity of pressure ulcer risk assessment scales: Cubbin and Jackson, Braden, and Douglas scale. Int J Nurs Stud. 2004 Feb;41(2):199-204.

38. Sousa B. Translation, adaptation and validation of the Sunderland scale and the Cubbin \& Jackson revised scale in Portuguese. Rev. bras. ter. intensiva. 2013 Apr-June;25(2). Disponível em: http://dx.doi.org/10.5935/0103-507X.20130021.

39. Bergstrom N, Allman RM, Carlson CE, Eaglstein W, Frantz RA, Garber SL, et al. Pressure ulcers in adults: prediction and prevention. Clinical Practice Guideline. Number 3. Rockville, MD: Agency for Health Care Policy and Research; 1992. 101 p. (US Department of Health and Human Services. AHCPR Publication n. 92-0047).

40. Paranhos WY, Santos VLCG. Avaliação do risco para úlcera de pressão por meio da Escala de Braden na língua portuguesa. Rev. Esc. Enferm. USP. 1999;33:191204.

41. National Institute for Clinical Excellence. Clinical guideline 7: pressure ulcer prevention. London: National Institute for Clinical Excellence, 2003.

42. Keller BPJA, Wille J, Ramshorst BV, Van Der Werkwn C. Pressure ulcers in intensive care patients: a review of risk and prevention. Intensive Care Med. 2002;28:1379-88.

43. Benoit R, Mion L. Risk factors for pressure ulcer development in critically III patients: a conceptual model to guide research. Res Nurs Health. 2012;35:34062.

44. Settervall CHC, Sousa RMC. Escala de coma de Glasgow e qualidade de vida pós-trauma cranioencefálico. Acta paul. enferm. [online]. 2012; 25(3):364-70. ISSN 1982-0194.

45. Teasdale G, Jennett B. Assessment of coma and impaired consciousness. A practical scale. Lancet. 1974 Jul;2:81-4.

46. Rhoney DH, Murry KR. National survey of the use of sedating drugs, neuromuscular blocking agents, and reversal agents in the intensive care unit. J Intensive Care Med. 2003 May-June;18(3):139-45.

47. Kuhn C, Müller-Werdan U, Schmitt DV, Lange H, Pilz G, Kreuzer E, Mohr FW, Zerkowski HR, Werdan K. Improved outcome of APACHE II score-defined escalating systemic inflammatory response syndrome in patients post cardiac surgery in 1996 compared to 1988-1990: the ESSICS-study pilot project. Eur J Cardiothorac Surg. 2000 Jan;17(1):30-7.

48. Alves AGP, Borges JWP, Brito MA. Avaliação do risco para úlcera por pressão em unidades de terapia intensiva: uma revisão integrativa. Rev. pesqui. cuid. fundam [on line]. 2014 abr.-jun.;6(2):793-804. 
49. Louro M, Ferreira M, Póvoa P. Avaliação de Protocolo de Prevenção e Tratamento de Úlceras de Pressão. Rev. bras. ter. intensiva. 2007;19(3):337-41.

50. Strazzieri-Pulido KC, Santos VLCG. Cultural adaptation and validation of STAR Skin Tear Classification System for Brazilians [abstract]. J Wound Ostomy Continence Nurs. 2011;38(3S):S92.

51. Strazzieri-Pulido KC. Adaptação cultural e validação do instrumento STAR Skin Tear Classification System, para a língua portuguesa no Brasil [dissertação]. São Paulo (SP): Escola de Enfermagem, Universidade de São Paulo; 2010.

52. LeBlanc K, Baranoski S. Skin tears: state of the science: consensus statements for the prevention, prediction, assessment, and treatment of skin tears. Adv Skin Wound Care. 2011 Sept; 24(9 Suppl):2-15.

53. White M, Karam S, Cowell B. Skin tears in frail elders: a practical approach to prevention. Geriatr Nurs. 1994 Mar-Apr;15(2):95-9.

54. Amaral AFS, Strazzieri Pulido KCS, Santos VLCG. Prevalence of skin tears among hospitalized patients with cancer. Rev. Esc. Enferm. USP [online]. 2012;46:44-50. ISSN 1980-220X.

55. Meuleneire F. Using a soft silicone-coated net dressing to manage skin tears. $\mathbf{J}$ Wound Care 2002 Nov;11(10):365-9.

56. Accursio CSC. Alterações de pele na terceira idade. RBM rev. bras. med. 2001 set.;58(9):646,648-652.

57. Baranoski S. Skin tears: staying on guard against the enemy of frail skin. Nursing 2000 Sept;30(9):41-6.

58. Penzer R, Finch M. Promoting healthy skin in older people. Learning Disability Practice. 2001 May; 4(1):33-9.

59. Reddy M. Skin and wound care: important considerations in the older adult. Adv Skin Wound Care. 2008; 21(9):424-36.

60. Payne R, Martin M. Defining and classifying skin tears: need for a common language. Ostomy Wound Manage. 1993 June;39(5):16-20, 22-4,26.

61. LeBlanc K, Christensen D, Orsted HL, Keast DH. Prevention and treatment of skin tears. Wound Care Canada. 2008;6(1):14-32.

62. Baranoski S. Skin tears: the enemy of frail skin. Adv Skin Wound Care. 2000 May-June;13(3 Pt 1):123-6.

63. Nazarko L. Maintaining the condition of ageing skin. Nursing and Residential Care 2007; 9(4):160-3.

64. Payne RL, Martin ML. The epidemiology and management of skin tears in older adults. Ostomy Wound Manage.1990;26:26-37. 
65. Ratliff CR, Fletcher KR. Skin tears: a review of the evidence to support prevention and treatment. Ostomy Wound Manage. 2007;53(3):32-42.

66. Selden S, Cowell B, Fenno J. Skin tears: recognizing and treating this growing problem. Skin Aging. 2002;10:55-60.

67. Thomas DR, Goode PS, LaMaster K, Tennyson T, Parnell LK. A comparison of an opaque foam dressing versus a transparent film dressing in the management of skin tears in institutionalized subjects. Ostomy Wound Manage. 1999;45(6):22-8.

68. McLane KM, Bookout K, McCord S, McCain J, Jefferson LS. The 2003 national pediatric pressure ulcer and skin breakdown prevalence survey: a multisite study. J Wound Ostomy Continence Nurs. 2004; 31(4):168-78.

69. Baharestani MM. An overview of neonatal and pediatric wound care knowledge and considerations. Ostomy Wound Manage. 2007;53(6):34-40.

70. Irving V, Bethell E, Burtin F. Neonatal wound care: minimizing trauma and pain. Wounds. 2006:2(1):33-41.

71. Pasek T, Geyser A, Sidoni M, et al. Skin care team in the pediatric intensive care unit: a model for excellence. Crit Care Nurse. 2008;28:125-35.

72. Carville K, Lewin G, Newall N, Haslehurst P, Michael R, Santamaria N, Roberts P. STAR: a consensus for skin tear classification. Primary Intention 2007 Feb;15(1):18-28.

73. Santos VLCG (tradução). SCALE - Modificações da pele no final da vida. Rev Estima. 2009;7(3):42-4.

74. Sibbald RG, Krasner DL, Lutz J. SCALE: skin changes at life's end: final consensus statement: October 1, 2009. Adv Skin Wound Care. 2010;23:225-36; quiz 237-8.

75. Strazzieri-Pulido KC, Peres GRP, Campanilli TCGF, Santos VLCG. Incidência de lesões por fricção e fatores de risco: revisão de literatura. No prelo.

76. Santamaria N, Carville K, Prentice J. Woundswest: identifying the prevalence of wounds within western Australia's public health system. EWMA Journal. 2009;9(3):13-8.

77. Strazzieri-Pulido KC, Peres GRP, Campanilli TCGF, Santos VLCG. Prevalência de lesões por fricção e fatores de risco: revisão de literatura. REEUSP, 2014 [em julgamento].

78. Malone ML, Rozario N, Gavinski M. The epidemiology of skin tears in institutionalized elderly. J Am Geriatr Soc. 1991;39(6):591-5. 
79. Everett S, Powell T. Skin tears - the underestimated wound. Primary Intent. 1994;2:8-30.

80. McGough-Csarny J, Kopac CA. Skin tears in institutionalized elderly: an epidemiological study. Ostomy Wound Manage. 1998;44(3A suppl):14S-25S.

81. Kennedy P, Kerse N. Pretibial skin tears in older adults: a 2-year epidemiological study. J Am Geriatr Soc. 2011;59(8):1547-8.

82. Fleck CA. Preventing and treating skin tears. Advances in Skin and Wound Care. 2007;20(6):315-20.

83. Dunkin CS, Elfleet D, Ling C, Brown TP. A step by step guide to classifying and managing pretibial injuries. J Wound Care. 2003;12(3):109-11.

84. Beldon P. Classifying and managing pretibial lacerations in older people. $\mathrm{Br} \mathrm{J}$ Nurs. 2008;17(11 suppl):S4-S18.

85. World Health Organization. BMI Classification. Global Database on Body Mass index: World Health Organization; 2013.

86. Ayello EA, Braden B. How and why to do pressure ulcer risk assessment. Adv Skin Wound Care, 2002; 15(3):125-32.

87. BRASIL. Ministério da Saúde. Portaria n. 3432, de 12 de agosto de 1998. Estabelece critérios de classificação para as unidades de tratamento intensivoUTI. Diário Oficial [da] República Federativa do Brasil, Poder Executivo. Brasília, DF, 13 ago. 1998. Seção 1, p. 108-10.

88. Raju D, Su X, PAtrician PA, Loan LA, McCarthy MS. Exploring factors associated with pressure ulcers: A data mining approach. Int J Nurs Stud. 2014. Disponível em: http://dx.doi.org/10.1016/j.ijnurstu.2014.08.002

89. Shahin ESM, Dassen T, Halfens RJG.Incidence, prevention and treatment of pressure ulcers in intensive care patients: a longitudinal study. Int J Nurs Stud. 2009;46(4):413-21.

90. Fife C, Otto G, Capsuto EG, Brandt K, Lyssy K, Murphy K, Short C. Incidence of pressure ulcers in neurologic intensive care unit. Crit Care Med. 2001;29:28390 .

91. Sayar S, Turgut S, Doðan H, Ekici A, Yurtsever S, Demirkan F, Doruk N, $\mathrm{Ta}^{\circ}$ delen $\mathrm{B}$. Incidence of pressure ulcers in intensive care unit patients at risk according to the Waterlow scale and factors influencing the development of pressure ulcers. J Clin Nurs. 2009;18(5):776-7. 
92. Manzano F, Navarro MJ, Roldán D, Moral MA, Leyva I, Guerrero C, Sanchez MA, Colmenero M, Fernández-Mondejar E; Granada UPP Group. Pressure ulcer incidence and risk factors in ventilated intensive care patients. J Crit Care. 2010; 25(3):469-76.

93. De Laat, EH.; Pickkers, P; Schoonhoven L; Verbeek AL; Feuth, T; Van Achterberg T. Guideline implementation results in a decrease of pressure ulcer incidence in critically ill patients. Crit Care Med. 2007; 35(3):815-20.

94. Suriadi SH, Sugama J, Thigpen B, Subuh M. Development of a new risk assessment scale for predicting pressure ulcers in an intensive care unit. Nurs Crit Care. 2008; 13(1): 34-43.

95. Nassaji M, Askari Z, Ghorbani R. Cigarette smoking and risk of pressure ulcer in adult intensive care unit patients. Int J Nurs Pract. 2014 Aug;20(4):418-23.

96. Chen HL, Shen WQ, Xu YH, Zhang Q, Wu J . Perioperative corticosteroids administration as a risk factor for pressure ulcers in cardiovascular surgical patients: a retrospective study. Int Wound J. 2013 Dec.

97. O'Brien DD, Shanks AM, Talsma A, Brenner PS, Ramachandran SK.. Intraoperative risk factors associated with postoperative pressure ulcers in critically ill patients: a retrospective observational study. Crit Care Med. 2014 Jan;42(1):40-7.

98. Lumbley JL, Ali SA, Tchokouani LS. Retrospective review of predisposing factors for intraoperative pressure ulcer development. J Clin Anesth. 2014 Aug.

99. Cox J. Pressure ulcer development and vasopressor agents in adult critical care patients: a literature review. Ostomy/wound Manage. 2013;59(4):50-4,56-60.

100. Hyun S1, Vermillion B, Newton C, Fall M, Li X, Kaewprag P, Moffatt-Bruce S, Lenz ER. Predictive validity of the Braden scale for patients in intensive care units. Am J Crit Care. 2013 Nov;22(6):514-20.

101. Corniello AL, Moyse T, Bates J, Karafa M, Hollis C, Albert NM. Predictors of pressure ulcer development in patients with vascular disease. J Vasc Nurs. 2014 Jun;32(2):55-62.

102. Catalá Espinosa AI, Hidalgo Encinas Y, Cherednichenko T, Flores Lucas I, González Tamayo R, García-Martínez MÁ, Herrero-Gutiérrez E. Correlation between body mass index and development of pressure ulcers in intensive care medicine. Enferm Intensiva. 2014 Jul-Sep;25(3):107-13.

103. Nahla Tayyib, Fiona Coyer, Peter Lewis. Pressure ulcers in the adult intensive care unit: a literature review of patient risk factors and risk assessment scales. J Nurs Educ Pract. 2013:3(11):28-42. 
104. Alderden J, Whitney JD, Taylor SM, Zaratkiewicz S. Risk Profile Characteristics Associated With Outcomes of Hospital-Acquired Pressure Ulcers: A Retrospective Review. Crit Care Nurse. 2011;31:30-43.

105. Bergstron N, Braden B, Champagne M, Ruby E. Multi-site study of incidence of pressure ulcers and the relationship between risk level, demographic characteristics, diagnoses, and prescription of preventive interventions. J Am Geriat Soc. 1996;41(1):22-30.

106. Baumgarten M, Margolis D, Van Doorn C, Gruber-Baldini AL, Hebel JR, Zimmerman S, Magazinerm J. Black/White differences in pressure ulcer incidence in nursing home residentes. J Am Geriatr Soc. 2004;52(8):1293-98.

107. Anthony D, Johnson M, Reynolds T, Russell L. Ethnicity in pressure ulcer risk assessment, with specific relation to the pakstani ethnic minority in Burton, England. J Adv Nurs. 2002;38(6):592-7.

108. Karadag M, Gümüskaya N. The incidence of pressure ulcers in surgical patients: a sample hospital in Turkey. J Clin Nurs. 2006;15(4):413-21.

109. Schoonhoven L, Defloor T, Grypdonck M. Incidence of pressure ulcers due to surgery. J Clin Nurs. 2002;11(4):479-87.

110. Pancorbo Hidalgo PL, Garcia Fernandez F.P. Risk factors for the development of pressure ulcers among hospitalized elderly patients. Gerokomos, 2001;12 (4):175-84.

111. Elias CMV, Gonçalves NPC, Silva Sales JC, Galvão IOGC , Carvalho ML, Carvalho LKCAA. Compilation of scientific evidence for the prevention of pressure ulcers. R. Interd. 2014;7(1):183-92.

112.Ülker Efteli E1, Yapucu Günes Ü. A prospective, descriptive study of risk factors related to pressure ulcer development among patients in intensive care units. Ostomy Wound Manage. 2013 Jul;59(7):22-7.

113. Compton F, Hoffmann F, Hortig T, Strauss M, Frey J, Zidek W, Schafer JH. Pressure ulcer predictors in ICU patients: nursing skin assessment versus objective parameters J Wound Care. 2008 Oct;17(10):417-20.

114. Strazzieri Pulido KC, Santos VLCG.Superfícies de Suporte: Parte I. Rev Estima. 2010;8(1):40-42.

115. Strazzieri Pulido KC, Santos VLCG.Superfícies de Suporte: Parte II*. Rev Estima. 2010;8(2):38-41. 
116. Horvath KA, Acker MA, Chang H, Bagiella E, Smith PK, Iribarne A, Kron IL, Lackner P, Argenziano M, Ascheim DD, Gelijns AC, Michler RE, Van Patten D, Puskas JD, O'Sullivan K, Kliniewski D, Jeffries NO, O'Gara PT, Moskowitz AJ, Blackstone EH. Blood transfusion and infection after cardiac surgery. Ann Thorac Surg. 2103 Jun;95(6):2194-201.

117.Peduzzi P, Concato J, Feinstein AR, Holford TR. Importance of events per independent variable in proportional hazards regression analysis. II. Accuracy and precision of regression estimates. J Clin Epidemiol. 1995 Dec;48(12):150310 .

118. Hajjar LA, Vincent JL, Galas FRBG, Nakamura RE, Silva CMP, Fukushima J, Kalil Filho R, Sierra DB, Lopes NH, Mauad T, Roquim AC, Sundin MR et al. Transfusion Requirements After Cardiac Surgery- The TRACS. Randomized Controlled Trial. JAMA. 2010;304(14):1559-67.

119. Koch CG, Li L, Duncan AI, et al. Morbidity and mortality risk associated with red blood cell and blood-component transfusion in isolated coronary artery bypass grafting. Crit Care Med. 2006;34(6):1608-16.

120. Murphy GJ, Reeves BC, Rogers CA, et al. Increased mortality, postoperative morbidity, and cost after red blood cell transfusion in patients having cardiac surgery. Circulation. 2007 Nov;116(22):2544-52.

121. Wu WC, Rathore SS, Wang Y, et al. Blood transfusion in elderly patients with acute myocardial infarction. N Engl J Med. 2001;345(17):1230-36. 
Apêndice 


\section{APÊNDICE}

APÊNDICE I - Instrumento de para coleta de dados

\section{ADMISSÃO}

\section{1- DADOS DE IDENTIFICAÇÃO}

Nome(iniciais):

Data de nascimento:

Data de internação hospitalar:

Sexo: (1) Feminino

Cor da pele: (1) branco

(2) negro

(3) amarelo

(4) parda

Peso:

Altura:

IMC:

\section{ANTECEDENTES PESSOAIS:}
( ) diabetes
( ) hipertensão arterial
( ) dislipidemia
( ) AVE
( ) tabagismo
( ) Insuficiência venosa
( ) Insuficiência arterial
( )outros

( ) Comprometimento visual ( uso de óculos ou lentes)

( ) contusões ( )agitação

( ) contratura de braços, pernas e ombro ( ) hemiplegia

( ) hemiparesia

( ) lesões nas extremidades (fungica, amputação, Ulcera venosa, Ulcera arterial)

( )pele seca ( ) pele escamosa 


\section{2- DADOS CLÍNICOS INTRA OPERATÓRIO}

Data da cirurgia:

Tipo de cirurgia: ( )Revascularização do miocárdio （ )Troca de valva qual?

( )Plástica de valva qual? ( ) Correção vascular tipo

( ) Outro

Uso de CEC: ( )sim tempo minutos ( )não

Uso de hemoderivados: ( ) sim

( )não

Tipo/quantidade de hemoderivados:
( )concentrado de hemácias
( ) plaquetas
( ) plasma
( ) crio

Tempo de cirurgia: horas

\section{PÓS OPERATÓRIO}

Quais drogas utilizadas na admissão:

( ) dobutamina $\mathrm{mcg} / \mathrm{Kg} / \mathrm{min}$

( ) primacor $\mathrm{mcg} / \mathrm{Kg} / \mathrm{min}$

( )noradrenalina $\mathrm{mcg} / \mathrm{Kg} / \mathrm{min}$

( ) nitroprussiato $\mathrm{mcg} / \mathrm{Kg} / \mathrm{min}$

( ) adrenalina $\mathrm{mcg} / \mathrm{Kg} / \mathrm{min}$

( ) nitroglicerina $\mathrm{mcg} / \mathrm{Kg} / \mathrm{min}$

( ) outro $\mathrm{mcg} / \mathrm{Kg} / \mathrm{min}$

Presença e número de cateteres na admissão:

( ) venoso periférico ( ) venoso central

( ) arterial

Presença e número de drenos e sondas na admissão:

( ) dreno mediano

( ) dreno pleural direito

( ) dreno pleural esquerdo

( ) SVD ( ) SNG

( )SNE 


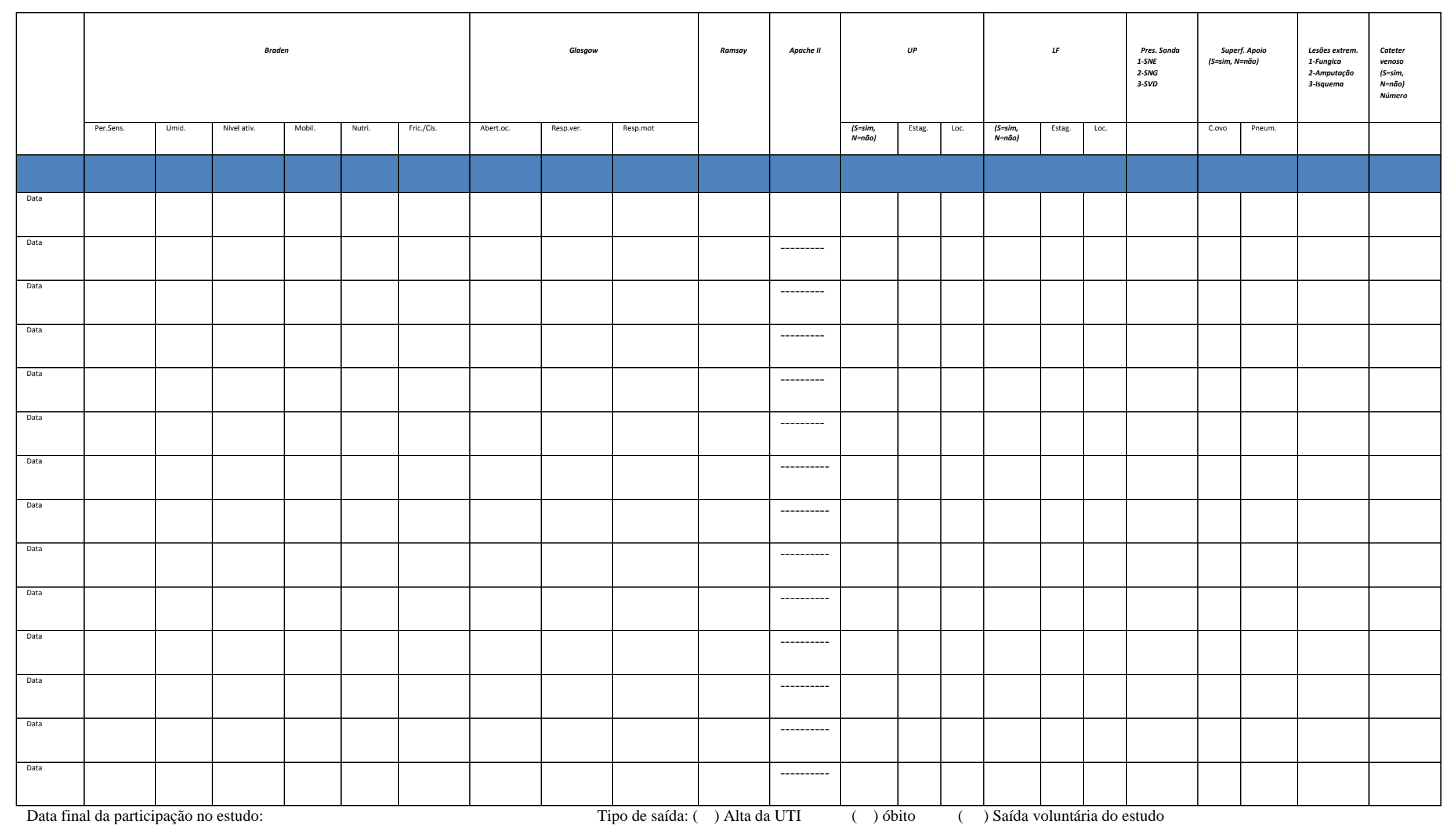


Anexos 


\section{ANEXOS}

\section{ANEXO I - TERMO DE CONSENTIMENTO LIVRE E ESCLARECIDO \\ HOSPITAL DAS CLÍNICAS DA FACULDADE DE MEDICINA DA \\ UNIVERSIDADE DE SÃO PAULO-HCFMUSP \\ TERMO DE CONSENTIMENTO LIVRE E ESCLARECIDO}

\section{DADOS DE IDENTIFICAÇÃO DO SUJEITO DA PESQUISA OU RESPONSÁVEL LEGAL}

\section{NOME:}

DOCUMENTO DE IDENTIDADE $\mathrm{N}^{\circ}$ : SEXO : .M

DATA NASCIMENTO: ........................

ENDEREÇO: IDADE

$\mathrm{N}^{\mathrm{o}}$ APTO:

BAIRRO: TELEFONE: DDD (............)

CEP:

2.RESPONSÁVEL LEGAL

NATUREZA (grau de parentesco, tutor, curador etc.)

DOCUMENTO DE IDENTIDADE : ..SEXO: $\mathrm{M} \square \quad \mathrm{F} \square$ DATA NASCIMENTO.: ..................... ENDEREÇO: $\mathrm{N}^{\mathrm{o}}$ APTO:

BAIRRO: CIDADE:

CEP: TELEFONE: DDD ( ).

DADOS SOBRE A PESQUISA

1. TÍTULO DO PROTOCOLO DE PESQUISA: INCIDÊNCIA DE ÚLCERA POR PRESSÃO E LESÃO POR FRICÇÃO EM PACIENTES DE UNIDADE DE TERAPIA INTENSIVA CARDIOPNEUMOLÓGICA

PESQUISADOR : Ticiane Carolina G.F.Campanili.

CARGO/FUNÇÃO: Enfermeira INSCRIÇÃO CONSELHO REGIONAL Nº117448

UNIDADE DO HCFMUSP: UTI Cirúrgica do InCor.

Orientadora: Prof ${ }^{a}$ Dra Vera Lúcia Conceição de Gouveia Santos

3. AVALIAÇÃO DO RISCO DA PESQUISA:

$\begin{array}{lll}\text { RISCO MÍNIMO } & X & \text { RISCO MÉDIO } \\ \text { RISCO BAIXO } & \square & \text { RISCO MAIOR }\end{array}$

4.DURAÇÃO DA PESQUISA : Agosto de 2012 a outubro de 2014 


\section{HOSPITAL DAS CLÍNICAS DA FACULDADE DE MEDICINA DA UNIVERSIDADE DE SÃO PAULO-HCFMUSP}

1- Gostaria de convidá-lo a participar de um estudo que identificará o número de pacientes que desenvolverão lesões de pele durante a sua permanência na UTI.

2 - Uma vez que aceite participar, eu colherei dados de seu prontuário sobre as suas características físicas como, por exemplo, idade, sexo, cor da sua pele etc (dados sócio-demográficos) e quanto a seu problema de saúde, ou seja, seus dados clínicos. Além disso, para conhecer o risco que o(a) $\operatorname{Sr}(a)$ tem para desenvolver feridas na sua pele, farei um exame físico do (a) $\operatorname{Sr}(a)$, principalmente de sua pele, durante sua permanência na UTI, do dia da sua entrada (admissão) até sua alta. Também checarei sua resposta diária a estímulos e seu nível de consciência. Caso receba algum sedativo, também avaliarei o grau de sedação diariamente (o quanto está dormindo ou sonolento). Em cada dia em que forem feitos, esses procedimentos durarão cerca de 30 minutos.

3-É preciso que o (a) Sr(a) saiba que não haverá risco ou desconforto;

4 - Além disso, sua participação é voluntária e não haverá benefício direto, ou seja, qualquer pagamento por essa participação.

5 - Como pesquisadora responsável pelo projeto, garanto que, em qualquer etapa do estudo, o(a) $\operatorname{Sr}$ (a) terá acesso a mim e à minha orientadora para esclarecimento de qualquer dúvida. Eu, Ticiane C.G.F.Campanili, enfermeira, sou a principal investigadora e posso ser encontrada no endereço do hospitala (Instituto do Coração - InCor), na Rua Dr Enéas de Carvalho Aguiar, 44, $4^{\circ}$ andar, UTI cirúrgica II Telefone(s) 996264227. Se houver qualquer consideração ou dúvida sobre a ética da pesquisa, o(a) $\mathrm{Sr}$ (a) pode entrar em contato com o Comitê de Ética em Pesquisa (CEP) da Escola de Enfermagem da USP - Rua Dr. Enéas de Carvalho Aguiar, 419 - 2 ${ }^{\circ}$ andar - tel: 3061-7548 ou através do e-mail: edipesq@usp.br.

6-O(a) $\mathrm{Sr}$ (a) pode retirar o seu consentimento a qualquer momento e deixar de participar do estudo, sem qualquer prejuízo à continuidade de seu tratamento na Instituição;

7 - As informações obtidas serão analisadas em conjunto com outros pacientes, não sendo divulgada a sua identidade ou de qualquer outro paciente do estudo;

8 - O(a) $\operatorname{Sr}$ (a) poderá solicitar a mim, em qualquer momento do estudo, a apresentação dos resultados da pesquisa, para se manter atualizado(a);

9 - Eu, pesquisadora responsável por este estudo, me comprometo a utilizar os dados e o material coletado somente para a pesquisa científica. 


\section{HOSPITAL DAS CLÍNICAS DA FACULDADE DE MEDICINA DA UNIVERSIDADE DE SÃO PAULO-HCFMUSP}

Acredito ter sido suficientemente informado a respeito das informações que li ou que foram lidas para mim, descrevendo o estudo "INCIDÊNCIA DE ÚLCERA POR PRESSÃO E LESÃO POR FRICÇÃO EM PACIENTES DE UNIDADE DE TERAPIA INTENSIVA CARDIOPNEUMOLÓGICA"

Eu discuti com a pesquisadora Ticiane C.G.F.Campanili sobre a minha decisão em participar deste estudo. Ficaram claros para mim quais são os objetivos do estudo, como ele será desenvolvido, as garantias de que minha identidade não será revelada e de que sempre receberei informações. Ficou claro também que não terei despesas e que não serei pago para participar do estudo bem como que continua garantido meu acesso ao tratamento hospitalar que venho recebendo. Estou esclarecido(a) que poderei retirar o meu consentimento a qualquer momento, antes ou durante o mesmo, sem penalidades ou prejuízo ou perda de qualquer benefício que eu possa ter adquirido, ou no meu atendimento neste Serviço. Assim, confirmo que concordo em participar deste estudo.

Assinatura do paciente/representante legal

Data

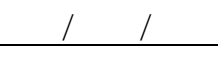

Assinatura da testemunha

Data 11

Para pacientes, analfabetos, semi-analfabetos ou com deficiência auditiva ou visual.

(Somente para o responsável do projeto)

Declaro que obtive, de forma apropriada e voluntária, o Consentimento Livre e Esclarecido deste paciente ou representante legal para a participação neste estudo.

Data 11

Assinatura do responsável pelo estudo

Rubrica do sujeito de pesquisa ou responsável

Rubrica do pesquisador 


\section{ANEXO II- CLASSIFICAÇÃO DAS ÚLCERAS POR PRESSÃO DE ACORDO NPUAP ${ }^{4}$}

\section{Categoria I: $\underline{\text { Hiperemia não reativa em pele intacta }}$}

Pele intacta com hiperemia não reativa de uma área localizada, normalmente sobre uma proeminência óssea. Calor, edema, tumefacção ou dor podem também estar presentes no local. Em pele escura pode não ser visível, com mudança na coloração local com a pele quando comparado a pele adjacente.

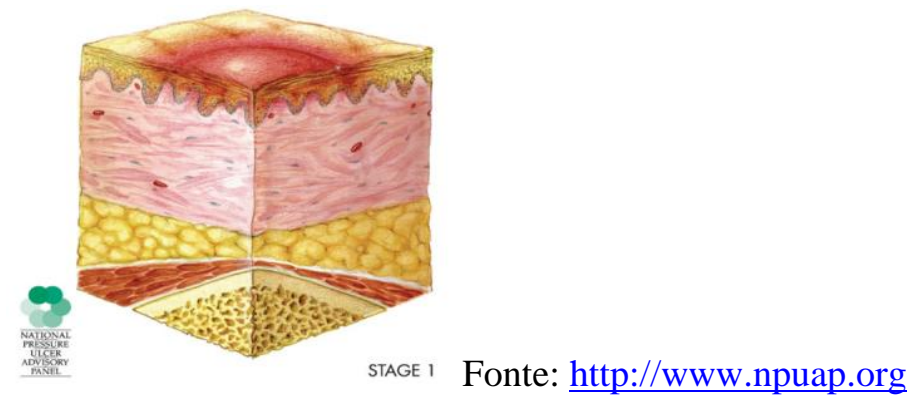

Descrição adicional: a área lesionada pode ficar dolorosa, endurecida, mais quente ou mais fria quando comparada ao tecido adjacente. Pode ser difícil de identificar em indivíduos com tons de pele escuro. Pode ser indicativo de pessoas "em risco". Categoria II: Perda parcial da espessura da pele ou flictena

Perda parcial da espessura da derme que se apresenta como uma ferida superficial (rasa) com leito vermelho a róseo sem esfacelo. Pode também apresentar-se como flictena (bolha) fechada ou aberta rompida preenchida por líquido seroso ou serohemático.

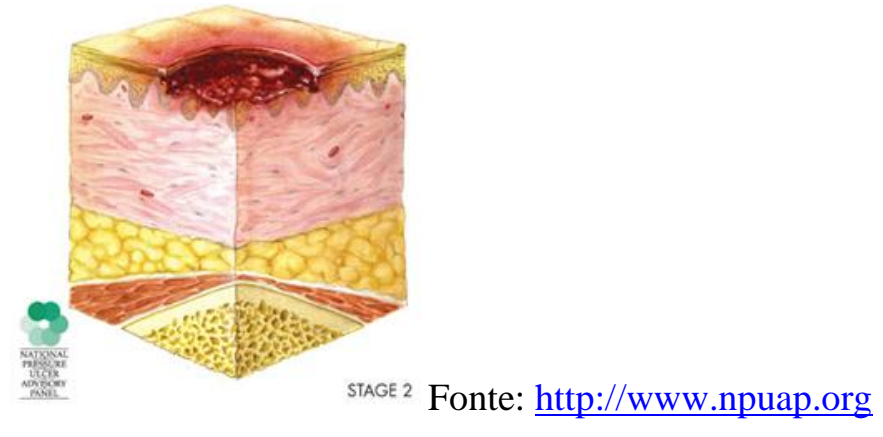

Descrição adicional: Apresenta-se como uma úlcera brilhante ou seca, sem esfacelos ou crostas. Esta categoria não deve ser usada para descrever fissuras da pele, abrasões, dermatite associada à incontinência, maceração ou escoriação.

Categoria III: Perda total da espessura da pele (tecido subcutâneo visível) 
Perda total da espessura tecidual. Pode ser visível o tecido subcutâneo, mas não estão expostos os ossos, tendões ou músculos. Pode estar presente algum tecido desvitalizado (esfacelo). Pode incluir lesão cavitária e encapsulamento.

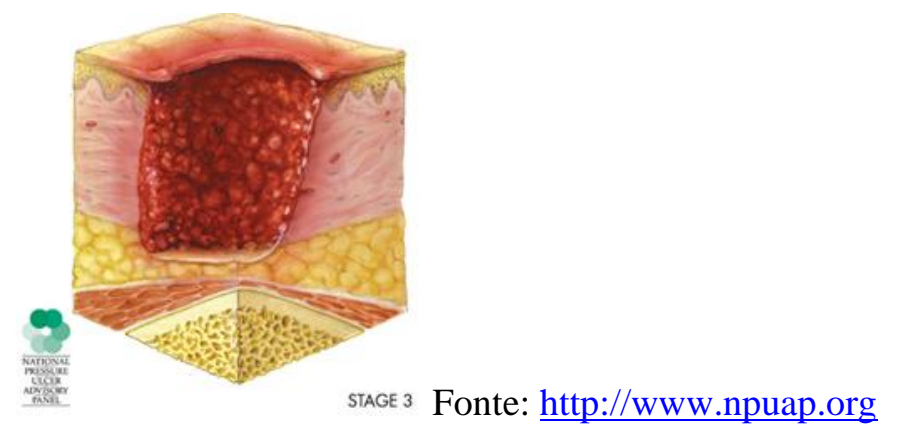

Descrição adicional: A profundidade de uma úlcera de categoria III varia com a localização anatómica. A asa do nariz, orelhas, região occipital e maléolos não têm tecido subcutâneo e uma úlcera de categoria III pode ser rasa (superficial); em contrapartida, em zonas com adiposidade significativa podem desenvolver úlceras de pressão de categoria III extremamente profundas. O osso/tendão não são visíveis ou diretamente palpáveis.

Categoria IV: Perda total da espessura dos tecidos (músculos e ossos visíveis)

Perda total da espessura dos tecidos com exposição dos tendões e músculos. Pode estar presente tecido desvitalizado (esfacelo) e ou necrótico. Frequentemente são cavitárias e fistuladas.

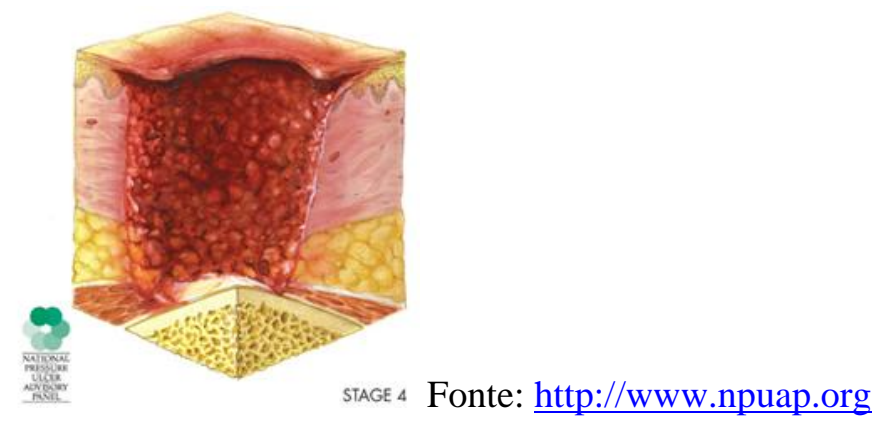

Descrição adicional: A profundidade de uma úlcera de pressão de categoria IV varia com a localização anatômica. A asa do nariz, orelhas, região occipital e maléolos não têm tecido subcutâneo e estas úlceras podem ser rasas (superficiais). Uma úlcera de categoria IV pode atingir as estruturas de suporte (ex. fáscia, tendão ou cápsula articular) tornado a osteomielite provável de acontecer. Existe osso/ musculo exposto visível ou diretamente palpável. Categorias adicionais para os Estados Unidos da $\underline{\text { América }}$

Não graduáveis/ indeterminadas: Perda total da espessura dos tecidos na qual a profundidade atual da úlcera está bloqueada pela presença de tecido necrótico 
(amarelo, acastanhado, cinzento, verde ou castanho) e ou escara (tecido necrótico acastanhado, castanho ou preto) no leito da ferida.

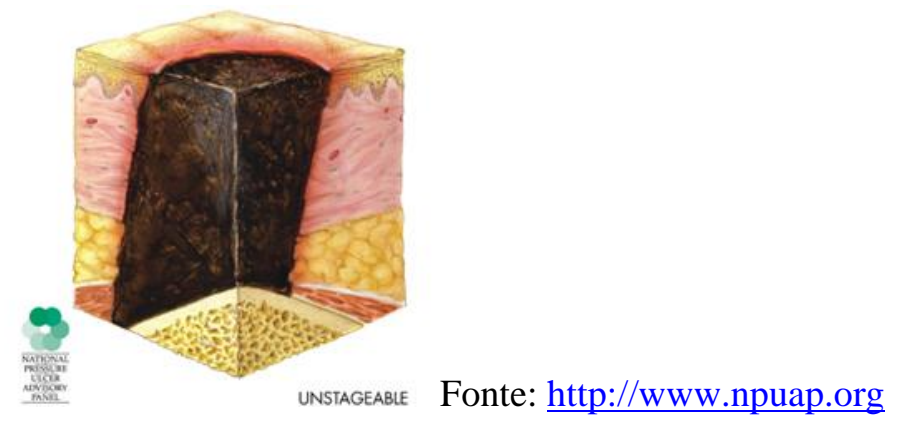

Descrição adicional: até que seja removido o tecido necrótico suficiente para expor a base da ferida, a verdadeira profundidade não pode ser determinada, mas é, no entanto uma úlcera de categoria III ou IV. Uma escara estável (seca, aderente, intacta e sem eritema ou flutuação) nos calcâneos, serve como proteção biológica natural e não deve ser removida.

Suspeita de lesão tissular profunda: Área vermelho escuro ou púrpura localizada em pele intacta e descolorada ou flictena preenchida com sangue, provocadas por danos no tecido mole subjacente pela pressão e ou forças de torção.

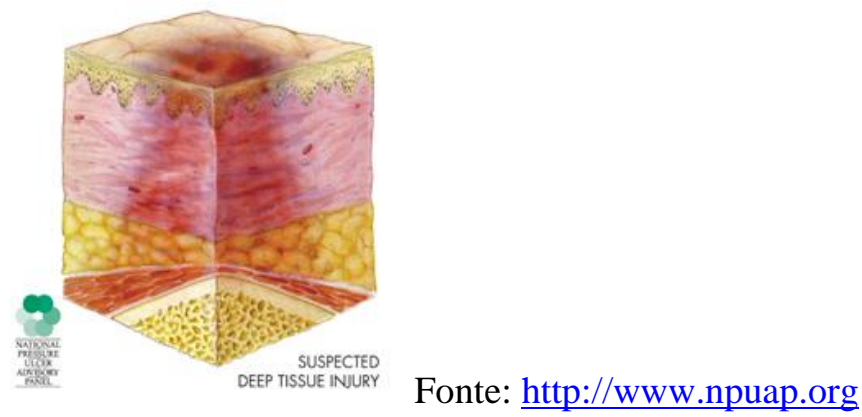

Descrição adicional: A área pode estar rodeada por tecido mais doloroso , firme, úmido, quente ou frio comparativamente ao tecido lesionado. A lesão dos tecidos profundos pode ser difícil de identificar em indivíduos com tons de pele escuro. A evolução pode incluir uma pequena flictena sobre o leito de uma ferida escura. A ferida pode evoluir adicionalmente ficando coberta por uma fina camada de tecido necrótico (escara). A sua evolução pode ser rápida expondo camadas de tecido adicionais mesmo com o tratamento. 


\section{ANEXO III- Sistema de Classificação STAR}

\section{Sistema de Classificação STAR - Lesão por Fricção}

\section{Diretrizes do Sistema de Classificação STAR - Lesão por Fricção}

1. Controlar o sangramento e limpar a ferida de acordo com o protocolo institucional.

2. Realinhar (se possível) qualquer segmento de pele ou retalho.

3. Avaliar o grau de perda tissular e a cor da pele ou do retalho utilizando o Sistema de Classificação STAR - Lesões por Fricção.

4. Avaliar as condições da pele adjacente à ferida quanto à fragilidade, edema, descoloração e arroxeamento (aspecto de equimose).

5. Avaliar a pessoa, a(s) ferida(s) e a cicatrização de acordo com o protocolo institucional.

6. Se a pele ou o retalho estiver pálido, opaco ou escurecido, reavaliar em 24-48 horas ou na primeira troca de curativo.

\begin{tabular}{|c|c|c|c|c|}
\hline \multicolumn{4}{|c|}{ Sistema de Classificação STAR - Lesão por Fricção } & \\
\hline $\begin{array}{l}\text { Categoria 1a } \\
\text { Lesão por fricção cujo } \\
\text { retalho de pele pode ser } \\
\text { realinhado à posição } \\
\text { anatômica normal (sem } \\
\text { tensão excessiva) e a } \\
\text { coloração da pele ou do } \\
\text { retalho não se apresenta } \\
\text { pálida, opaca ou } \\
\text { escurecida. }\end{array}$ & $\begin{array}{l}\text { Categoria 1b } \\
\text { Lesão por fricção cujo } \\
\text { retalho de pele pode ser } \\
\text { realinhado à posição } \\
\text { anatômica normal (sem } \\
\text { tensão excessiva) e a } \\
\text { coloração da pele ou do } \\
\text { retalho apresenta-se } \\
\text { pálida, opaca ou } \\
\text { escurecida. }\end{array}$ & $\begin{array}{l}\text { Categoria 2a } \\
\text { Lesão por fricção cujo } \\
\text { retalho de pele não } \\
\text { pode ser realinhado à } \\
\text { posição anatômica } \\
\text { normal (sem tensão } \\
\text { excessiva) e a } \\
\text { coloração da pele ou } \\
\text { do retalho não se } \\
\text { apresenta pálida, } \\
\text { opaca ou escurecida. }\end{array}$ & $\begin{array}{l}\text { Categoria } \mathbf{2 b} \\
\text { Lesão por fricção cujo } \\
\text { retalho de pele não } \\
\text { pode ser realinhado à } \\
\text { posição anatômica } \\
\text { normal (sem tensão } \\
\text { excessiva) e a } \\
\text { coloração da pele ou } \\
\text { do retalho apresenta- } \\
\text { se pálida, opaca ou } \\
\text { escurecida. }\end{array}$ & $\begin{array}{l}\text { Categoria } 3 \\
\text { Lesão por fricção cujo } \\
\text { retalho de pele está } \\
\text { completamente } \\
\text { ausente. }\end{array}$ \\
\hline
\end{tabular}




\section{Sistema de Classificação STAR - Lesão por Fricção}

\section{Glossário}

- Lesão por Fricção: "ferida traumática que ocorre principalmente nas extremidades de idosos, resultante de fricção ou de uma combinação de fricção e cisalhamento, levando à separação da epiderme da derme (ferida de espessura parcial) ou separando totalmente a epiderme e a derme das estruturas subjacentes (ferida de espessura total)."

- Pele ou retalho de pele pálido, opaco ou escurecido: quando comparada a pele "normal" do indivíduo ao redor da ferida pode indicar isquemia ou presença de hematoma, o que pode afetar a viabilidade da pele ou retalho.

- Isquemia: perfusão tissular inadequada evidenciada pela palidez, opacidade ou escurecimento do tecido.

- Hematoma: coleção de sangue ou coágulos sob um retalho ou pele realinhada.

- Realinhar: recolocar a pele ou retalho na sua posição anatômica normal sem tensão excessiva.

- Lesão por fricção linear: fissura ou rompimento da pele em linha reta.

- Retalho de pele: segmento de pele ou de pele e tecido subjacente separado das demais estruturas

\section{Referências:}

1 Payne, R., \& Martin, M. (1993). Defining and classifying skin tears: Need for a common language a critique and revision of the Payne-Martin Classification system for skin tears. Ostomy Wound Management, 39(5):16-20.

2 Photographs courtesy of the Skin Tear Audit Research (STAR) photographic library, Silver Chain Nursing Association and School of Nursing and Midwifery, Curtin University of Technology.

3 Carville, K., Lewin, G., Newall, N., Haslehurst, P., Michael, R., Santamaria, N., \& Roberts, P. (2007). STAR: A consensus for skin tear classification. Primary Intention, 15(1), 18-28. 


\section{ANEXO IV - ESCALA DE BRADEN}

\section{Escala de Braden* (versāo adaptada e validada para o Brasil)**}

\begin{tabular}{|c|c|c|c|c|}
\hline $\begin{array}{l}\text { Perceppâa sensorial: } \\
\text { Cupacidade de reagir } \\
\text { iignificativamente à pressao } \\
\text { relacionada ao desconforto }\end{array}$ & 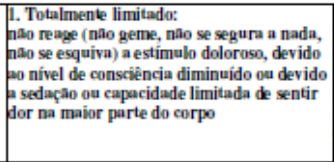 & 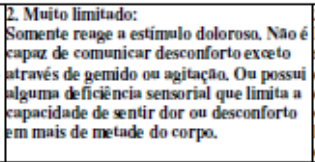 & $\begin{array}{l}\text { 3. Levemente limitadox } \\
\text { Responde a comando verbal, mas nem } \\
\text { sempre é capar de conunicar o } \\
\text { desconforto ou expressar necessidade } \\
\text { de ser madado de posicato ou tem um } \\
\text { certo grau de deficiência sensorial que } \\
\text { limita a capacidade de sentir dor ou } \\
\text { desconforto em } 1 \text { ou } 2 \text { extremidades. }\end{array}$ & $\begin{array}{l}4 \text { Nenhuma limitaça. } \\
\text { Responde a comandos verbais nao } \\
\text { temm déficit sensorial que limitaria a } \\
\text { capacidade de sentir ou verbalizar } \\
\text { dor ou desconforto }\end{array}$ \\
\hline 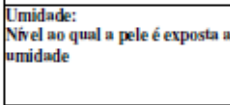 & $\begin{array}{l}\text { 1. Completamente molhadar } \\
\text { A pele é mantida molhada quase } \\
\text { constantemente por transpiraça, urina etc. } \\
\text { Umidade é detectada às movimentaçôes do } \\
\text { paciente. }\end{array}$ & $\begin{array}{l}\text { 2. Muito molhada: } \\
\text { a pele estí frequentemente, mas nem } \\
\text { sempre molhada A roupa de cama deve } \\
\text { ser trocada pelo menos una vez por } \\
\text { turno. }\end{array}$ & $\begin{array}{l}\text { 3. Ocasionalmente molhada: } \\
\text { A pele fica ocasionalmente molhada } \\
\text { requerendo uma troca extra de roupa } \\
\text { de cama por dia }\end{array}$ & $\begin{array}{l}4 \text {. Raramente molhada: } \\
\text { A pele geralmente está seca, a troca } \\
\text { de roupa de camaé necessiria } \\
\text { somente nos intervalos de rotina. }\end{array}$ \\
\hline \begin{tabular}{|l} 
Atividade: \\
Grau de atividade física
\end{tabular} & \begin{tabular}{|l|} 
A.Acarmado: \\
Confinado a cama. \\
\end{tabular} & \begin{tabular}{|l|} 
2. Confinado à cadeira: \\
Capacidade de andar está severamente \\
limitada ou nula Naoé capar de \\
sustentar o próprio peso e/ ou precisa ser \\
ejudado a se sentar.
\end{tabular} & $\begin{array}{l}\text { 3. Anda ocasionalmente: } \\
\text { Anda ocasionalmente durante o dia } \\
\text { embora distâncias mujto curtas com } \\
\text { ou sem ajuda. Passa a maior parte de } \\
\text { cada turno na cama ou na cadeira. }\end{array}$ & $\begin{array}{l}\text { Anda freqdentemente: } \\
\text { Anda fora do quarto pelo menos } 2 \\
\text { vezes por dia e dentro do quarto } \\
\text { pelo uma vez a cada } 2 \text { horas durante } \\
\text { as horas em que estai acordada. }\end{array}$ \\
\hline $\begin{array}{l}\text { Mobilidade: } \\
\text { Cupacidade de mudare } \\
\text { controlar a posiçâo do corpo }\end{array}$ & $\begin{array}{l}\text { 1. Totalmente imbivel: } \\
\text { Sao faz nem mesmo pequenas madanças na } \\
\text { posiçâ do corpo ou extremidades sem } \\
\text { pjuda. }\end{array}$ & \begin{tabular}{|l|} 
2. Bastante limitado: \\
Fus pequenas mudancas ocasionais na \\
posicano do corpoo ou extremidades mas é \\
nncapaz de fazer mudanças frequentes ou \\
significantes sazinho.
\end{tabular} & $\begin{array}{l}\text { 3. Levemente limitados } \\
\text { Fuz frequentes embora pequenas } \\
\text { mudancas na posicano do corpo ou } \\
\text { extremidades sem ajuda. }\end{array}$ & $\begin{array}{l}\text { 4 Nao apresentas limitapoes } \\
\text { Fuz importantes e frequentes } \\
\text { madanças sem auxilio. }\end{array}$ \\
\hline $\begin{array}{l}\text { utriçao: } \\
\text { Pudrao usual de consumo } \\
\text { alimentar }\end{array}$ & 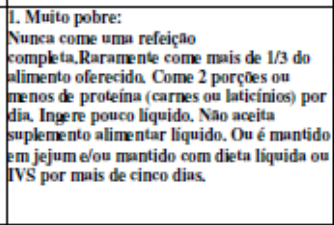 & 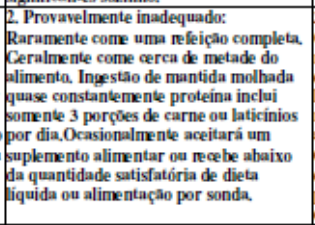 & 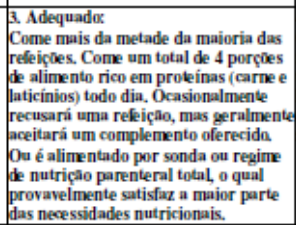 & 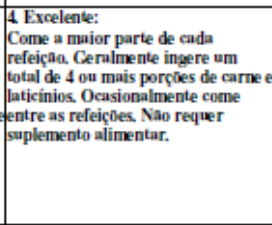 \\
\hline Friç̧ăa e cisallhamento & 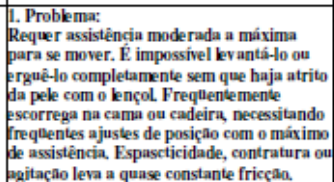 & 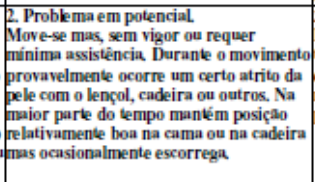 & $\begin{array}{l}\text { 3. Nenhum problema } \\
\text { Move-se sazinho na cama ou cadeira e } \\
\text { olem suficiente forca muscular para } \\
\text { erguer-se completamente durante o } \\
\text { movimento. Sempre mantém boa } \\
\text { posiçâo na cama ou na cadeira. }\end{array}$ & 4 \\
\hline
\end{tabular}

*Copyright (B Braden, Bergstrom 1988. Adaptada e validada no Brasil por Paranhos, Santos 1999.

**:Paranhos WY, Santos VLCG. Avaliação de risco para úlceras de pressão por meio da escala de Braden, na língua portuguesa. Rev Esc Enferm USP 1999; 33 (n esp): 191-206. 


\section{ANEXO V- ESCALA DE GLASGOW}

\begin{tabular}{|l|l|l|}
\hline \multirow{4}{*}{ Abertura ocular } & Espontânea & $\mathbf{4}$ \\
& Estimulação & $\mathbf{3}$ \\
& Dor & $\mathbf{2}$ \\
& Sem abertura & $\mathbf{1}$ \\
\hline \multirow{5}{*}{ Resposta verbal } & Orientado & 5 \\
& Confuso & 4 \\
& Inapropriada & 3 \\
& Incompreensível & 2 \\
& Sem resposta & 1 \\
\hline \multirow{5}{*}{ Resposta motora } & Obedece a comando & 6 \\
& Localiza dor & 5 \\
& Mov.inesp.: refl. de retirada & 4 \\
& Flexão a dor & 3 \\
& Extensão a dor & 2 \\
& Sem resposta & 1 \\
\hline
\end{tabular}

Fonte: Settervall CHC; Sousa RMC. Escala de coma de Glasgow e qualidade de vida póstrauma cranioencefálico. Acta paul. enferm. [online]. 2012, vol.25, n.3, pp. 364-370. ISSN 0103-2100 
ANEXO VI- ACUTE PHYSIOLOGY AND CHRONIC HEALTH EVALUATION

\begin{tabular}{|c|c|c|c|c|c|c|c|c|c|c|}
\hline \multirow[t]{2}{*}{ Physiologic Variable } & \multicolumn{5}{|c|}{ High Abnormal Range } & \multicolumn{5}{|c|}{ Low Abnormal Range } \\
\hline & +4 & +3 & +2 & +1 & $\mathbf{0}$ & +1 & +2 & +3 & +4 & Points \\
\hline $\begin{array}{l}\text { Temperature - rectal } \\
\left({ }^{\circ} \mathrm{C}\right)\end{array}$ & $\geq 41^{\circ}$ & $\begin{array}{l}39 \text { to } \\
40.9^{\circ}\end{array}$ & & $\begin{array}{l}38.5 \text { to } \\
38.9^{\circ}\end{array}$ & $\begin{array}{l}36 \text { to } \\
38.4^{\circ}\end{array}$ & $\begin{array}{l}34 \text { to } \\
35.9^{\circ}\end{array}$ & $\begin{array}{l}32 \text { to } \\
33.9^{\circ}\end{array}$ & $\begin{array}{l}30 \text { to } \\
31.9^{\circ}\end{array}$ & $\leq 29.9^{\circ}$ & \\
\hline $\begin{array}{l}\text { Mean Arterial Pressure } \\
-\mathrm{mm} \mathrm{Hg}\end{array}$ & $\geq 160$ & $\begin{array}{l}130 \text { to } \\
159\end{array}$ & $\begin{array}{l}110 \text { to } \\
129\end{array}$ & & $\begin{array}{l}70 \text { to } \\
109\end{array}$ & & $\begin{array}{l}50 \text { to } \\
69\end{array}$ & & $\leq 49$ & \\
\hline $\begin{array}{l}\text { Heart Rate (ventricular } \\
\text { response) }\end{array}$ & $\geq 180$ & $\begin{array}{l}140 \text { to } \\
179\end{array}$ & $\begin{array}{l}110 \text { to } \\
139\end{array}$ & & $\begin{array}{l}70 \text { to } \\
109\end{array}$ & & $\begin{array}{l}55 \text { to } \\
69\end{array}$ & $\begin{array}{l}40 \text { to } \\
54\end{array}$ & $\leq 39$ & \\
\hline $\begin{array}{l}\text { Respiratory Rate } \\
\text { (non-ventilated or } \\
\text { ventilated) }\end{array}$ & $\geq 50$ & $\begin{array}{l}35 \text { to } \\
49\end{array}$ & & $\begin{array}{l}25 \text { to } \\
34\end{array}$ & $\begin{array}{l}12 \text { to } \\
24\end{array}$ & $\begin{array}{l}10 \text { to } \\
11\end{array}$ & 6 to 9 & & $\leq 5$ & \\
\hline $\begin{array}{l}\text { Oxygenation: } \mathrm{A}-\mathrm{aDO} 2 \\
\text { or } \mathrm{PaO} 2(\mathrm{~mm} \mathrm{Hg}) \\
\text { a. } \mathrm{FIO}_{2} \geq 0.5 \text { record } \\
\mathrm{A}-\mathrm{aDO} 2 \\
\text { b. } \mathrm{FIO} 2<0.5 \text { record } \\
\mathrm{PaO} 2\end{array}$ & $\geq 500$ & $\begin{array}{l}350 \text { to } \\
499\end{array}$ & $\begin{array}{l}200 \text { to } \\
349\end{array}$ & & $\mathrm{PO} 2>70$ & $\begin{array}{l}\mathrm{PO} 2 \\
61 \text { to } \\
70\end{array}$ & & $\begin{array}{l}\mathrm{PO} 2 \\
55 \text { to } \\
60\end{array}$ & $\mathrm{PO} 2<55$ & \\
\hline $\begin{array}{l}\text { Arterial pH (preferred) } \\
\text { Serum HCO3 (venous } \\
\text { mEq/I) } \\
\text { (not preferred, but } \\
\text { may use if no ABGs) }\end{array}$ & $\begin{array}{l}\geq 7.7 \\
\geq 52\end{array}$ & $\begin{array}{l}7.6 \text { to } \\
7.69 \\
41 \text { to } \\
51.9\end{array}$ & & $\begin{array}{l}7.5 \text { to } \\
7.59 \\
32 \text { to } \\
40.9\end{array}$ & $\begin{array}{l}7.33 \text { to } \\
7.49 \\
22 \text { to } \\
31.9\end{array}$ & & $\begin{array}{l}7.25 \\
\text { to } \\
7.32 \\
18 \text { to } \\
21.9\end{array}$ & $\begin{array}{l}7.15 \\
\text { to } \\
7.24 \\
15 \text { to } \\
17.9\end{array}$ & $\begin{array}{l}<7.15 \\
<15\end{array}$ & \\
\hline Serum Sodium $(\mathrm{mEq} / \mathrm{l})$ & $\geq 180$ & $\begin{array}{l}160 \text { to } \\
179\end{array}$ & $\begin{array}{l}155 \text { to } \\
159\end{array}$ & $\begin{array}{l}150 \text { to } \\
154\end{array}$ & $\begin{array}{l}130 \text { to } \\
149\end{array}$ & & $\begin{array}{l}120 \text { to } \\
129\end{array}$ & $\begin{array}{l}111 \text { to } \\
119\end{array}$ & $\leq 110$ & \\
\hline $\begin{array}{l}\text { Serum Potassium } \\
(\mathrm{mEq} / \mathrm{l})\end{array}$ & $\geq 7$ & $\begin{array}{l}6 \text { to } \\
6.9\end{array}$ & & $\begin{array}{l}5.5 \text { to } \\
5.9\end{array}$ & $\begin{array}{l}3.5 \text { to } \\
5.4\end{array}$ & $\begin{array}{l}3 \text { to } \\
3.4\end{array}$ & $\begin{array}{l}2.5 \text { to } \\
2.9\end{array}$ & & $<2.5$ & \\
\hline $\begin{array}{l}\text { Serum Creatinine } \\
(\mathrm{mg} / \mathrm{dl}) \\
\text { Double point score for } \\
\text { acute renal failure }\end{array}$ & $\geq 3.5$ & $\begin{array}{l}2 \text { to } \\
3.4\end{array}$ & $\begin{array}{l}1.5 \text { to } \\
1.9\end{array}$ & & $\begin{array}{l}0.6 \text { to } \\
1.4\end{array}$ & & $<0.6$ & & & \\
\hline Hematocrit (\%) & $\geq 60$ & & $\begin{array}{l}50 \text { to } \\
59.9\end{array}$ & $\begin{array}{l}46 \text { to } \\
49.9\end{array}$ & $\begin{array}{l}30 \text { to } \\
45.9\end{array}$ & & $\begin{array}{l}20 \text { to } \\
29.9\end{array}$ & & $<20$ & \\
\hline $\begin{array}{l}\text { White Blood Count } \\
\text { (total } / \mathrm{mm}^{2} \text { ) } \\
\text { (in } 1000 \mathrm{~s} \text { ) }\end{array}$ & $\geq 40$ & & $\begin{array}{l}20 \text { to } \\
39.9\end{array}$ & $\begin{array}{l}15 \text { to } \\
19.9\end{array}$ & $\begin{array}{l}3 \text { to } \\
14.9\end{array}$ & & $\begin{array}{l}1 \text { to } \\
2.9\end{array}$ & & $<1$ & \\
\hline $\begin{array}{l}\text { Glasgow Coma Score } \\
\text { (GCS) } \\
\text { Score }=15 \text { minus } \\
\text { actual GCS }\end{array}$ & & & & & & & & & & \\
\hline \multirow{2}{*}{\multicolumn{10}{|c|}{$\begin{array}{l}\text { A. Total Acute Physiology Score (sum of } 12 \text { above points) } \\
\text { B. Age points (years) } \leq 44=0 ; 45 \text { to } 54=2 ; 55 \text { to } 64=3 ; 65 \text { to }\end{array}$}} & \\
\hline & & & 55 to 64 & $=3 ; 65$ to & $4=5 ; \geq 7$ & & & & & \\
\hline \multicolumn{10}{|c|}{ C. Chronic Health Points (see below) } & \\
\hline
\end{tabular}




\section{ANEXO VII- ESCALA DE RAMSAY}

\begin{tabular}{ll}
\hline RAMSAY & AVALIAÇÃO \\
\hline 1 & Paciente acordado e agitado, ansioso ou inquieto \\
\hline $\mathbf{3}$ & Paciente acordado e colaborativo \\
& Paciente dormindo, despertável com estímulo \\
$\mathbf{4}$ & verbal, responsivo a comandos \\
& Paciente dormindo, despertável com estímulo \\
& verbal vigoroso ou leve toque da glabela \\
$\mathbf{5}$ & Paciente dormindo, despertável com estímulo \\
& álgico leve (compressão glabelar) \\
& Paciente dormindo sem reposta a compressão \\
& glabelar
\end{tabular}

Fonte: Rhoney DH, Murry KR. National survey of the use of sedating drugs, neuromuscular blocking agents, and reversal agents in the intensive care unit. J Intensive Care Med. 2003;18(3):139-45. 